\title{
EFEITO DA INOCULAÇÃO DE FUNGOS MICORRIZZICOS NO APROVEITAMENTO DE FOSFATOS NATURAIS E NA SIMBIOSE COM Rhizobium, EM SOJA E NO FEIJOEIRO
}

\author{
MÁRCIA HELENA ALLEONI DE OLIVEIRA \\ Engenheiro Agrônomo
}

Orientadora: Profa. Dra. ELKE J. B. N. CARDOSO

\begin{abstract}
Dissertação apresentada à Escola Superior de Agricultura "Luiz de Queiroz", da Universidade de São Paulo, para obtenção do título de Mestre em Agronomia. Área de Concentração: Microbiologia Agricola.
\end{abstract}

PIRACICABA

Estado de São Paulo - Brasil

Abril - 1987 
Oliveira, Márcia Helena Alleoni de

048e Efeito da inoculação de fungos micorrízicos no aproveitamento de fosfatos naturais e na simbiose com Rhizobium, em soja e no feijoei ro. Pi racicaba; 1987.

$112 p$.

Diss. (Mestre) - ESALQ

Bibliografia.

1. Feijão - Micorriza. 2. Fosfato de rocha. 3. Micorriza - Inoculação. 4. Nitrogênio - Fixação. 5. Soja - Micorriza. 6. Dissertação. 1. Escola Su perior de Agricultura'Luiz de Queiroz', Piracicaba'.

CDD 633.34

635.652 
EFEITO DA INOCULAÇAO DE FUUROS MICORRIZZICOS NO APROVE ITAMENTO DE FOSFATOS NATURAIS E NA SIMBIOSE COM Rhizojium, EM SOJA E NO FEIJOEIRO.

\section{Márcia Helena Alleoni de Oliveira}

Aprovada em 10.06 .1987

Comissão julgadora:

Profą Dra. Elke J.B.N. Cardoso ESALQ/USP

Prof. Dr. Valdomiro C. de Bittencourt ESALQ/USP Dr. Eli S. Lopes

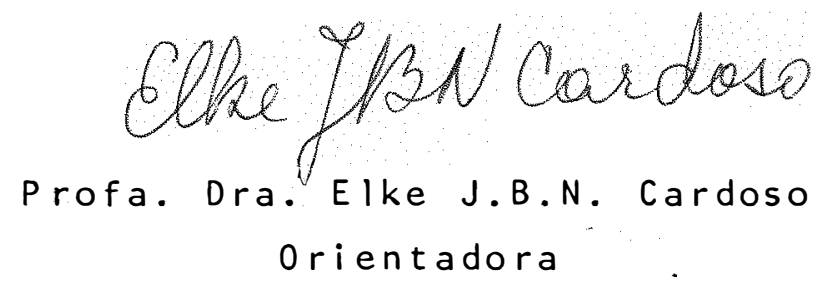


i i.

Aos meus pais Odair e Maria de Lourdes, e ao meu irmão Marcos Eduardo,

DEDICO. 


\section{AGRADECIMENTOS}

- A Profa. Dra. Elie J.B.N. Cardoso, pela orientação, estímu lo e amizade que nos foram demonstrados;

- A Escola Superior de Agricultura "Luiz de Queiroz" e a seus mestres;

- A CAPEs pela concessão da bolsa de estudos;

- Ao Departamento de Solos, Geologia e Fertilizantes pela oportunidade de trabalho concedida e auxilio prestado;

- Aos Profs. Drs. Toshiaki Kinjo e Ronaldo l. Silveira, pela orientação nos cálculos de adubação;

- Ao Prof. Dr. Décio Barbin, pela orientação nas anālises estatísticas;

- Ao Centro de Energia Nuclear na Agricultura pelos trabalhos prestados;

- Ao Centro de Informática na Agricultura pelas análises estatísticas processadas;

Aos colegas, amigos e outras pessoas que, de alguma maneira, contribuíram para que este trabalho fosse concluído, registramos nossos agradecimentos. 
Pägina

LISTA DE TABELAS .................. vi

RESUMO $\ldots \ldots \ldots \ldots \ldots \ldots \ldots \ldots \ldots \ldots \ldots \ldots \ldots \ldots \ldots \ldots \ldots \ldots \ldots \ldots$

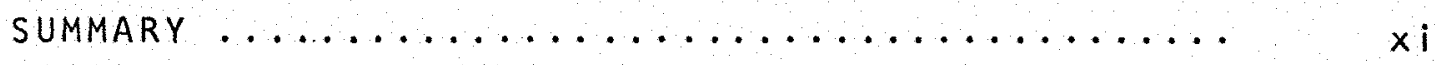

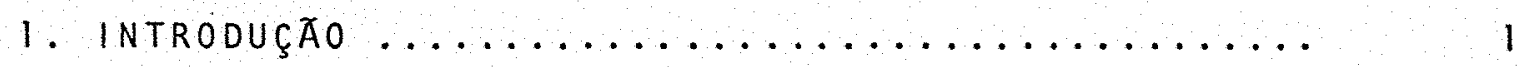

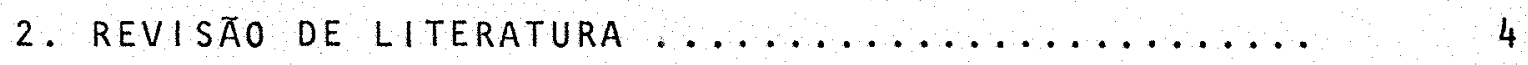

2.1. Aspectos gerais das micorrizas VA ....... 4

2.2. Micorrizas VA em leguminosas .......... 12

2.2 .1 . ocorrência e efeitos nas plantas ... 12

2.2 .2 . Efeitos do fosforo .......... 18

2.2 .2 .1 . Fosfatos solúveis ........ 18

2.2 .2 .2 . Fosfatos de baixa solubilidade $\ldots \ldots \ldots \ldots \ldots \ldots \ldots \ldots 25$

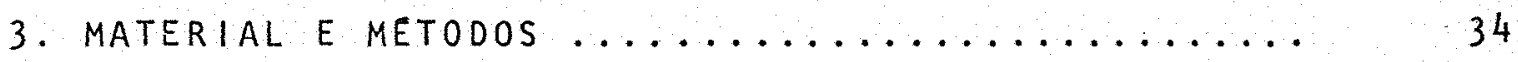

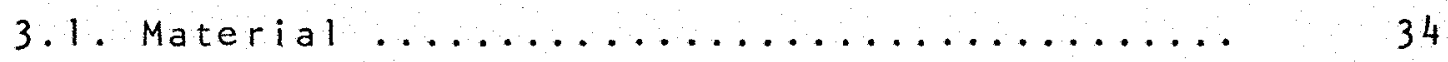

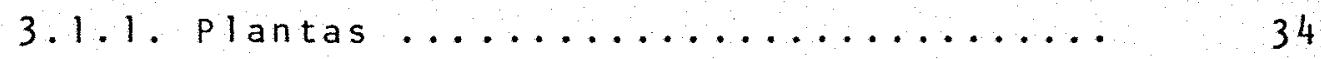

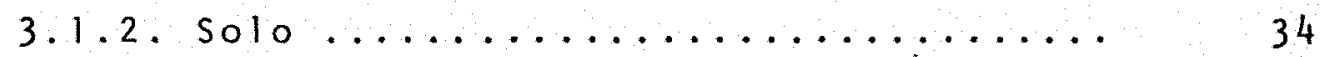

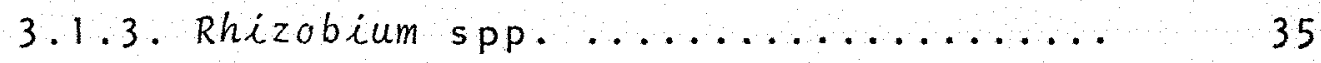

3.1.4. Fungos micorrizicos vesiculo-arbuscu

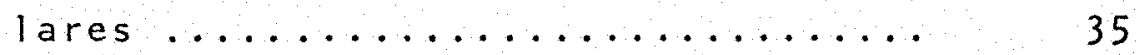

3.1 .5 . Fosfatos de rocha $\ldots \ldots \ldots \ldots \ldots \ldots$

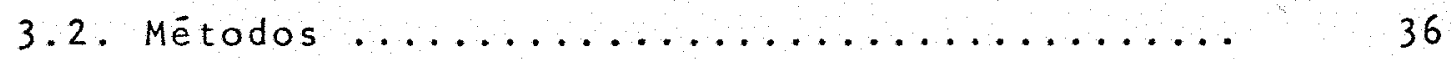

3.3.1. Preparo do solo e vasos de plantio 36

3.2 .2 . Calagem e adubação ........... 36

3.2 .3 . Preparo dos inóculos ........... 38

3.2.4. Instalação e condução das culturas . 39

3.2.5. Delineamento experimental ....... 41

3.2 .6 . Colheita dos experimentos ...... 41 
Pàgina

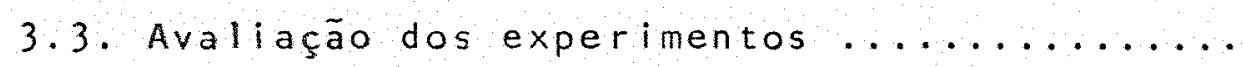

3.3.1. Peso de matéria seca da parte aèrea

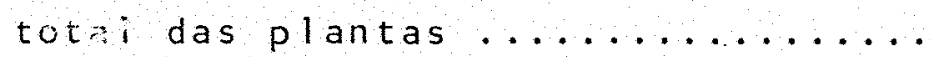

3.3 .2 . Peso de vagens $\ldots \ldots \ldots \ldots \ldots \ldots \ldots$

3.3.3. Atividade total e especifica da ni-

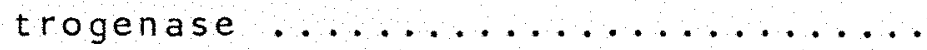

3.3.4. Relação entre os pesos de matéría se ca da parte aérea e matéria fresca da raiz.

44

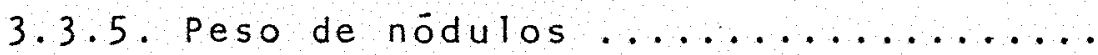

3.3.6. Análise quínica da parte aérea to-

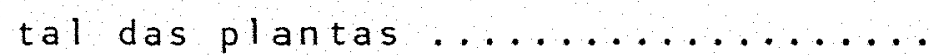

3.3.7. Determinação da porcentagem de colo-

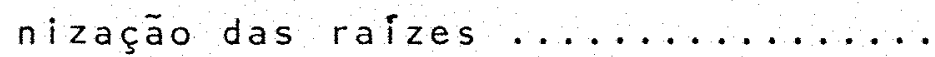

3.3.8. Contagem de esporos do fungo MVA no

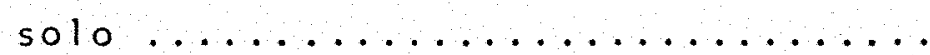

3.3.9. Análise estatistica $\ldots \ldots \ldots \ldots \ldots$

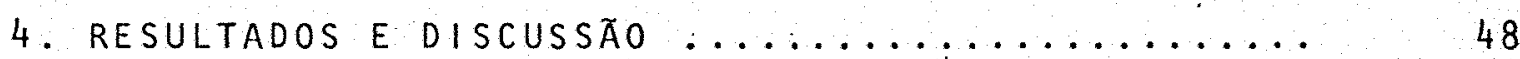

4.1. Experimento com soja ............. 48

4.2. Experimento com feijão ............ 69

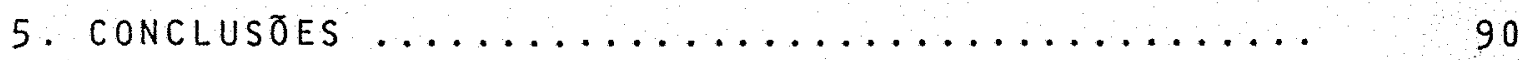

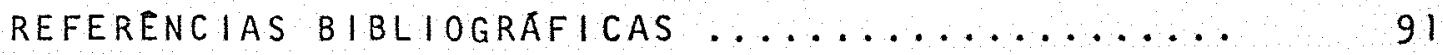




\section{LISTA DE TABELAS}

TABELA N :

Pàgina

Análise química das amostras do solo Areia

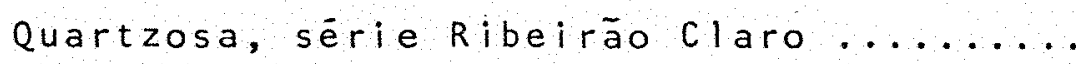

Tipos, teores de $\mathrm{P}_{2} \mathrm{O}_{5}$ total e solüvel em ácido citrico $2 \%$, e granulometria (ABNT)

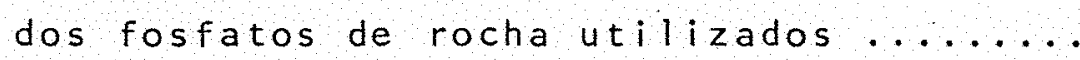

3 Pesos médios da matéria seca da parte aérea total (com vagens)e de vagens de soja cv. Viçoja, com os diferentes tipos e doses de fosfato empregados, na presença e ausência do fungo MVA Glomus macrocarpum (média de 4

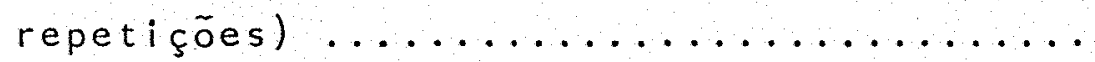

4

Teores médios de nitrogênio, fósforo e potássio na parte aérea total da soja cv. Vi çoja, com os diferentes tipos e doses de fosfato empregados, na presença e ausén cia do fungo MVA G. macrocarpum (média de

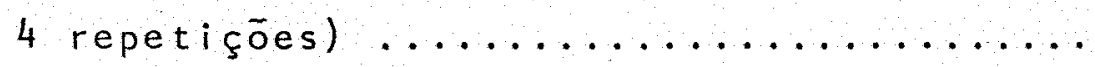

Médias das quantidades totais acumuladas de nitrogēnio, fósforo e potássio na parte aé rea total da soja cv. Viçoja, com os dife rentes tipos e doses de fosfato empregados, na presença e ausência do fungo MVA

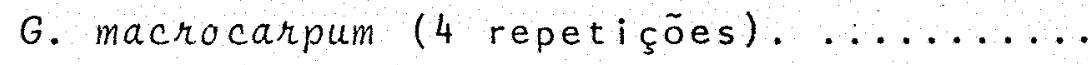


Valores médios relativos ao peso da matëria seco de nódulos, atividade total e especifica da nitrogenase, da soja cv. Viço ja, com os diferentes tipos e doses de fos fato empregados, na presença e auséncia do fungo MVA G. macrocarpum (média de 4 repe-

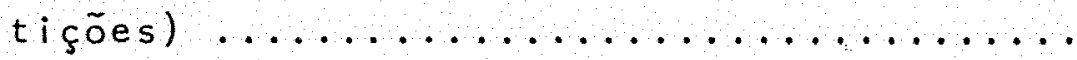

7 Valores médios da relação entre os pesos da matéria seca da parte aérea (MSPA) e matēria fresca de raízes (MFR), porcentagem de colonização das raízes e número de esporos no solo do fungo G. macrocarpum, com os di ferentes tipos e doses de fosfato empregados, na presença e ausência do fungo MVA G. macrocarpum, em soja cv. viçoja (média

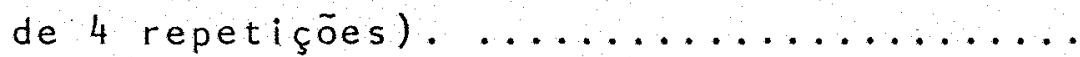

8 Pesos médios da matéria seca da parte aérea total (com vagens) e de vagens do feijão cv. Cario ca, com os diferentes tipos e doses de fos fato empregados, na presença e ausência do fungo MVA G. leptotichum (mëdia de 4 repetições).

Teores médios de nitrogēnio, fósforo e potásio na parte aérea total do feijão cv. Carioca, com os diferentes tipos e doses de fosfato empregados, aa presença e ausência do fungo MVA G. leptotichum (média

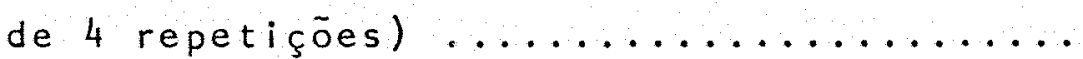


Médias das quantidades totais acumuladas de nitrogénio, fósforo e potássio na parte aèrea total do feijäo cv. Carioca, com os di ferentes tipos e doses de fosfato emprega dos, na presença e ausencia do fungo MVA G. leptotichum $(4$ repetiçöes $) \ldots \ldots \ldots \ldots$

11 Valores médios do peso da materia seca de nödulos, e da relação entreos pesos da matéria seca da parte aérea (MSPA) e matéria fresca de rá́zes (MFR) do feijão cv. Ca rioca, com os diferentes tipos e doses de fosfato empregados, na presença e ausēn cia do fungo MVA G. leptotichum (média de

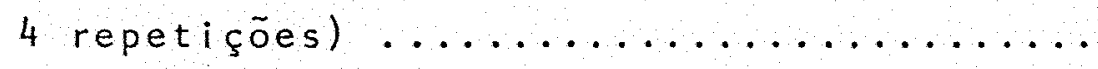

12 Valores médios relativos à porcentagem de colonização das raízes e ao nümero de espo ros do fungo MVA G. leptotichum no solo, com os diferentes tipos e doses de fosfato empregados, na presença e ausência de inoculação com o fungo MVA G. leptatichum

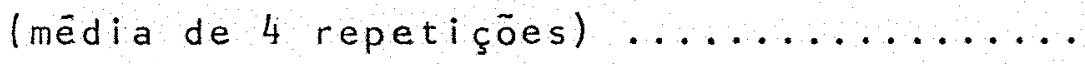


EFEITO DA INOCULAGAO DE FUNGOS MICORR IZILOS NO APROVEITAMENTO DE FOSFATOS NATURAIS E NA SIMBIOSE COM Rinizobium, EM SOJA E NO FEI JOEIRO

Autora: MARCIA HELENA ALLEONI DE OLIYE:RA

Orientadora: Profa. Dra. ELKE J.B.N. CARDCSO

\section{RESUMO}

Foram conduzidos dols experimentos em casa de vegetação, um com soja [Glycine max (L.) Merril] cv. Viçoja, e outro com feijäo (Phaseolus vulgaris L.) cv. Carioca. Ambos os experimentos se constituiram de 28 tratamentos, com 4 blocos ao acaso: quatro tipos de fosfato de rocha (Patos de Minas, Araxá, Jacupiranga e Cataläo), todos com très doses de fósforo $(64,128$ e $256 \mathrm{ppm}$ de P), mais dois controles, um sem fósforo e outro com superfosfato triplo na dose de $18 \mathrm{ppm}$ de $P$, testados na presença e na ausência de fungo micorrizico VA

Todos os tratamentos do experimento com soja foram inoculados com Bradyrhizobium japonicum e o fungo MVA utilizado foi Glomus macrocarpum. No experimento com feijão todos os tratamentos foram inoculados com Rhizobium phaseo$l i$ e o fungo MVA utilizado foi Glomus leptotichum. Em ambos os experimentos usou-se uma Areia Quartzosa previamente esterilizada através da tindalização com vapor fluente. A colhei ta do experimento com soja foi realizada aos 70 dias após a semeadura, e a do experimento com feijão aos 76 días após a semeadura.

No experimento com soja observou-se que em todos os tratamentos a presença do fungo MVA aumentou significa tivamente os pesos da matéria seca da parte aérea total e de nódulos, as quantidades totais acumuladas de nitrogênio e fós 
foro na parte aérea, e a at lvidade total da n,trogenase, não influindo porém, na atividade especifica da nitrogenase. De maneira geral, os tratamentos com $G$. machocarpum apresentaram tendéncia em possuir maior teor em fósforo jo que aqueles sem este endofito, ocorrendo o conträrio nos teores de nitrogénio e potássio, provavelmente devido ao efeito de diluição. Na ausência do fungo MVA, nenhum dos fosfatos de rocha, em qualquer dose, mostrou vantagem sobre o controle sem fósforo. Para a maioria das variáveis analisadas houve equivaléncia entre os tratamentos com superfosfato triplo e fungo MVA, e a maior dose de fosfato Catalão e Araxá na presença deste endófito.

No experimento com feijão, os tratamentos com micorriza de maneira geral não apresentaram diferenças significativas em relação aos tratamentos sem micorriza, embora houvesse tendência das plantas micorrizadas apresentarem maio res valores para peso da matéria seca da parte aérea total, de nódulos, de vagens, para a relação entre os pesos da matéria se ca da parte aérea matéría fresca de rá́zes, e para as quantidades to tais acumuladas de nitrogénio e potássio. A maioria dos tratamentos inoculados com o fungo G. Leptotichum apresentou maior quantidade total acumulada e teor em fósforo, mas não influiu nos teores de nitrogénio e potássio, provavelmente devido ao efeito de diluição. Na presença ou ausência de fungo MVA os fosfatos de rocha não mostraram vantagem sobre o controle sem fösforo, sobressaindo-se apenas o superfosfato triplo, em alguns casos.

Em ambos os experimentos, os tratamentos que receberam o fungo MVA não apresentaram diferenças entre si em relação à porcentagem de colonização das rafzes e esporulação dos fungos. 
EFFECT OF VAM FUNGI AND ROCK PHOSPHATES ON THE DEVELOPMENT OF BEANS AND SOYBEANS AND THEIR SYMBIOSES WITH Rhizobium

Author: MARCIA HELENA ALLEONI DE OLIVEIRA

Adviser: Profa. Dra.ELKE J.B.N. CARDOSO

\section{SUMMARY}

Two experiments were conducted in a greenhouse, with soybeans [Glycine max (L.) Merril] cv. Viçoja, and with beans (Phaseolus vulgaris L.) cv. Carioca. Twenty - eight different treatments were used, in four random blocks: four types of rock phosphate (Patos de Minas, Araxā, Jacupiranga, and (atalão), all of them with three doses of phosphorus (64, 128 and $256 \mathrm{ppm}$ P), plus two contols, one without phosphorus and the other with $18 \mathrm{ppm} \quad \mathrm{p}$ from triple superphosphate, tested in the presence and in the absence of VAM fungus.

All treatments of the experiment with soybeans were inoculated with Bradyrhizobium japonicum and the VAM fungus used was Glomus macrocarpum. In the experiment with beans all treatments were inoculated with Rhizobium phaseoli and the VAM fungus used was Glomus leptotichum. In both experiments were used a Quartz Sand previously sterilized by continuous steam. The soybean experiment was harvested 70 days after sowing, and the bean experiment after 76 days.

In the soybean experiment was observed that in all treatments the presence of VAM fungus increased significantly the total shoot and nodules dry weights, the total accumulated amounts of shoot nitrogen and phosphorus, and the total nitrogenase activity, having no influence, 
however, over the specific nitrogenase activity. Ingeneral, the treatments with G. macrocarpum showed a tendency of having greater shoot phosphorus concentrations than the ones without this endophyte, the opposite occurring with the nitrogen and potash concentrations, probably due to dilution effect. In the absence of VAM fungus, none of the rock phosphates, in any dose, showed any advantage over the control without phosphorus. The treatments with triple superphosphate and VAM fungus were equivalent to the ones with the highest dose of Cataläo and Araxá phosphates in the presence of this endophyte for the majority of the analyzed parameters.

In the bean experiment the treatments with mycorrhiza didn't show significant differences in relation to the treatments without mycorrhiza, although there had been a tendency of the mycorrhizal plants in showing greater values of shoot, nodules and pods dry weights, of the total shoot dry weight/root fresh weight ratio, and of the total accumulated amounts of shoot nitrogen and potash than nonmycorrhizal plants. The majority of the treatments inoculated with $G$. leptotichum showed greater total accumulated amount of shoot phosphorus and shoot phosphorus concentration, but it didn't influence the nitrogen and potash concentrations probably due to dilution effect. In the presence or in the absence of VAM fungus the rock phosphates didn't show any advantages over the control without phosphorus, only the triple superphosphate standing out in some cases.

In both experiments the treatments that received VAM fungus didn't show differences among each other in relation to the root colonization percentage and fungi sporulation. 


\section{INTRODULÃO}

Os microrganismos exercem um papel vital em multos processos fisiológicos no ecossistema, e estáo invariavelmente presentes na rizosfera das plantas (BAREA \& AZ CON-AGUILAR, 1983). A absorçäo de nutrientes inorgânicos pelas plantas é influenclada pelos microrganismos presentes na rizosfera, na superficie e no interior dos tecidos da raiz, e podem alterar a morfologia e fisiologia das mesmas (DAFT $\&$ $E L-G \mid A H M I, 1975)$.

Endófitos simbióticos como Rhizobium e fungos micorrízicos vesículo-arbusculares são exemplos de microrganismos envolvidos na nutrição vegetal, relacionados a dols elementos imprescindiveis às plantas, o nitrogénio e ofósforo. A maioria das leguminosas possui em suas raízes esses dois tipos de microrganismos simbióticos (ASAl, 1948).

- Rhizobium em culturas de leguminosas bem manejadas, pode ser responsável pela fixaçáo de quase todo o nitrogénio das plantas, substituindo com vantagem económica, a adubação nitrogenada (CARDOSO, 1984).

A associação micorrízica do tipo vesículo-arbuscular é o tipo mais comum de as sociação benéfica existente entre as ralzes de plantas e espécies de fungos da familia Endogonaceae (MOSSE, 1973). A micorriza, através do aumento da superfície de absorção das raízes proporcionado pelas hifas do fungo, é responsável pelo aumento da absorção de fósforo 
e 03 outros elementos de pequena mobilidade no solo, principalmente em solos de baixa fertilidade (SANDERS ETINKER, 1971; MOSSE, $1977 b)$.

Com o aumento na absorção de fósforo, nota-se - melhor desenvolvimento da planta hospedeira e, no caso de leguminosas, um aumento na nodulação e na atividade da nitrogenase (DAFT \& EL-GIAHMI, 1974, 1975), com consequentes reflexos na produtividade (ROSS \& HARPER, 1970), uma vez que o fósforo é necessärio para tais processos.

A maioria dos solos de regióes tropicals, particularmente os solos brasileiros, é extremamente deficiente em fósforo, e apresenta também o fenómeno de fixaçäo deste elemento. Portanto, para a obtenção de bons rendimentos das culturas, são necessárias pesadas adubaçóes fosfatadas. Neste caso, os fungos micorrizicos têm papel de destaque, podendo reduzir parte da necessidade de adubação fosfatada, uma vez que exploram melhor o fösforo do solo.

Os aumentos dos preços de fertilizantes fosfatados solúveis, a dependéncia externa do pais aos produtos, e a descoberta de novas jazidas de fosfato de rocha, induziram a pesquisa com o objetivo de utilizar os fosfatos de rocha "in natural, moldos, ou semi-industrializados, como fonte alternativa de suprimento de fósforo para a planta, podendo se tornar uma maneira econômica de se fertilizar o solo (OLIVEL RA et alii, 1984; LOPES, 1983).

Muitos experimentos tém sido realizados com le guminosas usando fontes de fósforo de baixa solubilidade, como os fosfatos de rocha, em adição à micorriza, com resultados bastante promissores (MOSSE et ali1, 1976 ; CARDOSO, 1984, $1985,1986)$. 
Entre as leguminosas cultivadas no Brasil, a soja se destaca pela orande importancia econômica, cultivada numa àrea total de 9.421 .202 ha e produção de $15.540 .792 \mathrm{t}$ de grãos (ANUARIO ESTATISTICO DO BRASIL, 1985), O feijão, embora cultivado em meror àrea, de 5.320 .150 ha, e produção bem mais baixa de 2.625 .676 t de grãos (ANUARIO ESTATISTICO DO BRA S(L, 1985), é parte indispensável na dieta do brasileiro, cons tituindo-se na principal fonte de proteina para as populaçóes de baixa renda.

Em vista disso, torna-se necessärio um manejo adequado dessas culturas, considerando as duas simbioses e - melhor aproveitamento dos adubos, visando incrementos cada vez maiores na produtividade e economia de insumos.

Este trabalho teve como objetivo avaliar o efei to da inoculação com fungos micorrizicos sobre o aproveitamen to de quatro tipos de fosfato de rocha usados em três doses, comparando-o com o do fosfato solüvel, e sobre a simbiose com Rhizobium, em soja e no feijoeiro. 


\section{REVISÃO DE LITERATURA}

\subsection{ASPECTOS GERAIS DAS MICORRIZAS VA}

Micorrizas são associaçōes simbiöticas entre certos fungos do solo e raízes da maioria das espécies vegetais. os estudos sobre este tipo de associação foram iniciados por volta do ano de 1885, quando Frankl, citado por POWELL E BAGYARAJ (1984) empregou o termo micorriza.

As micorrizas podem ser agrupadas quanto ao tipo de colonização das raízes, em ectomicorrizas, endomicorr 1 zas e ectoendomicorrizas (GERDEMANN, 1968). Em todos os tipos, o fungo penetra a raiz colonizando apenas o cörtex, intercelularmente no caso das ectomicorrizas e intracelularmente no caso das ectoendomicorrizas e endomicorrizas.

LEWIS (1975) sugeriu a classificação das micorrizas em quatro categorias principais: ectomicorriza, endomicorriza vesiculo-arbuscular (MVA), micorrizas ericáceas e micorrizas orquidaceas. Nas ectomicorrizas, a superficie do sistema radicular fica recoberta por um manto compacto formado pelas hifas do fungo. As hifas penetram entre as células epidermais e corticais da raiz, formando uma rede de hifas

FRANK, A.B. Uber die auf Wuezelsymbiose beruhende Eranahrung gewiser Baume durch unterirdische Pilze. Ber. Dtsch. Bot. Ges., s.1., 3: 128,1885 . 
intercelulares denominada rode de Hartig (GERDEMANN, 1974). São encontradas principalmente em espécies das familias pinaceae, setulaceae e Fagaceae, cujos hospedeiros são, com poucas excessóes, árvores ou arbustos de clima temperado. A maioria dos fungos que produzem ectomicorriza são basidiomicetos, alguns ascomicetos, poucos fungos imperfeitos e ficomicetos. A colonização típica das ectomicorrizas induz a um encurtamento, engrossamento e ramificação das raizes, modificando a morfologia das mesmas (GERDEMANN, 1974).

Plantas da familla Ericaceae são normalmente infectadas por fungos micorrízicos. Dois tipos de associação micorrizica foram encontrados, conhecidos como tipo ericóide e arbutóide. o tipo ericóide é o mais importante e encontrado em plantas do gênero Erica, Vaccinium, Rhododendron e Calluna; a infeç̧ão consiste de um complexo de hifas intracelulares nas células corticais externas, e não formam manto. Um dos fungos envolvidos neste tipo de associação é o ascomiceto Pezizella ericae (READ, 1974; READ \& STRIBLEY, 1975). As micorrizas do tipo arbutóide são do tipo ectoendomicorriza, e encontradas nos gêneros Actous, Arbutus e Arctostaphylos (READ E STRIBLEY, 1975). As plantas apresentam tanto um revestimen to micelial externo nas raízes modificadas, semelhante ao que ocorre nas ectomicorrizas, como penetração intracelular de hi fas em células do córtex, semelhante a estruturas de endomicorrizas. Os fungos envolvidos neste tipo de associação são normalmente basidiomicetos, alguns identicos aos que formam ectomicorriza em plantas florestais (HAYMAN, 1978).

A plántula de orquidea, que se desenvolve a partir de uma semente minúscula, com muito pouco material de reserva, tem no início crescimento reduzido, e demora bastante tempo para que se instale um processo eficiente de fotossintese. Nesse estágio, a plântula é dependente de fungos micorrizicos, cujas espēcies são na maioria das vezes perten- 
centes ao gênero Rhizocton a, as quais formani um complexo de hifas intracelulares no córtex da raiz, fornecendo os nutrien tes carbonados necessários ao desenvolvimento das plántulas (HADLEY, 1975; PURVES \& HADLEY, 1975; WARCUP, 1975).

As associaçós micorrízicas do tipo vesiculo arbuscular (MVA) formam o grupo mais comum das associaçóes sim bióticas que se estabelecem entre as raízes da maioria das plantas e espécies de fungos da familla Endogonaceae (GERDEMANN, 1968, MOSSE, 1973). EsSa assoclação ocorre em um grupo extremamente diverso de plantas, desde Briófitas até Pteridö fitas, Gymnospermas e Angiospermas (GERDEMANN, 1968; NICOLSON, 1967). Certas plantas, porém, como as das famil ias Juncaceae, Chenopodiaceae, Urticaceae, Amaranthaceae, Cruciferae e outras, näo formam micorrizas (GERDEMANN, 1968), embora já tenha se obtido infeç̧ão micorrízica em Cruciferas (FRONTERA \& DELORENZINI, 1981 ).

As micorrizas vesiculo-arbusculares são de extrema importáncia, uma vez que ocorrem um inúmeras culturas de interesse agronómico, como as pertencentes às famílias das Gramineas e Leguminosas (GERDEMANN, 1968) e, nesta revisão, serão descritos alguns aspectos apenas deste tipo de associaçào micorrízica.

A compreensão da taxonomia dos fungos formadores de micorriza VA tem sido dificultada, uma vez que esses fungos não podem ser cultivados "in vitro" e são considerados simbiontes obrigatórios. As espécies de fungos formadores de MVA pertencem, segundo GERDEMANN \& TRAPPE (1974) à famíla En dogonaceae, da ordem Endogonales, e constam dos géneros Glomus, Gigaspora, Sclerocystis e Acaulospora. Posteriormente, Trappe Eschenck, citados por CARDoso (1984), em trabalho so-

TRAPPE, J.M. E SCHENCK, N. Taxonomy of the fungi forming endomycorrhizae. A. Vesicular-arbuscular mycorrhizal fungi 
bre taxonomis de fungos MVA, incluíram na ordem Endogonales - gênero Endogone, que não forma micorriza VA e, alēm dos qua tro generos descritos anteriormente, Entrophospora e Glazlella, como possivels formadores de MVA.

Neste tipo de associação a infecção é inter e intracelular no córtex da raiz, havendo a formação de estruturas tipicas.

o estabelecimento da associação inicla-se pela quebra da dorméncla dos propágulos do simbionte na regiáo da rizosfera, ocorrendo a germinação dos esporos e emíssáo do tubo germinativo. o alongamento do tubo germinativo resulta em hifas altamente ramificadas, septadas, chamadas infecti vas (POWELL, 1976). Estas, encontrando uma parte da raiz sus cetivel à colonização, formarão o apressório e penetrarão nas células da epiderme, provavelmente através de produção de enzimas e pressão na parede celular (SWARD, 1978), ou poderäo penetrar entre as células da epiderme e se espalharem intercelularmente (COX \& SANDERS, 1974; GIANINAZZI-PEARSON et al11, 1981b). o fungo então coloniza o cörtez da raiz e as hifas se multiplicam inter e intracelularmente, embora náo invadam a endoderme nem a regía meristemática de raízes jovens.

Logo após a infeç̧á, a hifa que cresceu dentro de uma cêlula pode mostrar inümeras ramificaçóes dicotómicas, formando uma estrutura denominada arbúsculo. A funçāo do arbúsculo parece ser a de local de troca de nutrientes entre o fungo e o hospedeiro (MARX et alii, 1982). Estudos revelaram que os arbüsculos estäo continuamente envolvidos pe-

(Endogonales). In: SCHENCK, N., ed. Methods and principles of Mycorrhizal research. St. Paul, The American Phytopatholo gical Society, 1982 . p. $1-10$. 
10 plasmalema da céibla do hospedeiro (KINDEN \& BROWN, $1975 a, b)$.

Vesículas são estruturas geralmente - terminais, de forma oval ou arredondada, que contém gotas de óleo e podem se desenvolver inter ou intracelularmente. Algumas espécies do endófito produzem vesículas cujas paredes permanecem relativamente finas. Em outras, as paredes das vesículas se tornam grossas, transformando-as em clamidosporos. As vesiculas são consideradas estruturas de armazenamento ou, se as paredes se engrossarem e formarem clamidosporos, podem funcionar como estruturas reprodutivas (GERDEMANN, 1968).

Uma vez consolidada a infecção, a hifa externa se ramifica e pode crescer ao longo da superficie da raiz, for mando mais pontos de infeç̧ão, e também crescer pelo solo em volta, formando uma extensa rede tridimensional de micélio. Es sá rede de hifas não chega a ser täo compacta quanto aquela formada pelas ectomicorrizas. Uma característica típica das MVA è a natureza dimörfica das hifas externas: o micélio è constituido por hifas grossas, consideradas permanentes e que sustentam o esporo, e destas partem hifas mais finas, de vida efêmera, que se difundem no solo, consideradas hifas absorven tes (NICOLSON, 1967). o micélio externo geralmente produz grandes esporos de parede grossa elou pequenos esporos secundärios ou vesículas externas. Em algumas espécies os esporos podem formar em esporocarpos (GERDEMANN, 1975).

As infecções micorrizicas produzem pouca mudan ça na morfologia externa da raiz, portanto, macroscopicamente, näo se diferenciam raízes micorrizadas das não micorrlzadas. Elas podem ser reconhecidas em raizes relativamente finas, näo suberizadas, pela leve coloração amarela, mas esta cor desaparece rapidamente com a exposição à luz (GERDEMANN, 1968, 1974). 
A colonização é um processo altamente equilibra do, sem aparecimento de lesões e invasões do sistema vascular da planta, sendo essa uma diferença entre os fungos micorrizl cos e patógenos da raiz. Por esse motivo Garret citado por LOPES et alii (1983) considerou a associação micorrizica ápice de evolução do parasitismo de raiz por fungos, dominado pela sua natureza mutualística.

A importância da micorriza vesículo-arbuscular, deve-se ao fato de que ela promove um melhor crescimento do hospedeiro, em função do maior fornecimento de nutrientes. MOS SE (1957) comparou as composiçóes minerais de plantas de macieira micorrizadas ou não, e observou que certos nutrientes se encontravam em maior concentração e outros em menor, sugerindo que a resposta ao crescimento refletiu a melhor nutrição da planta. MOSSE (1973) afirmou que a melhor resposta das plantas micorrizadas ocorre principalmente quando o nível de fósforo assimilável no solo é baixo. O fósforo é o principal nutriente envolvido, sendo encontrado em altas concentraçôes nas plantas micorrizadas (MOSSE, 1973; TINKER, 1980).

As hifas externas das micorrizas absorvem ofós foro do solo e o transloca ao hospedeiro. A absorção mais eficiente das raizes infectadas seria devido ao micélio no solo, formando uma rede que se estende além da zona de depleção, retirando o nutriente de uma parte do solo distante até $8 \mathrm{~cm}$ da raiz (Rhodes \& Gerdemann ${ }^{2}$, citados por TINKER, 1980), levando-o diretamente para o interior desta, uma vez que o micèlio externo está ligado ao interno (MOSSE, 1973). 0 au-

TGARRET, S.D. Biology of root infecting fungi. London, Cambridge University Press, 1956. 293p.

2 RHODES, L.H. \& GERDEMANN, J.W. Phosphate uptake zones of mycorrhizal and nonmycorrhizal onions. New Phytol., 0xford, 75: 555-561, 1975. 
mento no volume de solo explorado se torna mu to importante no caso da absorção de nutrientes de balxa difusão no solo, como o fósforo (SANDERS \& TINKER, 1971) e o zirCo (GILMORE, 1971). Além do mais, os finos ramos do micélio podem ser capazes de explorar micro-ambientes normalmente não atingidos pelas raízes (MOSSE, 1973). Também se mostra importante para espécies de plantas com rafzes e pélos radiculares escassos (BAYLIS, 1970 e 1975). Por isso, multos estudos com MVA têm concentrado a atenção na nutrição fosfatada de plantas como leguminosas (ABBOTT \& ROBSON, 1984).

Durante algum tempo, suspeitou-se que as micor rizas teriam a capacidade de poder utilizar formas náo assimiláveis pelas plantas, de fósforo insolüvel adicionado ao so10 (MURDOCH et alii, 1967). Posteriormente, através de pesqui sas com 32 , demonstrou-se que tanto plantas infectadas como não infectadas absorvem fosfato da mesma fonte: solução do so Io (SANDERS E TINKER, 1971 ; GIANINAZZI -PEARSON et al11, 1981a).

Tambēm tem sido sugerido que a micorriza VA po de estimular o desenvolvimento das plantas atraves de efeltos fisiológicos, além do aumento na absorção de nutrientes.

Schultz et ali i citados por ABBOTT \& ROBSON (1984), sugeriram que o estimulo da atividade hormonal ou o aumento na absorção de àgua poderia estar envolvido na respos ta de crescimento das plantas à inoculação.

SCHULTZ, R.C.; KORMANIK, P.P.; BRYAN, W.C.;BRISTER, G.H.. Vesicular-arbuscular mycorrtiza influence growth but not mineral concentration in seedlings of eight sweetgum families. Can. J. For. Res, Ottawa, 9: $218,1979$. 
KRISHNh et alii $(1981)$ encontraram diferenças anatomicas e histoquim cas em folhas de Eleusine coracanc, in duzidas pelo fungo MVA. Tais diferenças resultam em aumento do tecido vascular do pianta, podendo facilitar a translocaça de ägua e de nutrientes. E possivel que parte da resposta positiva da planta micorrízica seja decorrente deste efeito. Estes autores sugeriram que o desenvolvimento das plantas pode ser devido a aumento de citocininas. ALLEN et alil (1980 e 1982) também encontraram aumentos na produçäo de citó cininas em ralzes e folhas de Bouteloua gracilis inoculada com MVA, e também aumentos nos teores de substáncias semelhantes a giberelinas e ácido abscísico. Vários autores encontraram aumentos no teor, ou até o aparecimento de vários ácidos graxos e lipídeos em plantas hospedeiras de fungos MVA (NORDBY et a11i, 1981; NAGY et a Ii , 1980; COOPER \& LOSEL, 1978).

outros efeitos das MVA em plantas referem-se à redução do índice de mortalidade das mudas por ocasião do transplante (MENGE et al1i, 1978), provavelmente devido à dimi nuição da resistência interna da planta ao fluxo de água (SAFIR et alii, 1972); participação na agregação do solo (MOSSE \& HAYMAN, 1979); aumento na resistencia de plantas às doenças de rafzes causadas por nematóides (Hussey E Roncadori $1,{ }_{1}$ tados por BAGYARAJ, 1984), bactérias (HALOS E ZORILLA, 1979) e fungos (DAVIS \& MENGE, 1981); e finalmente, exercerem efeitos favoráveis na nodulação e fixação de nitrogénio atmosféri co por Rhizobium em leguminosas (MOSSE, 1977b).

As micorrizas VA resultam de uma condição equi librada entre o fungo, a pianta e o ambiente (clima e solo).

HUSSEY, R.S. E RONCADORI, R.W. Vesicular-arbuscular mycorrhyzal may limit nematode activity and improve plant growth. Plant Dis., St. Paul, 66: 9,1982 . 
Caco um desses componentes é afetado e/ou controlado oor um fator ou série de fatures que podem atuar separadamente, inter-relacionados direta ou indiretamente (LOPES et al11, 1983). Assim, o estabelecimento, funcionamento e multiplicação das micorrizas VA, poden ser afetados por uma série de fatores: disponibilidade de nutrientes (MOSSE, 1973), pH do solo (LAMBERT et alii, 1980a), salinidade do solo (HIRREL \& GERDEMANN, 1980), e fatores físicos como umidade (READHEAD, 1975), aeração (SAIF, 1981) e temperatura (HAYMAN, 1974). Outros fatodes como manejo do solo, fatores biológicos, fatores genéticos da planta, pesticidas e outros, podem afetar direta ou indire tamente as associações micorrizicas VA.

\subsection{Micorrizas VA EM LEguminosas}

\subsubsection{OCORRENCIA E EFEITOS NAS PLANTAS}

As associações triplas entre leguminosas, fungos micorrizicos e bactérias fixadoras de nitrogénio atmosferico têm sido objeto de interesse desde 1896 , quando Jansel, citado por BAGYARAJ (1984), descreveu pela primeira vez tal associação simbiötica na leguminosa Pithecolobium montanum. Mas somente em 1948, ASAl sugeriu que a micorriza era uma précondição necessäria para uma nodulação eficiente em multas leguminosas. Este autor demonstrou que algumas leguminosas, crescendo em solos com pouco $P$, só nodulavam bem e apresenta vam bom crescimento, se os vasos, com solo esteril e inocula dos com o Rhizobium especifico da leguminosa, fossem inoculados também com um pouco de solo de jardim, havendo, então a formação de micorrizas vesículo-arbusculares. Nessa época ainda

JANSE, J.M. Les endophytes radicaux des quelques plantes Javanaises. An. Jard. Bot.Buitenz, s.1., 14: 53 , 1896. 
não se conhecia o papal da micorriza VA na absorção de fósforo para a planta.

As micorizas VA têm sido encontradas em leguminosas que se desenvolvem nos mais variados habitats (CRUSH, 1975; PFEIFFER \& BLOSS, 1980, SAITO et alii, 1983). STRZEMSKA (1975) confirmou a ocorrência de micorriza VA em várias leguminosas cultivadas e MILLER et alii (1979) em algumas leguminosas forrageiras tropicais.

Plantas com pêlos radiculares curtos ou escassos, como as leguminosas, podem ser mais dependentes de micor riza para absorver nutrientes do solo do que plantas com pêlos radiculares bem desenvolvidos, como as gramineas (BAYLIS, 1975). CRUSH (1974) observou que leguminosas tropicais como Centrosema e Stylosanthes, que produzem relativamente poucos pêlos radiculares, foram mais dependentes de micorriza do que leguminosas temperadas como trevo e Lotus, as quais possuíam pélos radiculares mais desenvolvidos. PLENCHETTE et alil (1983) observaram alta dependência de algumas leguminosas à micorriza, em um solo de fertilidade moderada.

- papel das micorrizas VA na produção das leguminosas foi estabelecido em estudos realizados a partir da dëcada de 70 .

Estudos realizados por ROSS \& HARPER (1970) e ROSS (1971) com soja, demonstraram que a inoculação micorrizI ca aumentava a produção, e que plantas micorrizadas continham concentração e conteüdo de nitrogénio na parte aérea maiores do que plantas controle sem micorriza.

SCHENCK \& HINSON (1973) trabalharam com isol! nhas nodulante e não-nodulante de soja no campo, em solo fumi gado e inoculado com fungo micorríco VA. Observaram que a mi corriza aumentou significativamente a produção de grãos e ou- 
tros aspectos das plantas nodulantes, nas nao das não-nodulan tes, além de não verificarem aumentos significativos na absorção de nitrogénio das ültimas.

Efeito da micorriza no estímulo à nodulação foi reafirmado por CRUSH (1974). Este autor demonstrou que a micorriza estimulava o crescimento e nodulação de centrosema pubescens, Stylosantes guyanensys, Trifolium repens e Lotus pedunculatus, e que as plantas não micorrizadas apresentavam taxas menores de fixação do nitrogênio, medidas através da técnica da redução do aceti leno.

Informações posteriores obtidas por DAFT E ELGIAHMI $(1974,1975,1976)$, confirmaram que vários parámetros relacionados diretamente ao processo de fixação de nitrogênio em espécies de Phaseolus, Medicago e Arachís, eram afetados pela infeç̧ão micorrizica. A quantidade de tecido nodular, concentração de leg-hemoglobina e taxas de redução do acetile no foram maiores em plantas micorrizadas do que em plantas con trole não micorrizadas.

REDENTE \& REEVES (1981) trabalhando com a leguminosa Hedysarum boreale em solo estëril, infestado ou não com Glomus fasciculatus e Rhizobium sp., ou com a combinação de ambos, observaram que plantas com a dupla inoculação possuíam níveis maiores de nitrogēnio e fósforo, havendo um efeito sinergístico com relação à taxa de fixação de $\mathrm{N}_{2} \cdot$

Também estudos realizados no campo, com solo natural, mostram os efeitos positivos da inoculaçäo com fungos micorrizicos em leguminosas. AZCON-AGUILAR \& BAREA (1981) inocularam plantas de alfafa no campo com Rhizobium melilotie Glomus mosseae, em um solo com grande capacidade de fixaçäo de fosfato. observaram que a dupla inoculação estimulou o crescimento, a incorporação do nitrogênio e absorção de fós- 
fcro, concluindo que G. mosseae + Rhizobium foram um eficien te "fertilizante biclugico".

\section{BAGYARA et alii (1979) estudaram a respos-} ta da soja à dupla noculação com MVA e Bradyrhizobium em condições de campo, com solo natural. obtiveramaumentos sig nificantes no peso da matéria seca da parte aérea e de nódulos, e conteúdo de nitrogénio, em plantas duplamente inocula das, em comparação com a simples inoculação com Glomus Bradyrhizobium, sugerindo também que a MVA pode ajudar a nodulação e fixação de nitrogênio em soja inoculada com Bradyrhí zobuum, mesmo em condições de campo. HALOS et alii (1972) obti veram resultados semelhantes com soja no campo, onde plantas inoculadas com dois isolados eficientes de fungo MVA e Bradyrhizobium japonicum, apresentavam extraordinärio aumento na formação de nódulos e produção de plantas, comparado com aquelas inoculadas somente com B. japonicum. Concluiram que isolados eficientes de fungo MVA $e$ B. japonicum podiam reduzir as despesas com fertilizantes e aumentar a produção, mesmo em solos pouco produtivos.

A maioria dos estudos sobre a interação MVA Rhizobium sugere que a infecção com enđófitos eficientes aumenta significativamente a nutriçăo em fosforo e, consequente mente, a nodulação e fixação de nitrogênio pelas leguminosas. Tem sido mostrado que as leguminosas requerem níveis adequados de fósforo para o crescimento e boa nodulação e fixação do nitrogênio (BERGERSEN, 1971; DEMETRI0 et ali1, 1972). A micorriza também pode aumentar a nodulação e fixação do $\mathrm{N}_{2}$ como resultado do incremento na nutrição de outros elementos como cobre, zinco, enxofre e outros, os quais são requeridos pelas plantas em quantidades mais elevadas, quando estáo em processo ativo de fixação de $N_{2}$ pelo Rhizobium (LOPES et alil, $1983)$. 
Nas leguminozas noduladss e micorrizadas, nem sempre é possível separar os efeltos na produçáo de matérla seca total, do nitrogénio extra produzido pela melhor nodulação, e fösforo extra absorvido devido à micorriza.

Existe intima relação entre o estado nutricional do hospedeiro e a formação de nödulos. MOSSE et alli (1976) demonstraram que as plantas näo nodulavam a menos que a concentração de fósforo delas fosse no mínimo $0,15 \%$. A colonização micorrizica ajudou as plantas a chegarem nesse nivel, ocorrendo então a nodulação. ROBSON et alil (1981) verificaram que o efelto positivo da micorriza na produção e fixação do nitrogēnio em trevo ocorreu ao mesmo tempo ou depois do efeito no crescimento, indicando que a micorriza aumentou a nodulação e fixação do nitrogênio através do aumento na absorf̧ão de fósforo e no desenvolvimento da planta.

Isto porém discorda de SMITH \& DAFT $(1977)$ os quais afirmaram que o aumento da fixaçäo de nitrogênio em Medicago sativa induzido pela micorriza precedeu ao efeito no crescimento da planta, sugerindo que a demanda do nódulo pelo fósforo vem em primeiro lugar. SMITH et alil (1979) também chegaram à mesma conclusão, principalmente em solos pobres em nutrientes. ASIMI et alii (1980) sugeriram que o Rhizobium seria sensfuel ao efeito da micorriza para satisfazer a alta demanda de fósforo necessária à nodulação e fi xação do $N_{2}$ - Além do mais, o aumento nas adições de fosfato eliminou primeiramente os efeitos da micorriza no crescimento e, progressivamente, os efeitos na nodulação e atividade da nitrogenase, evidenciando que o crescimento da planta e funciona mento dos nódulos mostram respostas diferenciais à demanda por fósforo, devido às suas diferentes dependéncias por esse elemento.

Por algum tempo foi sugerida a possibilidade de 
haver interação di reta entre o fungo MVA e o Rhizobsum. CARLING et alii (1978) trabalharam com isolinhas nodulanics e não nodulantes de soja, usando tratamentos que combinavam Glomus basciculatum, Bradyrhizobium japonicum e fertilizante fosfata do, para tentar avaliar esta interação. Plantas de soja nodulantes duplamente infectadas mostraram aumentos no peso da matéría seca total e de nódulos, bem como altos níveis de atividade da nitrogenase sobre as plantas infectadas com apenas um dos simbiontes ou näo infectadas. Quando o fósforofoi substituído pela infeç̧ão micorrizica, o efel to foi semelhante para o crescimento e atividade enzimática, sugerindo entäo que o fungo micorrízico, que melhora a absorção de fósforo pe las leguminosas, não interage diretamente com a bacteria fixadora do nitrogênio.

A existência de uma disponibilidade de fósforo para os nódulos através das hifas micorrizicas reforça a importáncia de uma nutrição adequada deste elemento na planta hospedeira devido á inoculação mi corrízica, como condição para fixação eficiente de nitrogênio. Os nódulos, como parte da planta, também irão receber suprimento adequado de fósforo para as suas funções se a planta estiver bem nutrida neste elemento (BAREA \& AZCON-AGUILAR, 1983). MOSSE (1981), não deixa dūvida que, de alguma forma, os dois sistemas simbioticos interagem.

Em adição aos efeitos relacionados com a nutriçāo de fósforo, a micorriza pode auxiliar as leguminosas de várias maneiras, como reduzir a severidade de algumas doenças causadas por fungos (Krishna \& Bagyaraj, citado por BAGYARAJ, 1984) e nematóides (KELLAM \& SCHENCK, 1980). outro efei-

KRISHNA, K.R. E BAGAYRAJ, D.J. Interaction between Glomus fasciculatus and Sclerotium rolfsil in peanut. Can. J. Bot., Ottawa, 61: 2349-2351, 1983. 
to benéfico se relaciona com a água, como a diminulgão à resistência ao transporte de água (SAFIR et aliii, 1971 e 1972). HARDIE \& LEYTON (1981) encontraram aumento da condutividade hidrálica dos sistemas radiculares micorrizados em trevo, - que deve resultar em benefícios para a planta quando em quantidade limitante de umidade. A micorriza também pode aumentar a absorção de outros nutrientes pelas leguminosas, como cobre e zinco (ROSS e HARPER, 1970; ROSS, 1971; LAMBERT et al I i, 1980b; NIELSEN \& JENSEN, 1983).

Os fatores que podem afetar o estabelecimento das MVA em leguminosas podem ser, como já relatados para outras culturas: nivel de fertilidade do solo (EL-HASSANIN \& LYND, 1985; LYND et alii, 1985; PURCINO \& LIND, 1985);, pH (SKIPPER \& SMITH, 1979); temperatura (SCHENCK \& SCHRDDER, 1974; SMITH \& BOWEN, 1979); tipo de solo (PARADA, 1984; CARDOSO, 1986); concentração do inóculo (ANTUNEs et alii, 1983); espēcie do endofito (LOPES et alii, 1980; KUO \& HUANG, 1982; B0NETTI, 1984); cultivar da planta hospedeira (MULLIGAN et alii, 1985); práticas culturais (MULLIGAN et alii, 1985), e outros.

\subsubsection{EFEITOS DO FOSFORO}

\subsubsection{Fosfatos solüveis}

A principal contribuição do fungo micorrizico VA para a planta hospedeira em solos deficientes em fósforo, como já foi visto, é alcançar e translocar através de suas hifas extracorticals nutrientes relativamente imóveis, os quais de outra forma estariam fora do alcance para o hospedeiro.

Essa característica das micorrizas é bastante adequada às nossas condições, uma vez que a maioria dos solos brasileiros è de baixa fertilidade, principalmente em fósforo. 
0 melhor desenvolvimento da planta hospedeira, resultado do aumento na absorção de nutrientes relativamente imóveis, tem sido definido como micotrofia (COOPER, 1975). Quan do a concentração de fósforo disponivel está acima ou abaixo do nivel que suporta a micotrofia, o hospedeiro é independente de seu endófito (fungo micorrizico) para a nutrição do fós foro, ou pode competir com a microflora pelo fósforo (Bowen e Barber \& Loughman ${ }^{2}$, citados por BETHLENFALVAY et alii, 1983).

RATNAYAKE et alli (1978) observaram que o aumento nos niveis de fósforo tornavam as membranas celulares das raízes menos permeáveis, resultando em decréscimo na exsudação de aminoácidos e açúcares na rizosfera, desfavorecendo a colonização pelos fungos MVA. SAME et alli (1983) verificaram que havia correlação entre o decréscimo da colonização da raiz de trevo e o decréscimo da concentração de carboidratos solüveis na raiz, em plantas que receberamaltos niveis de fósforo.

Uma vez que as hifas externas são capazes de absorver íons fosfatos da solução do solo, as micorrizas então não somente ultrapassam as zonas de depleção em volta das raizes, mas também provocam novas zonas de depleção deste nutriente. Consequentemente, isto irá causar um empobrecimento do solo após vārias colheitas (LIM \& COLE, 1984). 0 estoque de fosfá

BOWEN, G.D. Disfunction and short falls in symbiotic responses. In: HORSFALL, J.G. \& COWLING, E.B., ed. Plant disease. New York, Academic Press, 1978. Vol.111, p.231256.

2 BARBER, D.A. \& LOUGHMAN, B.C. The effect of microorganisms on the absorption of inorganic nutrients in intact plants 11. Uptake and utilization of phosphate by barley plants grown under sterile and non-sterile conditions. J. Exp. Bot, Oxford, 18: 170-176, 1967. 
to deve então ser restituito, o que oodes ser feito através da aplicação de fertilizantes fosfatados solúeis ou, em algumas circunstáncias, usar formas menos solúvels de fósforo. A interação desses fosfatos com fungos micorrílos VA no de senvolvimento das leguminosas tem sido objeto de vários estudos (BAREA \& AZCON-AGUILAR, 1983). Entretanto, do ponto de vísta prático, os resultados dessas interaçóes entre adição de fosfato e MVA no sistema leguminosa - Rhizobium nem sempre são generalizáveis, uma vez que as respostas são depen dentes de uma serie de fatores. Estes incluem caracteristicas do solo, espécies ou cultivares de plantas, espécies do endófito envolvido e finalmente, a interação entre esses fato res (BAREA \& AZCON-AGUILAR, 1983; PARADA, 1984).

Fol observado que o nitrogento em excesso pode diminuir a nodulação (FRANCO \& DOBEREINER, 1968). Já o fósforo em excesso pode diminuir a infecção micorrizica (AS।MI et aIIi, 1980; BETHLENFALVAY \& YODER, 1981), diminuindo os efeitos positivos na nodulação e atividade da nitrogenase (ASIMI et alii, 1980) em leguminosas. Assim, o endófito produz seu máximo efeito sob condições de estresse de ambos os elementos, sendo que os níveis relativos de cada um são determina dos pelo hospedeiro. Embora muitas leguminosas dependam da micorriza para melhor absorverem o fósforo em solos com pouco fósforo disponível, essa dependencia varia entre as especies de leguminosas (MOSSE, 1977b).

Como a concentração de fósforo no substrato pa rece ser determinante para a colonização micorrizica, os experimentos devem entäo incluir as interaçós dos fungos MVA em uma série de níveis de fosfato, para avaliar em qual nivel de fósforo disponível as diferentes especies de plantas cessam de responder a um bom endófito (OWUSU-BENNOAH E MOSSE, 1979).

Entretanto, alguns desses estudos têm sido rea 
lizados em apenas dois niveis de fósforo, un controle, sem a aplicação, e outro com uma dose de aplicação de fósforo (RoBSON et alii, 1981).

SMITH \& DAFT (1977) observatran que todas as plantas de Medicago sativa, micorrizadas ou não, absorveram mais fosfato de solo ou areia fertilizados com fosfato soluvel, do que de solo ou areia não fertilizados.

VARMA (1979), trabalhando com soja em um solo natural, em vasos, observou que plantas que receberam um inóculo de fungo micorrizico e Bradyrhizobium obtiveram melhor nodulação quando comparadas às plantas que receberam o Bradyr hizobium e fertilização fosfatada $(35 \mathrm{~kg} \mathrm{P} / \mathrm{ha})$. Esse autor concluiu que a infeç̧ão micorrizica pode substituir a aplicação de fosfato neste solo, para se obter uma boa nodulação da soja:

KUO \& HUANG (1982) verificaram que a soja cultivada em um solo natural não tratado, semeada entre restos de cultura de arroz, produziu mais grãos em tratamentos que receberam uma mistura de fungos MVA. o tratamento em que se combinou adição de fosfato e micorriza também promoveu a produção, mas este aumento deve ter sido devido apenas à micor riza, uma vez que a adição de fosfato somente, não promoveu a produção de grãos.

GANRY et ali $(1982)$ em estudo de inoculação com fungo MVA e Bradyrhizobium em soja, no campo, com solo natu ral, observaram que os efeitos benéficos na colhelta se expressaram quando uma pequena quantidade de $p(22 \mathrm{~kg} p / \mathrm{ha})$ foi aplicado ao solo. Conclusōes semelhantes foram obtidas por MANJUNATH \& BAYGARAJ (1984), que obtiveram o mäximo beneficio da dupla inoculação com Rhizobium e MVA, em vasos, com a adição da mesma quantia de fösforo em caupi e Cajanus cajan. 
ROSS (1971) trabalhou com soja em solo fumigado, $\operatorname{com} 3$ niveis de fósforo adicionado $(0,44 \mathrm{e} 176 \mathrm{~kg} \mathrm{p} / \mathrm{ha})$. A produção de plantas quando inoculadas com fungo micorrizico (Endogone) foi sempre maior em relação às não inoculadas, mas não fol relacionada com os níveis da fertilização fosfata da, enquanto que a produção de plantas não micorrizadas foi diretamente relacionada com a aplicação de fosfato. Em niveis baixo, médio e alto de fósforo, os aumentos na produçáo devido à MVA foram 122,67 e $12 \%$, respectivamente. Esses resultados sugerem que a aplicação de doses mais elevadas de fósforo à soja mi corrizada pode diminuir a dependência pelo endófito.

HALL et alil (1977) trabalharam com duas cult 1 vares de trevo branco, utilizando Rhizobium em todos os tratamentos, e vários níveis de $P$ aplicado $(0,10,30,60,90 .$. $240 \mathrm{~kg} \mathrm{P} / \mathrm{ha}$. A inoculação com fungo micorrizico estimulou a absorção de fósforo e aumentou o crescimento das plantas nos niveis mais baixos de p aplicado $(0,10 \mathrm{e} 30 \mathrm{~kg} / \mathrm{p} / \mathrm{h})$, em relação à plantas não inoculadas. A cultivar 'Tamar' produziu mais parte aérea do que a cultivar 'Grasslands Huia', principalmente em niveis maiores que $30 \mathrm{~kg} P / \mathrm{ha} e$, em niveis mais baixos de $P$ aplicado, a maioria de suas raízes se converteram em micorrizas, sendo mais micotrofica do que 'Grasslands Huia! Esses autores concluíram que a MVA pode beneficiar planta de trevo no solo utilizado no experimento, com a aplicaça de, possivelmente, muito mais do que $20 \mathrm{~kg} \mathrm{P} / \mathrm{ha}$

OWUSU-BENNOAH \& MOSSE (1979) utilizaram cebola, cevada e alfafa (inoculada tambem com Rhizobium), en vasos com solo natural, usando dols tipos de fungos MVA, com doses crescentes de fósforo. A melhor resposta da cevada a inoculação confinou-se no nível mais baixo de fósforo disponível ( $8 \mathrm{ppm}$ de fósforo). Alfafa e cebola mostraram aumentos na produção de matéria seca, principalmente com a introdução de um dos endöfitos, com o aumento no conteúdo de fós- 
for no solo, e esta tendéncia poderia ter continuado acima de $14 \mathrm{ppm}$ de $\mathrm{P}$ disponivel, concentração esta considerada ainda baixa pelos autores.

BETHLENFALVAY \& YODER (1981) observaram que em soja inoculada com Bradyrhizobium e fungo micorrízico, cultivada em meio de enraizamento estéril com doses crecentes de fósforo, as plantas possuíam em todos os níveis (com excessāo do mais elevado), maior taxa de fixação de $\mathrm{N}_{2}$, massa de planta e de nōdulos e conteúdo de fósforo, em relação às plantas não inoculadas com o fungo micorrízico. No nivel major $(500 \mathrm{\mu M}$ de P), a infecção pelo Glomus fasciculatum foi muito baixa e não afetou os parâmetros medidos, isto é, não houve diferenças entre soja micorrizada e não micorrizada. 0 maior aumento nas variáveis analisadas, provocado pelo fungo micorrizico, ocorreu no nivel mais baixo de fósforo (20 $\mu M$ de P).

ROBSON et alii $(1981)$, trabalhando com trevo subterrâneo, inoculado com Rhizobium thibolie e Glomus monosporus, em 4 níveis de fósforo $(0,1 ; 0,2 ; 0,6$ ou $1,2 \mathrm{~g}$ P/ vaso de $3 \mathrm{~kg}$ ) aplicados como superfosfato e com 4 épocas de colhel ta $(22,29,37$ e 50 dias apōs semeadura), constataram que no nível mais baixo de fósforo, plantas micorrizadas mostraram, com o passar do tempo, aumentos na produçäo de parte aérea, nódulos e redução do acetileno por planta. Aos 50 días após a semeadura, observaram que aumentos no nível de fósforo na ausência de MVA aumentou a taxa de redução do acetileno por planta, a concentração do nitrogênio da parte aérea e a concentração de fósforo na parte aérea, raízes e nódulos. Na pre sença da micorriza, os valores dessas variáveis diminuiram no nível maior de fósforo aplicado, mas nos niveis mais baixos, plantas micorrizadas se mostraram superiores em relação às não micorrizadas.

ABBOTT \& ROBSON (1978), trabalhando com trevo, 
em solo natural, com três niveis de fósforo $(1,2$ ou $8 \mathrm{~g} P /$ vaso de $3 \mathrm{~kg}$ ), introduziram 3 fungos MVA de origens diferentes. 0 isolado de Glomus monosporus (MtBGM) foi o mais eficiente para produção de matéria fresca da parte aérea após 7 semanas do plantio, mas o aumento relativo à MVA, para os três isolados em relação ao controle (fungos MVA nativos) diminuiu com o aumento no nível de fósforo no solo. Os dois isolados de Glomus monosporum ( $M G M$ e MtBGM), mas não de Glomus fasclculatum, promoveram o desenvolvimento das plantas mesmo na maior dose de fósforo, e aumentaram a absorção de fósforo em todos os niveis. A sensibilidade dos endófitos a altas taxas de fósforo adicionado, pode depender de sua origem. os isolados de G. monosporus vieram de solos que possuíam níveis rela tivamente altos de fósforo disponível, resultado de aplicaçóes repetidas de superfosfato. Os dois isolados devem entáo ter desenvolvido uma habilidade em formar micorrizas nos niveis relativamente mais altos (ABBOTT \& ROBSON, 1978).

LIM E COLE (1984), trabalhando também com trevo em dois tipos de solo, fumigados e inoculados com Rhizobium e Glomus fasciculatum, em värios niveis de fósforo, observaram aumentos significativos na parte aérea em plantas micor rizadas, em colheitas sucessivas, em todos os niveis de P. Porém, a magnitude da resposta micorrizica diminuiu com o aumento no nível de fosforo ou com sucessivas collheitas. A res posta positiva de plantas micorrizadas e não micorrizadas à aplicação de níveis mais altos de fösforo $(150,1$ e $81,0 \mathrm{~kg} \mathrm{P} /$ ha) em ambos os solos, indica que a concentração supra - ótima de fósforo, provavelmente, não foi alcançada. Esses autores sugerem que fungos micorrízicos mais eficientes em altos niveis de fósforo poderiam ser selecionados para uso agronomi co, onde tais níveis são vantajosos para elevar a produção.

SIQUEIRA \& PAULA (1986) concluiram que a micor rização da soja pelo fungo Glomus macrocarpum em um solo de 
cerrado, fumigado, aumentou os teores e quantidades absorvidas de fósforo, efelto este que também ocorreu com o aumento do suprimento de fósforo ao solo $(0,15,30,60,120$ e 240 ppm de $P_{2} O_{5}$ ), obtendo-se efeito mäximo da micorriza quando se aplicaram $120 \mathrm{ppm}$ de $\mathrm{P}_{2} \mathrm{O}_{5}$ o aproveitamento do fósforo apllcado foi cerca de duas vezes maior nas plantas com G. macrocarpum que nas demais, em todas as doses de fósforo. A eficiência simbiótica deste fungo MVA foi equivalente à 210 ppm de $\mathrm{P}_{2} \mathrm{O}_{5}$, enquanto que os fungos nativos (presentes nos tratamentos com solo natural) apresentaram balxa eficiencia.

PAULA \& SIQUEIRA $(1986)$, em trabalho semelhan te, já haviam observado que tanto a aplicação de fósforo quan to as MVA influenciaram significativamente o desenvolvimento da soja, e que o efeito benéfico do fungo $G$. macrocarpum estendeu-se à dose de $240 \mathrm{ppm}$ de $\mathrm{P}_{2} \mathrm{O}_{5}$, nível que ja se mostrou inI bitório à colonização das raízes.

\subsubsection{Fosfatos de baixa solubilidade}

Existem värias evidéncias de que as leguminosas se beneficiam das micorrizas na presença de fosfatos "in solúveis"l ou de baixa solubilidade. Uma série de trabalhos com esse tipo de fosfato têm sido realizados em solo estéril, natural e mesmo em solução nutritiva.

os ensaios em que se usa fósforo marcado $\left({ }^{32} \mathrm{P}\right)$ no solo, indicam que plantas mi corrizadas e não micorrizadas absorvem o fósforo da mesma fonte que as plantas, $15-$ to é, fósforo solúvel (GIANINAZZI-PEARSON et al11, 1981a). Como se sabe, a MVA explora melhor os fosfatos pouco solúveis pois as hifas podem fazer um contato mais intimo que as raizes com as partículas de fosfato, onde os íns soluvels estão sendo dissociados quimicamente. Portanto, a utilização de uma fonte de fósforo não läbil pela micorriza ocorre na 
condição de existir a liberação, mesmo lenta, de alguns íons fosfato (BAREA \& AZCON-AGUILAR, 1983).

ROSS E GILLIAM (1973) compararam a produção de grãos de soja, em solo fumigado e inoculado com fungo micorrízico ou não, na presença de fosfato de alumínio, de ferro, de rocha ou monocálcico obtendo aumentos de $79,53,0$ e $56 \%$, respectivamente, para cada fonte de fosfato. As melhores fontes de $P$ para a soja, tanto na presença como na ausēncia de micorriza, foram o fosfato monocalcico e o fosfato de alumínio. A produção de plantas fertilizadas com o fosfato de ferro correspondeu a $1 / 6$ e a $1 / 5$ daquelas fertilizadas com fosfato monocálcico ou fosfato de alumínio, respectivamente. Neste experimento o fosfato de rocha não foi disponível para as plantas, nem às micorrizadas, provavelmente por causa da pequena quantidade utilizada $(17,6 \mathrm{mg} \mathrm{P} / \mathrm{kg}$ de solo).

MOSSE et alii (1976) mostraram que uma nodulação eficiente das leguminosas Centrosema, Stylosanthes e trevo, em uma série de solos deficientes em fósforo (pH variando de 5,3 a 8,1$)$, pode ser conseguida pela introdução de micorriza e fösforo extra, mesmo sendo este fósforo originado de fosfato de rocha de baixa solubilidade. 0 fosfato de rocha $(100 \mathrm{mg} /$ $250 \mathrm{~g}$ de solol aumentou significativamente a absorção de p nos solos àcidos, principalmente em plantas micorrlzadas. Porem, em solos neutros e alcalinos, o fosfato de rocha não se mostrou disponivel, para plantas micorrizadas ou não. Quando o solo era muito deficiente em fósforo, a nodulação ocorria somente na presença da micorriza.

Aumentos na nodulação, fixação de nitrogēnio e crescimento de plantas de Stylosanthes por causa da micorriza e do fosfato de rocha também foram observados em solos não este rilizados da Nigéria. Oendófito introduzido estabeleceu-se bem em Il dos solos, e seus efeitos foram maiores em solos que previamente apresentavam baixa infectividade (MOSSE, 1977a). 
WAIDYANATHA et alil (1979) também trahalharam com Stylosanthes e Pueraria, em solo fumigado e inoculado com fungo micorrizico, utilizando dois tipos de fosfato de rocha. A presença do fungo micorrízico ou a presença de fosfato de rocha, usado na quantidade de $500 \mathrm{mg} / \mathrm{kg}$ de solo, estimulou o crescimento e a nodulação de pueraria e Stylosanthes, e a at vidade da nitrogenase de Pueraria. A combinação de micorriza com fosfato de rocha produziu incrementos máximos nas variáveis analisadas e também aumentou a absorção de fósforo. 0 efelto do fosfato de rocha importado (Jordan) fol superior à apatita (Eppawela), como era de se esperar, devido à malor so lubilidade em àcido cítrico do primeiro.

Em solos naturais, ISLAM et ali (1980) observaram o efeito da inoculação de fungo MVA no caupi, em experimentos com vasos e no campo, usando fosfato de rocha. A no dulação, fixação de nitrogênio e utilização do fosfato foram significativamente incrementadas pela inoculação micorrizica no experimento em vasos, mas no campo esses incrementos não foram significativos. A resposta também variou com o tipo de solo empregado.

CABALA-ROSAND E WILO (1982) observaram que a resposta à produção de matēria seca de Stylosanthes guyanensis e Desmodium intortum pela adição de $100 \mathrm{\mu g} \mathrm{P} / \mathrm{g}$ solo como fosfato de rocha (Patos), aumentou através da inoculação com - fungo MVA Glomus fasciculatum, em solo irradiado. Esses autores concluíram que a inoculação dessas leguminosas, combinada com uma aplicação suficiente do fosfato de rocha patos pode ser uma maneira económica para aumentar a produtividade de pastagens em solos de baixa fertilidade.

LYND et alii (1985) estudaram os efeitos da inoculação de siratro com Rhizobium leguminosarum e Glomus fas. ciculatum, em um solo fumigado, na presença ou não de fosfato 
po,co solüvel loomg $\mathrm{P} / \mathrm{kg}$ solo como Ca $\left.3\left(\mathrm{PO}_{4}\right)_{2}\right]$ e 4 nivels de adubação potássica $(0,100,200$ e $300 \mathrm{mg} \mathrm{K} / \mathrm{kg}$ solo como KCl). Es ses autores observaram que maiores respostas de peso de nódulos frescos e atividade especifica da nitrogenase foram conseguidas pelos tratamentos com fungo micorrizico na presença do fosfato, no maior nível de potássio. A maior produção de matéria seca da parte aérea fol obtida no nível mais alto de potássio, na presença da micorriza. Resultados semelhantes foram obtidos por PURCINO \& LYND (1985) com Stylosanthes scabra, em solos com mesmo tratamento de fertilidade. Em ambos os tra balhos, concluiu-se que práticas culturais que atinjam uma eficiente simbiose tripla leguminosa-Rhizobium-fungo MVA são importantes para aumentar a produtividade de leguminosas forrageiras

CARDOSO (1985) avaliou o efeito da micorriza isolada ou em combinação com o fosfato de rocha Alvorada, sobre o desenvolvimento da soja e sobre a simbiose soja - Bradyrhizobium em solo estéril. Esta autora observou que tanto a micorriza como o fosfato de rocha provocaram incrementos no peso da matéria seca de plantas e de sementes, no número e pe so de nódulos, na concentração de fósforo da matéria seca, e na quantidade total dos elementos absorvidos pela planta. os incrementos maximos em todas as variáveis analisadas foram obtidas em tratamentos que combinavam micorriza e fosfato. A micorriza tambèm provocou uma redução no teor de manganês e um aumento no teor de zinco na parte aérea das plantas.

Com o objetivo de verificar a eficiência de vá rios fungos micorrizicos MVA em soja, cultivada em diferentes tipos de solo, fertilizados com o fosfato de rocha Alvorada e inoculados com B. japonecum, CARDOSO (1986) observou que os fungos MVA mais eficientes no Latossolo Roxo da série Luiz de Queiroz esterilizado foram Glomus fasciculatum, Glomus machocarpum e Gigaspora heterogama. Porém, não houve benefícios da 
inoculação de qualquer um dos endófitos neste solo em estado natural. Nas areias quartzosas, séries Sertãozinho e Ribelrão claro, os dois fungos mais eficientes foram G. macrocar pum e G. heterogama, favorecendo o desenvolvimento da soja tan to em solo natural como no esterilizado.

Esses fungos foram eficientes, causando aumentos na produção de matéria seca da parte aérea, de vagens, e de nödulos, além de aumentos significativos na concentração de fósforo e nas quantidades totais da maloria dos outros nutrientes vegetais.

BONETTI (1984) jà havia verificado que em plan tas de siratro, todas inoculadas com Rhizobium e adubadas com fosfato de rocha, a inoculação com fugos MVA de diferentes es pécies aumentava significativamente o peso da matéria seca das plantas, peso e número de nódulos e teores de nitrogénio e fósforo na parte aērea, em relação às plantas não inoculadas.

EL-HASSANIN E LIND (1985) trabalharam com Vicia baba L., inoculada com R. legumenosarum e inoculada ounãocomGlomus fasciculatum, em solo estéril, adubado com fosfato pouco solüvel $\left[\mathrm{Ca}_{3}\left(\mathrm{PO}_{4}\right)_{2}\right]$ em quatro niveis $(0,100,200$ e $300 \mathrm{mg} \mathrm{P} /$ $\mathrm{kg}$ de solo), e adubado ou não com KCI $(0$ ou $100 \mathrm{mg} \mathrm{K} / \mathrm{kg}$ de so10). Observaram que a presença da micorriza promoveu incrementos máximos no peso da matéria seca da parte aérea e peso da matèría fresca de nódulos em tratamentos que receberam o potássio e o fósforo nos malores niveis. Entretanto, a atividade da nitrogenase foi a mais alta no maior nível de fósforo na presença da micorriza, e a adição de potássio não foi consistente para esse aumento.

SPARLING \& TINKER (1978) avaliaram doses cres centes de fosfato solúvel $(10$ a $500 \mathrm{mg} / \mathrm{kg}$ de solo) e fosfato 
de rocha $(0,1$ a $20 \mathrm{~g} / \mathrm{kg}$ de solo) sobre o desenvolvimento do trevo na presença e ausêncila de três fungos micorrizicos. As doses mais elevadas de cada fosfato deram respostas equivalen tes e, nestas doses, o melhor endófito ainda causoú incrementos no crescimento. Mesmo na ausencla dos fungos MVA, houve resposta da planta à adubação com o fosfato de rocha, embora em menor proporção.

o efeito da micorriza em trevo foi avaliado na presença de doses crescentes de três fosfatos de diferentes so lubilidades (superfosfato, fosfato de rocha calcinado e fosfato de rochal por PAIRUNAN et ali i (1980), nas quantidades respectivas de 0,50 a $8,00 \mathrm{~g} ; 0,7$ a 11,4 e 3,6 a $343 \mathrm{~g}$ por $\mathrm{kg}$ de solo. A micorriza aumentou sensivelmente o crescimento e conteúdo de fósforo da parte aérea nos níveis intermediários de cada fosfato, esses autores também observaram que desde que fosse aplicada quantidade suficiente de fosfato de rocha, as plantas não micorrizadas cresciam tão bem quanto as micorrizadas.

EZETA \& SANTOS (1980) avaliarama eficiêncla da micorriza formada pela associação do fungo MVA Gigaspora margarita e as raizes de Vigna unguiculata no crescimento e absorção de nutrientes, em casa de vegetação, com solo natural e adubado ou não com fosfato solüvel ou fosfato de rocha Patos de Minas, equivalentes a $20 \mathrm{ppm}$ de $P$. A inoculação favoreceu o crescimento com todas as fontes de fosfato, incluin do a testemunha não adubada, sendo que a fonte solúvel resultou no maior incremento de matéria seca. A inoculaçáo resultou em maior absorção de fósforo pela Vigna, havendo interação slgnificativa entre fontes e inoculação, porém, a concentração média no tecido foi a mesma em todos os tratamentos. Na testemunha e na rocha fosfatada, o incremento na acumulação de P na matéria seca foi em média $37 \%$ maior nas plantas inocula das, enquanto que na fonte solüvel de p esse valor foi somente $17 \%$ em favor da inoculação. 
BONETTI E DONALD (1986) estudaram o sfeito da micorriza em soja inoculada com B. japonicum, com a aplicação de fosfato solúvel e de rocha, potāssio, cälcio e magnésio, num Latossolo Amarelo argiloso, esterilizado ou náo. observaram um efeito favorável no crescimento e nodulação da soja pela micorriza, efeito este acentuado em solo esteriliza do, sugerindo haver no solo uma população de fungos nativos eficientes. A aplicação de fosfato de rocha com mi corriza pro moveu resposta superior àquela provocada pelos fatores isolados, igualando ao tratamento com fosfato solüvel.

Em experimento conduzido no campo, com superfosfato simples e fosfato de rocha em diferentesdoses de adubação, MIRANDA (1982) observou que a introdução dos fungos MVA Gigaspora margarita e Glomus macrocarpum promoveu a produção da cultura da soja nos tratamentos com superfosfato simples $\left(100\right.$ e $\left.200 \mathrm{~kg} \mathrm{P}_{2}{ }_{5} / \mathrm{ha}\right)$. 0 efeito da associaçäo micorrízica na produção, em tratamentos com fosfato natural de Patos de $M i-$ nas, foi observado apenas na maior dose de $\mathrm{P}_{2} \mathrm{O}_{5}$ aplicada $(400$ $\mathrm{kg} \mathrm{P}_{2} \mathrm{O}_{5} / \mathrm{ha}$.

PAULINO et alii (1986) avaliaram, em solo esté ril, com baixo nível de fósforo disponivel, o efeito de duas espécies de fungo micorrizico, Glomus mosseae e Glomus fasciculatum, e duas fontes de fósforo, fosfato solüvel e fosfato de rocha, nas leguminosas forrageiras centrosema pubescens, Galactia striata e siratro. Esses autores observaram que o siratro respondeu melhor à MVA, que incrementou a produção da matéria seca, a atividade da nitrogenase e a absorçáo de $N$ e $P$, sendo $G$. fasciculatum superior a G. mosseae. Geralmente, com G. mosseae na presença de adubação fosfatada, a elevação na matéria seca foi mais acentuada, enquanto que com $G$. fasciculatum sozinho ou com adubação fosfatada, o aumentou foi semelhante. o fosfato de rocha mais $G$. mosseae beneficiou a fixação de $\mathrm{N}_{2}$ e a absorção de nutrientes. 
Para a centrosema, a MVA favoreceu o crescimen to, sendo $G$. fasciculatum superior a $G$. mosseae, mas a fixação do $\mathrm{N}_{2}$ não fol afetada pela inoculação, a não ser quando se utilizou fosfato solüvel. Para a galaxia, as respostas ao crescimento e absorçao de $P$ foram ligeiramente influenciados pe los fungos micorrizicos. A absorção de nitrogênio teve pouca variação, tendo sido maior para os tratamentos com MVA na presença de fosfato solúvel.

BETHLENFALVAY et a 111 (1982) observaram que, em fei joeiro cultivado em substrato inerte com solução nutritiva, usando doses crescentes de hidroxiapatita $(0,25,50$, 100 e $200 \mathrm{mg} / \mathrm{vaso}$, o crescimento, nodulação e atividade dos nódulos aumentaram para plantas controles e micorrizadas, com - aumento da disponibilidade de fósforo. Porém, os valores para plantas micorrizadas foram significativamente menores em todos os parámetros, em relação ao controle. lsso pode ser explicado devido à pequena quantidade de luz disponível para as plantas neste experimento, gerando condiçōes sub-ótimas para a fotossintese e consequente competição por fotossintatos entre os simbiontes.

Também em substrato inerte, BETHLENFALVAY et alii (1983) usando hidroxiapatita nos mesmos niveis anteriores, observaram que no nível mais baixo $(0 \mathrm{mg})$ e nos mais altos $(100$ e $200 \mathrm{mg})$ deste fosfato, a soja micorrizada mostrou 20,25 e $38 \%$ de diminuição no crescimento, respectivamente, em relação às plantas não micorrizadas. Apesar disto, as plantas micorrizadas ou não, responderam aos nívels de fosfato quanto ao crescimento e conteüdo de fósforo na planta. No ni vel de $50 \mathrm{mg}$ de hidroxiapatita, o crescimento de plantas micorrizadas aumentou significativamente $(14 \%)$ em relação às não micorrizadas. Neste nível de fosfato, a relação entre micélio extra-radical e intra-radical, um findice sugerido para avaliar a eficiência da micorriza, foi o maior, coincidindo com o aumento de crescimento da planta hospedeira. 
MOSSE \& THONOSON (1984) em estudos para produção de inóculo de MVA, utilizaram plantas de feijão em soluçäo nutritiva recirculante em bandejas, contendo 1,3 e 8 mg/ 1 de fósforo como fosfato monocálcico, e $5 \mathrm{mg} / \mathrm{m}$ de bandeja co mo farinha de ossos ou fosfato de rocha, espainados em volta das ralzes, no início do experimento. Esses autores observa ram que as plantas do tratamento com fosfato de rocha apresentaram melhor crescimento, e suas ralzes possuíam infecçáo mais vigorosa e, consequentemente, apresentaram maior infectividade em plantas testes, em um estudo posterior. ELMES \& MOSSE (1984) em experimento semelhante, observaram que o pH da solução era muito importante por causa do seu efeito na solubilidade do fosfato de rocha. 


\section{MATERIAL E MÉTODOS}

o presente trabalho foi realizado em casa-devegetação e em laboratório, no Departamento de Solos, Geologia e Fertilizantes da ESALQ/USP, e constou de dois experimen tos, um com soja (Glycine max (L.) Merril) e outro com feijäo (Phaseolus vulgaris L.).

o objetivo desses experimentos fol avaliar o efeito da inoculação com fungos MVA sobre o aproveitamento de quatro tipos de fosfato de rocha, usados em três doses, compa rando-o com o do fosfato solüvel, e sobre a simbiose com $R h$ hzobium, nas duas leguminosas.

\subsection{Material}

\subsubsection{PLANTAS}

Nos experimentos foram empregados a soja cv. Viçoja, cujas sementes foram obtidas na Seção de Leguminosas do Instituto Agronômico de Campinas; e o feijão cr. Carioca, com sementes provenientes do Centro Nacional de Pesquisa - Ar roz, Feijão/EMBRAPA - Goiânia.

3.1.2. SOLO

Nos dois experimentos foi utilizada uma Areia Quartzosa da Série Ribeirão Claro, coletada no município de Santa Maria da Serra, São Paulo, e cuja análise química se en 
contra na Tabela 1. A amostra l foi utilizada para o experimento com soja e a amostra 2 para o experimento com feijão.

TABELA 1. Análise química das amostras do solo Areia Quartzosa, Série Ribeirão Claro.

\begin{tabular}{|c|c|c|c|c|c|c|c|}
\hline \multirow{2}{*}{ Amostra } & \multirow{2}{*}{$\mathrm{pH}$} & \multirow{2}{*}{$\mathrm{C} \%$} & $\mathrm{PO}_{4}^{3-}$ & $\mathrm{k}^{+}$ & $\mathrm{Ca}^{2+}$ & $\mathrm{Mg}^{2+}$ & $\mathrm{Al}^{3+}+\mathrm{H}^{+}$ \\
\hline & & & \multicolumn{5}{|c|}{ meq $/ 100 \mathrm{~g}$ de terra } \\
\hline 1 & 4,6 & 0,30 & 0,02 & 0,04 & 0,16 & 0,16 & 2,88 \\
\hline 2 & 5,8 & 0,42 & 0,03 & 0,04 & 0,29 & 0,12 & 3,24 \\
\hline
\end{tabular}

3.1.3. Rhizobium spp.

No experimento com soja foi usada uma mistura de três estirpes de Bradyrhizobium japonicum, previamente purificadas: CPAC 93, SEMIA 580 e SEMIA 5061 . No experimento com feijāo utilizou-se uma mistura de trēs estirpes de Rhizobium phaseoli, também previamente purificadas: C-05, C-13 e $127 \mathrm{~K}-$ 17.

\subsubsection{FUNGOS MICORRTZICOS VESTCULO-ARBUSCULARES}

No experimento com soja o fungo MVA empregado foi Glomus macrocarpum Tul. e Tul. var. macrocarpum, e no experimento com feijão empregou-se Glomus leptotichum schenck e Smith. 


\subsubsection{FOSFATOS DE ?OCHA}

Em ambos os experimentos foram utilizados quatrotipos de fosfato de rocha: Patos de Minas. Araxá, Jacupiranga e Catalão. Todos eles são fosfatos apatíticos, de origem ígnea, com excessão do fosfato patos de Minas que é uma fosforita de origem sedimentar-metamörfica.

o teorem $\mathrm{P}_{2} \mathrm{O}_{5}$ total, solubilidade e granulome tria desses fosfatos se encontram na Tabela 2.

\subsection{MÉTODOS}

\subsubsection{PREPARO DO SOLO E VASOS DE PLANTIO}

Em ambos os experimentos, o solo foi coletado da camada superficial até $20 \mathrm{~cm}$ de profundidade, peneirado e esterilizado através da tindalização com vapor fluente por 2 horas em 3 dias consecutivos. A seguir foi misturado com arela de rio esterilizada, na proporção de $3: 1$ (solo :areia), e acondicionado em vasos de barro com capacidade para $3 \mathrm{~kg}$ de solo, e no fundo de cada vaso havia sido colocada uma camada de pedregulho esterilizado, para facilitar a drenagem.

\subsubsection{CALAGEM E ADUBAÇAOO}

Em ambos os experimentos foi realizada a calagem para elevar o $\mathrm{pH}$ a valores entre 6,0 e 6,5 , usando em cada vaso $0,6 \mathrm{~g}$ do corretivo Minercal $(43 \% \mathrm{CaO}$ e $24 \% \mathrm{MgO})$.

Tambēm se fez a adubação corretiva em função da análise química do solo e necessidades das plantas, uti1 izando em ambos os experimentos, $125 \mathrm{mg}$ de cloreto de potassio e $1,0 \mathrm{~g}$ de sulfato de cálcio em cada vaso. 


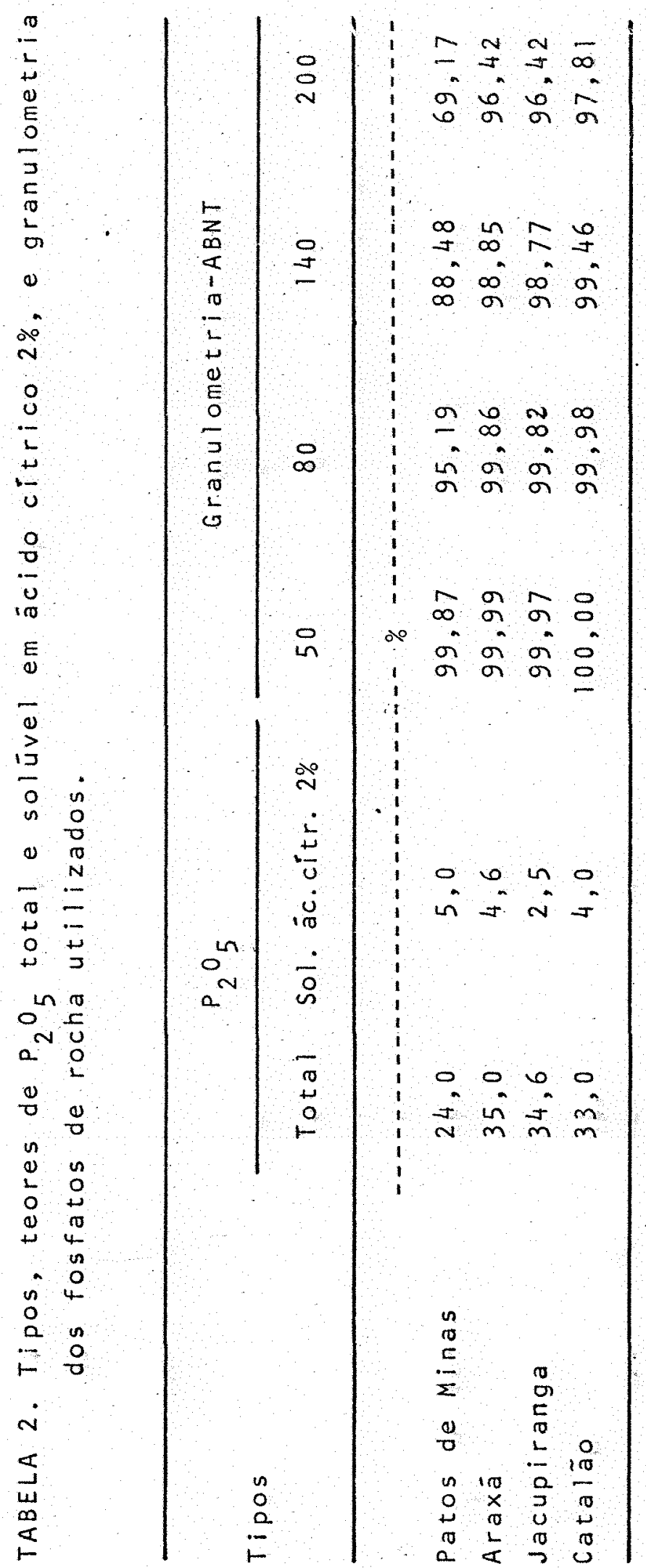


A adubação tosfatada ralizada com os fosfatos de rocha constou de 3 niveis: 54 , 128 e 256 ppm de $P$, sendo que as quantidades do adubo pesado para cada vaso foi baseada no teor de $\mathrm{P}_{2} \mathrm{O}_{5}$ total. Houve um tratamento conerole em que se usou o superfosfato triplo, ao nivel de $18 \mathrm{ppm}$ de $\mathrm{p}$, cuja quantidade colocada em cada vaso foi baseada no teor de $P_{2} 0_{5}$ solúvel em água. Também houve um tratamento controle sem adi ção de fósforo.

0 solo contido nos vasos, os adubos e corretivos pesados para cada vaso foram colocados em sacos plásticos e agitados até que a mistura ficasse homogênea. A seguir, os vasos preenchidos com o solo foram umidecidos.

Fez-se a aplicação de $0,5 \mathrm{ml} / 1 \mathrm{i}$ tro de solução de micronutrientes de NORRIS (1964) contendo cobre, zinco, molibdênio e boro; e $0,5 \mathrm{ml} / \mathrm{litro}$ de solução de sulfato de ferro em äcido citrico, di luidos na água de irrigação, aplicando-se $200 \mathrm{ml}$ por vaso.

\subsubsection{PREPARO DOS INOCULOS}

As estirpes de Rhizobium spp estavam conservadas em meio YMA (Yeast-Manitol-Agar) modificado por NoRRIS (1964), com a seguinte composição: $10 \mathrm{~g}$ de manitol; $0,5 \mathrm{~g}$ de extrato de levedura; $0,5 \mathrm{~g}$ de $\mathrm{K}_{2} \mathrm{HPO}_{4} ; 0,8 \mathrm{~g} \mathrm{de} \mathrm{MgSO}_{4} \cdot 7 \mathrm{H}_{2} 0 ; 0,2 \mathrm{~g}$ de $\mathrm{NaCl} ; 0,01 \mathrm{~g} \mathrm{FeCl}{ }_{3} .6 \mathrm{H}_{2} 0 ; 0,01 \mathrm{~g}$ de azul de bromotimol; $18 \mathrm{~g}$ de agar; em $1000 \mathrm{ml}$ de àgua destilada. para o $R$. phaseoli foram adicionadas $3 \mathrm{~g}$ de $\mathrm{CaCO}_{3}$ por litro.

Retirou-se duas alçadas de cada estirpe, separadamente, colocando-as em tubo $\operatorname{com} 9 \mathrm{ml}$ de água destilada es tëril. Desta duspensäo retirou-se $1 \mathrm{ml}$ e inoculou-se em fras coserlenmeyers de $250 \mathrm{ml}$, com $50 \mathrm{ml}$ do meio líquildo (YMB: Yeast-Manitol-Broth). Foram delxadas crescer sob agi tação 
constante em temperatura ameiente durante quatro (B. japonicum) e três dias ( $R$. phaseole), quando se obseryaram mudanças na coloração do melo e turbidez.

- fungo MVA Glomus macrocarpum foi obtido através da multiplicação em vaso com solo estēril, tendo o crisântemo como planta hospedeira. O fungo MVA Glomus leptotichum fol obtido da mesma forma, sendo o milho a planta hospedeira. 0 inöculo fol então constituído do solo contendo esporos e raízes das plantas infectadas com o fungo micorrízico. Para a soja, em cada vaso foram colocados $60 \mathrm{ml}$ desse solo contendo aproximadamente 1000 esporos do fungo G. macrocarpum. Como controle foi usada a mesma quantidade de solo autoclavado dos vasos do crisantemo que não tinham sido inoculados com o fungo, misturando um pouco de filtrado da suspensão do mesmo solo antes de ter sido autoclavado, sem os propägulos do fungo MVA, para fornecer a mesma microflora. Pa ra o feijão, em cada vaso utilizou-se $100 \mathrm{ml}$ do solo inöculo com cerca de 200 esporos do fungo micorrízico G. leptotichum, e como controle, a mesma quantidade de solo autoclavado do milho que não tinha sido inoculado com o fungo. Na ocasião da semeadura, em cada vaso do controle foi colocado sobre o inóculo, $5 \mathrm{ml}$ de uma suspensäo de filtrado desse último solo antes de ter sido autoclavado, para fornecer a mesma microflora, mas livre dos propágulos do fungo MVA.

\subsubsection{INSTALAÇÃO E CONDUÇÄO DA CULTURA}

o primeiro experimento foi realizado com a soja, sendo instalado em 18/12/84. o feijäo fol instalado em $09 / 05 / 85$.

Em ambos os casos, na ocasião da semeadura, as sementes foram desinfetadas superficialmente com uma solução de hipoclorito de sódio a $1 \%$, durante 10 minutos, e lavadas 
em śgua corrente. A seguir as sementes foram colocadas em contato com a suspensäo de bactérias fixadoras de $\mathrm{N}_{2}$ especificas para cada leguminosa, e que continha a mistura das estirpes. As sementes foram deixadas embeber nessa suspensão durante uma hora.

A semeadura nos vasos deu-se então da seguinte forma: retirou-se uma pequena quantidade de solo do vaso e colocou-se o inóculo do fungo micorrizico especifico paracada leguminosa. Para o feljão, fol colocado sobre este inócu$105 \mathrm{ml}$ de suspensão de filtrado de solo, como descrito anteriormente. A seguir colocou-se uma camada com cerca de 3 $\mathrm{cm}$ de terra retirada do vaso e sobre ela espalharam-se 10 sementes já embebidas com o inoculante de Rhizobium. Sobre as sementes colocaram-se $10 \mathrm{ml}$ da suspensão de Rhizobium em cada vaso e cobriu-se com o resto do solo retirado. Também foi realizada no mesmo dia, semeadura em caixas com areia estéril para encobrir as possiveis falhas de germinação nos vasos, com sementes inoculadas com o Rhizobium.

A germinação aconteceu por volta de 7 a dias e o desbaste foi realizado aos 15 dias após a semeadura, mantendo-se 2 plantas por vaso.

Aos 15 dias apōs a semeadura, realizou-se a segunda inoculação da soja com B. japonicum, colocando-se 20 ml da suspensão com a mistura das estirpes no colo das plantas e, no mesmo dia aplicaram-se as soluções de micronutrientes diluídas na àgua de irrigação. A segunda inoculação do feijão com $R$. phaseoli ocorreu aos 20 dias apóa a semeadura, colocando-se também $20 \mathrm{ml}$ da suspensão com a mistura das estirpes, ao redor das plantas. As soluçōes de micronutrientes foram colocadas aos 33 dias após a semeadura, tambem diluídas na àgua de irrigação. 
Em anbos os experimentos foi pulverizado duas vezes o inseticida Fhosdrin-CE 20 (fosfato-2-Carbometoxi - 1 metil, vinil, dimetil a $24 \%$ ), na concentraçäo de 1 ml por 1 itro de àgua, para controlar trips e ácaros.

A irrigação foi realizada diariamente ou à medida em que era necessária, com àgua de torneira, utilizando-se um copo e despejando a ägua culdadosamente para evitar respingos que poderiam causar contaminação entre os vasos.

\subsubsection{DELINEAMENTO EXPERIMENTAL}

Ambos os experimentos foram realizados em delineamento experimental de blocos ao acaso, constando de 4 blocos e 28 tratamentos, onde se combinaram 4 tipos de fosfato de rocha (Patos de Minas, Araxá, Jacupiranga e Cataláo), 3 doses de fósforo $(64,128$ e $256 \mathrm{ppm}$ de $\mathrm{P})$ e dols controles (sem fósforo adicional e com superfosfato triplo na dose de $18 \mathrm{ppm}$ de $\mathrm{P}$ ), na presença e ausēncia de fungo micorrizico vesículo-arbuscular.

\subsubsection{COLHEITA DOS EXPERIMENTOS}

A colheita da soja foi realizada em 2 dias, coThendo-se 2 blocos por dia, aos 69 e 70 dias apos a semeadura, na época do florescimento. 0 mesmo aconteceu para o feljão, que foi colhido aos 74 e 76 dias após a semeadura, no final do florescimento.

\subsection{AVALIAGÃO DOS EXPERIMENTOS}

3.3.1. PESO DA MATERIA SECA DA PARTE AEREA TOTAL DAS PLANTAS Na colheita, as plantas foram cortadas na altu 
ra do colo e toda a parte aenea fol acundicionada em saco de papel e levada à estufa a $60-659 \mathrm{C}$, com ventilacáo forçada, ate peso constante. As folhas mals velhas que cairam durante o experimento foram guardadas e colocadas junto con a parte aérea total para secagem.

\subsubsection{PESO DE VAGENS}

Em ambos os experimentos, oflorescimento não ocorreu de maneira uniforme e, na época da colheita, algumas plantas já mostravam a formação de vagens. As pequenas vagens foram então separadas da materia seca da parte aérea e pesadas.

\subsubsection{ATIVIDADE TOTAL E ESPECTFICA DA NITROGENASE}

- cálculo da medida da atividade da nitrogena se foi realizado usando a técnica da redução do acetileno. Essa avaliação só foi feita no experimento com soja, usando a metodologia de HARDY et alii (1968), procedendo-se da seguinte maneira: durante a colheita, os sistemas radiculares das plantas foram retirados cuidadosamente de cada vaso, procurando-se tirar o excesso de solo que os encobriam e a seguir foram colocados em frascos de volume aproximado de $500 \mathrm{ml} e$ fechados com tampas apropriadas. os frascos foram entäo levados imediatamente à sala de cromatografia, onde se retiraram com uma seringa, $50 \mathrm{ml}$ de ar contido neles para em seguida in jetar $50 \mathrm{ml}$ de gás acetileno $\left(\mathrm{C}_{2} \mathrm{H}_{2}\right)$. Depols de 1 hora de incubação, retirou-se com uma seringa $0,5 \mathrm{ml}$ do ar contido nos frascos, injetando-o no cromatógrafo a gàs, onde se realizou a leitura no papel do pico do gás etileno $\left(\mathrm{C}_{2} \mathrm{H}_{4}\right)$ produzido pela amostra.

Também foi realizada uma prova em branco, que constou de um frasco fechado vazio de volume também aproxima- 
do de $500 \mathrm{ml}$, do qual se retiraram $50 \mathrm{ml}$ de ar e se injataram $50 \mathrm{ml}$ de găs acetileno. A seguir retirou-se $0,5 \mathrm{ml}$ de ar deste frasco, injetando-o no cromatógrafo e fazendo-se a leisura do pico do gás etileno.

\section{os cálculos foram feitos através da förmula:}

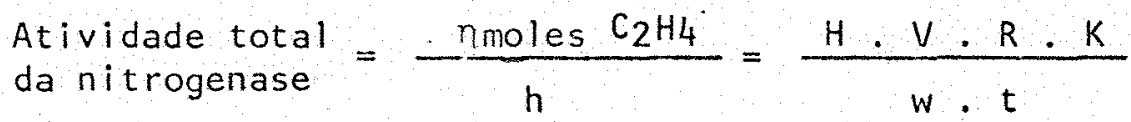

sendo $H=$ laltura do pico de $\mathrm{C}_{2} \mathrm{H}_{4}$ (mm) da amostra x atenuação] - altura do pico da prova em branco.

$V=$ volume do frasco de incubação da amostra (ml)

$w=$ volume da amostra injetado (mi)

$t=$ tempo de incubação (h)

$R=$ "range" do cromatógrafo

$K=$ constante.

A constante $K$ está relacionada com a calibração do cromatógrafo para uma quantidade conhecida de $\mathrm{C}_{2} \mathrm{H}_{4}$ $(500 \mathrm{vpm})$.

Uma amostra de $0,5 \mathrm{ml}$ de $500 \mathrm{vpm} \mathrm{de} \mathrm{C}_{2} \mathrm{H}_{4}$ contèm $0,25 \times 10^{-3} \mathrm{ml} \mathrm{C}_{2} \mathrm{H}_{4}$. Em Condições Normais de Temperatura e Pressão (C.N.T.P.), temos:

$$
\begin{aligned}
& 1 \mathrm{~mol} \mathrm{C}_{2} \mathrm{H}_{4} \longrightarrow \quad \begin{array}{r}
22400 \mathrm{ml} \\
\times \quad 25 \times 10^{-3} \mathrm{ml}
\end{array} \\
& \quad x=11,16 \text { nmoles } \mathrm{C}_{2} \mathrm{H}_{4}
\end{aligned}
$$

A mesma amostra de $0,5 \mathrm{ml}$ de 500 vpm $\mathrm{C}_{2} \mathrm{H}_{4}$ vai dar $Z(\mathrm{~mm})$ de pico, portanto:

$$
K=\frac{11,16}{Z} \text { y nmoles } \mathrm{C}_{2} \mathrm{H}_{4} / \mathrm{mm}
$$


sendo que $Z(\mathrm{~mm})=$ sltura $(\mathrm{mm}) \times$ Atenuação $x$ Range.

A atividade especifica da nitrogenase (nmoles $\mathrm{C}_{2} \mathrm{H}_{4} / \mathrm{g}$ nödulo, $x$ h) foi obtida dividindo-se a atividade total da nitrogenase da amostra pelo peso da matéria seca dos nódulos (g) da respectiva amostra.

\subsubsection{RELAÇÃO ENTRE OS PESOS DA MATERIA SECA DA PARTE AEREA E MATERIA FRESCA DAS RATZES}

As raizes foram lavadas para retirar todo o so 10, enxugadas com papel absorvente e, após a retirada dos nódulos, pesadas. A seguir fez-se uma relação entre o peso da matéria seca da parte aērea e o peso das raízes frescas, dividindo um valor pelo outro, para comparar o desenvolvimento radicular em relação ao desenvolvimento vegetativo.

\subsubsection{PESO DE NODULOS.}

Os nódulos retirados das raízes foram colocados em saquinhos de papel e levados à estufa a $60-65^{\circ} \mathrm{C}$, com ventilação forçada, até peso constante, obtendo-se o peso da matéria seca.

3.3.6. ANALISE QUTMICA DA PARTE AEREA TOTAL DAS PLANTAS

A parte aérea total das plantas, incluindo foThas, caules, ramos, flores e vagens, após a secagem e pesagem, foi moída em moinho de plantas do tipo wiley. A análi se de $N, P$ e $K$ seguiu a metodologia de SARRUGE \& HAAG (1974). 


\subsubsection{DETERMINAÇÃO DA PORCENTAGEM DE COLON ZAÇÃO} DAS RATZES

O sistema radicular, depois de lavado e pesado, foi colocado em frascos contendo A.F.A. (ácido acético: $5 \mathrm{ml}$, formol: $13 \mathrm{ml}$ e álcool etílico $50 \%$ : $200 \mathrm{ml}$ ), para consrva ção.

Para se estimar a porcentagem de colonização pe10 fungo MVA, as rálzes foram preparadas pelo método modificado de PHILLIPS \& HAYMAN (1970), da seguinte maneira: tomou-se uma amostra dos sistemas radiculares de cada parcela, procurando as rafizes mais finas, e colocou-se em um becker de $100 \mathrm{ml}$. A seguir foram clareadas com KOH $10 \%$ em banho-maria a $900 \mathrm{C}$ por 50 minutos. Depois as raizes foram lavadas com água e neutralizadas com solução diluída de $\mathrm{HCl}$, a frio, por 2 a 3 minutos, quando se escorreu a solução e procedeu-se a coloração com lactoglicerol com $0,05 \%$ de "trypan blue", em banho-maria a $900 \mathrm{C}$ por 3 a 4 minutos. 0 líquido foi então escorrido e colocou-se, até cobrir as raizes, lactoglicerol incolor para perder o excesso de corante. Depois de alguns dias, tomou-se uma porção das raizes assim preparadas, pesan do aproximadamente $0,5 \mathrm{~g}$ depois de enxutas com papel absorven te. A seguir foram cortadas em segmentos de 0,5 a $1,0 \mathrm{~cm} e$ espalhadas com um pouco de lactoglicerol incolor em placa de Petri riscada, de acordo com o método de GlovaneTTl \& MOS SE (1980). Foram observadas então, a presença ou ausência de estruturas füngicas nos segmentos de raizes nos pontos de in terseç̧ão com os riscos da placa. A porcentagem de raízes colonizadas fol calculada da seguinte forma:

porcentagem de raízes colonizadas número de pontos de intersecção com presença de micorriza

número total de pontos de intersecção contados 
Após a colheita, o solo foi bem homogeneizado e guardado em sacos plásticos. Depois tomou-se uma amostra de $100 \mathrm{ml}$ do solo para a contagem do nümero de esporos através da peneiragem úmida, segundo a técnica descrita por GERDEMANN E NICOLSON (1963). Esta técnica consiste de lavagens sucessivas da alíquota de solo com água e passagem dela por um conjunto de peneiras. Devido ao tamanho dos esporos a serem coletados, empregou-se somente peneiras de malha 100 e $50 \mu$. os esporos foram recolhidos em um becker com água e, para se obter uma suspensão livre de partículas de solo e outros detritos, esta recebeu $30 \mathrm{ml}$ de solução de sacarose a $50 \%$, segundo ANDREOLA (1982). Agitou-se e deixou-se decantar por 3 a 4 minutos, sendo que os resíduos mais pesados i am para o fundo, ficando os esporos suspensos e peneirados novamente na peneira $50 \mu$.

A contagem dos esporos foi feita em estereomicroscópio, empregando-se placa nematológica com anéis concen tricos.

\subsubsection{ANALISE ESTATISTICA}

Os dados experimentais foram submetidos à análise de variancia, em blocos ao acaso, e no caso de dados ex pressos em porcentagem, como teores de N, P, K e colonização de raizes, e no caso de contagem, como número de esporos no solo, tais análises foram precedidas por uma transformação de variáveis. Para dados em porcentagem, representados por $X$, foi utilizada a transformada

$$
Y=\operatorname{arcsen} \sqrt{X / 100}
$$

para dados de contagem, representados por $Z$, foi utilizada a transformada 


$$
y=\sqrt{l}
$$

o objetivo dessas transformações foi a de estabilizar a variancia, segundo PIMENTEL GOMES (1984).

A comparação das médias, foi feita pelo teste de Tukey.

Esta análise estatistica foi realizada no centro de Informática na Agricultura (CIAGRI), da ESALQ/USP. 


\section{RESULTADOS E DISCUSSÃO}

\subsection{EXPERIMENTO COM SOJA}

\section{- Peso da matéria seca da parte aérea}

Como pode se observar na Tabela 3 , a micorriza favoreceu a produção da matêria seca da parte aérea da soja em todos os tratamentos, promovendo aumentos, em relação aos tratamentos sem micorriza, na ordem de $120 \%$ em média para todos os fosfatos de rocha, $83 \%$ na ausência de fosfato e $50 \%$ com fosfato solüvel. Também se observa que não houve, entre os fosfatos de rocha, um que se destacasse como o melhor, não havendo também efeito de doses dentro de cada fosfato, embora os fosfatos Catalão nas doses 1 e 3 e Araxá na dose 3 tenham sido estatisticamente os melhores quando na presença de Glomus macrocarpum, igualando-se ao efeito do fosfato solüvel. Esse efeito só foi observado em tratamentos com micorriza.

- fato da micorriza favorecer o incremento da matéria seca da soja já fol verificado anteriormente por Ross \& HARPER (1970), ROSS (1971) e BETHLENFALVAY \& YODER (1981). Entretanto os resultados deste experimento diferem dos de MOS SE et alii (1976), ISLAM et alii (1980) e CARDOSO (1985), os quais verificaram aumentos na materia seca devido aos fatores isolados, fosfato de rocha e micorriza, além de um incremento máximo com os dois fatores combinados. Como já foi visto, no presente experimento praticamente só se observaram aumentos 


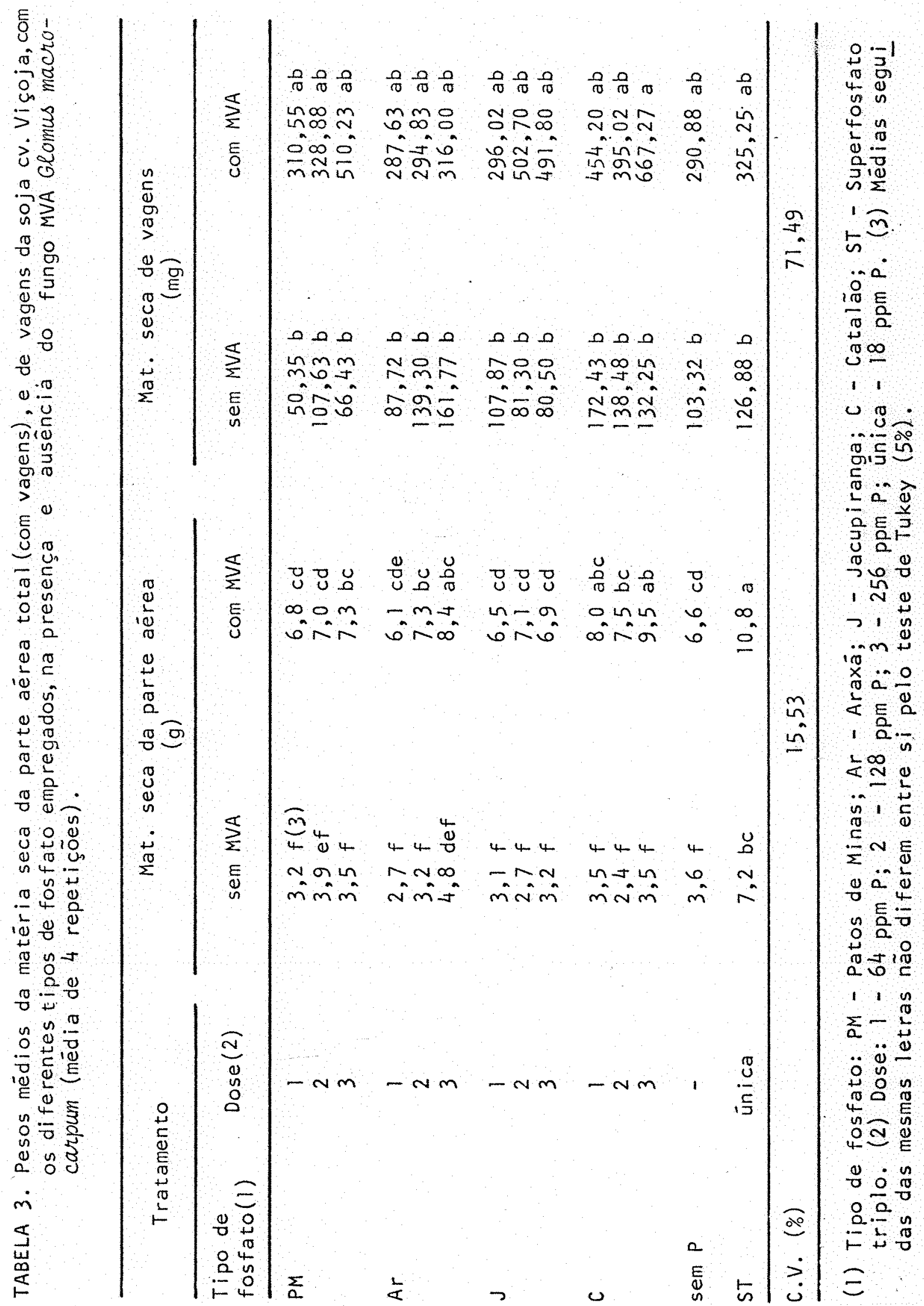


devido a micorriza, exceto para os tratamentos com fosfatos de rocha Araxá na dose 3 e Catalão nas doses 1 e 3 na presença da micorriza.

Não foram observadas diferenças marcantes entre os tipos de fosfato de rocha ou doses utilizados neste experimento. Porém, WAIOYANATHA et alii (1979), utilizando dois tipos de fosfato de rocha, observaram que um deles foi superior na produção de matéria seca de Pueraria, verificando também efeltos de doses tanto na ausência como na presença de fungo micorrízico, uma vez que possuía maior solubilidade em ácido cítrico que o outro. A auséncia de um efeito pronunciado no presente experimento, pode ser devido ao fato de os fosfatos de rocha utilizados possufrem solubilidades se melhantes em ácido cítrico.

PAIRUNAN et alii (1980) constataram que os fos fatos de rocha empregados em plantas de trevo micorrizadas, produziram efeitos semelhantes ao superfosfato triplo, porém as doses dos fosfatos de rocha foram bem mais altas em relação à forma soluvel. Desde que fosse aplicada quantidade suficien te de fosfato de rocha, as plantas não micorrizadas cresciam tão bem quanto as micorrizadas.

No presente experimento, nos tratamentos sem micorriza, a presença dos fosfatos de rocha não promoveu o aumento do pe so da matéria seca da soja, enquanto que em plantas micorrizadas encontrou-se efelto favorāuel dos mesmos. lsto deve ter ocorrido porque as hifas dos fungos micorrizicos podem funcionar como tubos de condução dos fons fosfatos que vão sendo solubilizados mesmo fora da zona da rizosfera, levando-os diretamente para a planta, e evitando que se tornem novamente indisponiveis pelo processo de fixação dos fosfatos (BAREA e AZCON-AGUILAR, 1983). Nas plantas não micorrizadas, verificou-se o efeito favorävel apenas do superfosfato triplo, 
concordando com BRAGA et ali (1980) em experimento de campo. Contudo, esses autores näo trabalharan com fungos MVA. Verificaram que os fosfatos Patos de Minas, Araxá e Cataláo foram completamente inativos em qualquer dose empregada $\left(100,200\right.$ e $400 \mathrm{~kg} \mathrm{P}{ }_{2} 0_{5}$ total/ha $)$ na cultura da soja.

Entretanto, esses resultados discordam de alguns trabalhos publicados sobre nutrição da soja onde esses fertilizantes são usados. MASCARENHAS et ali i (1978) observa ram que em cada localidade estudada o comportamento dos fos fatos foi diferente, e que o hiperfosfato e o fosfato de Ara$x$ á levaram a produções maiores do que aquelas proporcionadas pelo superfosfato triplo em alguns casos. GoEPFERT et alil (1976) demonstraram que a adubação fosfatada, independente da fonte, aumentou o rendimento de grãos de soja. o superfosfato triplo destacou-se pelo seu efeito a curto prazo e os fosfatos de rocha pelo seu efeito residual, destacando-se o fosfato de Gafsa, e com menor eficiencia o fosfato de Araxä, Mar rocos e Jacupiranga.

\section{RAMOS (1982) verificou que entre os fosfatos} naturais utilizados na cultura da soja, sobressaiu-se o Alvorada, sendo mais eficiente que os superfosfatos, a partir do segundo ano de utilização. Deve-se ressaltar que no presente trabalho não se fez o estudo de efeito residual dos fosfatos, mas sim o imediato. OLIVEIRA et alii (1984), em dois ciclos completos da sucessäo milho - trigo - soja - trigo, utilizando diversas fontes de fosfato (superfosfato triplo, hiperfosfato, termofosfato IPT e os fosfatos de rocha Maranhão, Alvorada, Araxá, Patos de Minas e Cataláo), em duas doses $(100$ e $400 \mathrm{~kg} \mathrm{P}_{2} \mathrm{O}_{5}$ /ha), observaram que as diferenças entre as fontes para a soja foram pequenas. Contudo, evidenciou-se a baixa eficiencia do fosfato catalão. Cordeiro et ali llcitados por

ICORDEIRO, D.S.; BORKERT, C.M.; SFREDO, G.J.; PALHANO, T.B.; DITTRICH, R. C.; QUEIROZ, E.F. Acidez do solo, calcário e cultura de soja. In: EMBRAPA, Resultados de pesquisa de soja 1977/78, 1978. p.47-52. 
ROSOLEM (1982) também notaram essa ba xa eficiência do fosfato Catalão, não se observando nenhum efeito do doses $(0$ a $600 \mathrm{~kg} \mathrm{P} 2_{5} \mathrm{O}_{5}$ total/ha). Mas para os fosfatos Patos de Minas e Araxá observaram efeito de doses, porém as produções foram sem pre inferiores ao superfosfato triplo, em qualquer dose.

Outros trabalhos na literatura dão indicação de que o superfosfato e as fosforitas fornecem mais fósforo às p.lantas que as apatitas (CATANI \& GLORIA, 1961). Cordeiro et al i 1 citados por ROSOLEM (1982), demonstraram que o superfosfato triplo, fosfato de Gafsa e Patos de Minas apresentarama mesma eficiência no quarto ano de efeito residual. Além do mais, outros trabalhos indicam que a eficiencia dos fertilizantes fosfatados com solubilidade diversa pode estar relacionada com o tamanho dos grânulos. Segundo Terman \& Allen ${ }^{2}$ citados por RAMOS (1982), a eficiencia dos fertilizantes con tendo fosfatos insolúveis em água em geral aumenta com o menor tamanho dos grânulos, uma vez que a superficie de contato com as particulas do solo é maiar. Os fosfatos naturais tambêm podem ter sua eficiência afetada por características do solo, como pH, e pela capacidade das plantas em absorver e utilizar o fósforo dos fosfatos naturais (KHASAWNEH \& DOLL, $1978)$.

CORDEIRO, D.S.; BORKERT, C.M.; SFREDO, G.J.; PALHANO, J.B.; DITTRICH, R.C. Efeitos de diversos níveis de fósforo de diferentes fontes fosfatadas na concentração de macro e micronutrientes na parte aérea de plantas de soja. In: SEMINARIO NACIONAL DE PESQUISA DE SOJA, 1., LONdrina, 1979. P. $275-281$.

2 TERMAN, G.L. E ALLEN, S.E. Fertilizer and soil p uptake by maize as affected by soil, granule size and solubility of phosphate sources. J.Agric. Sci., Cambridge, 73 : $417-424$. 
No caso do presente experimento, as apatitas (fosfato de Araxa, úse 3 e Catalão, doses 1 e 3 ), com micor riza, foram mais eficientes na produção de matéria seca do que a fosforita (Patos de Mnas, em qualquer dose), com micorriza, talvez porque este último fosfato apresentasse granulo metria mais grosseira que os primeiros, como se observa na Tabela 2. Isto faz com que diminua a superfícle de contato dos grânulos passiveis de serem solubilizados e apro veitados pela planta sozinha, ou através das hifas do fungo MVA.

A micorriza também foi responsável neste expe rimento, pela maior produção de matéria seca mesmo em plan tas que não receberam nentium fosfato adicional, condizendo com HALOS et alil (1982) e PLENCHETTE et ali i (1983). Este efeito foi semelhante àquele causado apenas pela adição de fosfato solúvel. Porém, esses valóres foram significativamen te inferiores aqueles encontrados em tratamentos em que se combinou fosfato solúvel e micorriza.

0 fato da porcentagem de aumentó na produção de matéria seca de plantas micorrizadas ter sido maior quan do se usou o fosfato de rocha em relação ao fosfato soluvel explica-se da seguinte forma: no tratamento com superfos fato triplo, o fósforo se encontrava em forma solúvel, sendo facilmente aproveitado pelas raízes das plantas micor rizadas ou não, dependendo então menos do fungo micorrizico. Com o fosfato de rocha, apenas a superfície dos gránulos apresentava ions fosfatos que eram lentamente solubilizados, e nesse caso, mais difíceis de serem alcançados pelas raízes das plantas. As hifas do fungo MVA seriam então capazes de alcançar esses íons, mesmo em regióos fora da rizosfera, explicando a maior dependéncia da planta pelos fun gos MVA quando se usou essa forma de fosfato.

\section{- Peso da matēria seca de vagens}

Como se verifica na Tabela 3 , a produção de ma 
térla seca de vagens não fol afetada estatisticamente pela pre sença do fungo Glomus macrocarpum, destacando-se apenas o tra tamento com o fosfato Catalão na dose 3 . Porém, o que se observa com os resultados, é que houve uma tendencia de maior produção de vagens pelas plantas micorrizadas em qualquer tra tamento. Não se verificou diferenças entre os tipos de fosfato e nem efeito de doses, com ou sem micorriza.

Esses resultados discordam de CARDoso (1986), que verificou a eficiencia do fungo G. macrocarpum na produção de vagens em soja no mesmo tipo de solo usado neste experimento, tanto no estado natural como no esterilizado, e na presença de fosfato de rocha. Porém, esta autora empregou o fosfato Alvorada, o qual, como encontrado por RAMOS (1982), foi o que mais se sobressaiu entre os vários fosfatos de rocha testados para a soja no campo. GIANINAZZI-PEARSON ali ( 1981 a) observaram aumento significativo na produção de vagens em soja devido à micorriza na ausência de fosfato adicionado, ou na presença de fosfato de câlcio pouco solúvel, mas este aumento foi devido apenas à micorriza. ASIMI et alli (1980) encontraram aumento na produção de vagens de plantas micorrizadas mesmo sem a adição de fosfato e, HALOS et alii (1982) observaram que plantas de soja inoculadas com fungo mi corrizico possuíam maior número de vagens, aumento este ainda maior quando em combinação com Bradyrhizobium.

Outros autores ainda notaram aumentos na produ f̧ão de grãos em soja micorrizada (ROSS \& HARPER, 1970, ROSS, 1971; KUO \& HUANG, 1982). ROSS \& GILLIAM (1973) constataram que plantas micorrizadas produziram mais grãos quando se adicionou fosfato de ferro, de alumínio ou monocálcico, mas não sem a adição de fosfato ou com adição de fosfato de rocha, talvez por causa da pequena dose do fosfato de rocha utiliza da $(17,6 \mathrm{mg} \mathrm{P} / \mathrm{kg} \mathrm{solo})$. 
MIRANDA (1982) observou que na dose iesidual de $400 \mathrm{~kg}$ de $\mathrm{P}_{2} \mathrm{O}_{5}$ /ha aplicado como fosfato de rocha $\mathrm{fatos}$ de Minas, a produção de grãos de soja obtida em presença de espēcies de fungo micorrízico introduzidasno campo, fol estatist icamente maior em relação ao tratamento não inoculado. A maior disponibilidade de fósforo no solo nesse tratamento te ria permitido melhor atuação dos fungos introduzidos, e pela análise química do solo, notou-se que o teor de fósforo extraível nessa dose estava relativamente próximo ao da dose de $100 \mathrm{~kg}$ de $\mathrm{P}_{2} \mathrm{O}_{5}$ /ha como superfosfato simples, onde se constatou a melhor eficiência da espécie introduzida Glomus macrocarpum.

Convém observar que no presente experimento, a colheita foi realizada logo após o florescimento e, como este näo foi uniforme, alguns tratamentos ainda apresentavam flo res e outros, com plantas mais desenvolvidas (micorrizadas), já apresentavam vagens de tamanho médio ou pequeno, o que le va a deduzir que houve um adiantamento na produção, ou seja, observou-se precocidade das plantas micorrizadas.

\section{- Absorção de NPK}

Os teores médios de nitrogênto, fósforo e potássio na parte aérea total da soja se encontramna Tabela 4.

Com relação ao teor de nitrogênio na parte aérea da planta $(\% N)$, o que se observa é que, de um modo geral, plantas micorrizadas apresentavam teores menores em relação às não mi corrizadas, não havendo também efeito de doses ou $t$ pos de fosfato utilizados, embora o superfosfato triplo sem micorriza apresentasse menor teor em relação aos outros tratamentos sem micorriza. Isto pode ser explicado pelo possível efeito de di luíçāo encontrado por EZETA \& SANTOS (1980), onde as plantas mais desenvolvidas apresentaram os menores teores em nitrogenio.

Embora não houvesse, de maneira geral, diferenças estatísticas entre os tratamentos em relação ao teor de 


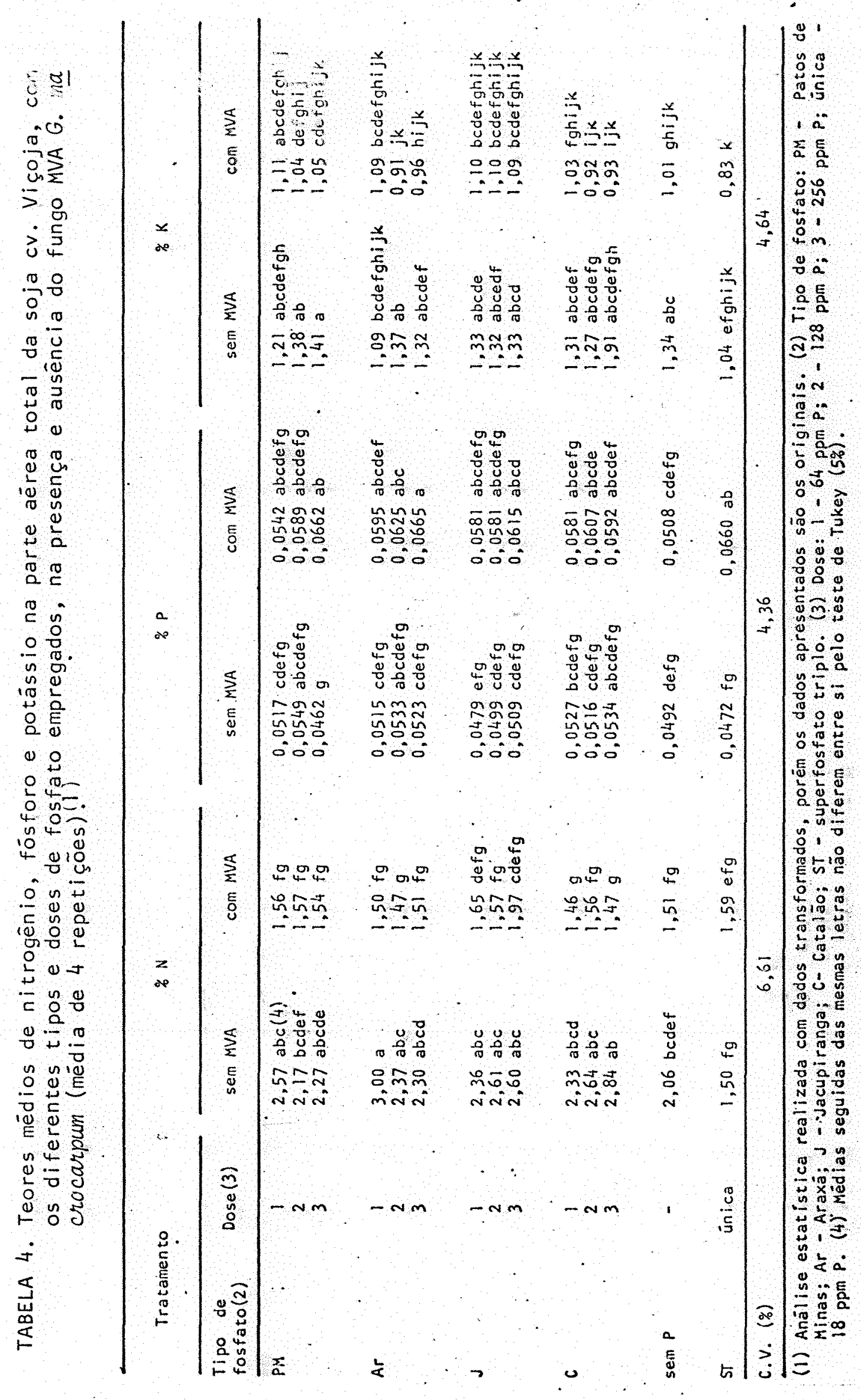

56. 
fösforo na parte aérea das plantas (\%p), verifica se que hou ve uma tendência das plantas mi corrizadas possuírem teores mais elevados desse elemento quando se comparavam plantas micorrizadas com as näo micorrizadas, dentro de cada tipo e dose de fosfato aplicado. As ünicas diferenças observadas en tre as plantas micorrizadas foram que os fosfatos patos. de Minas e Araxá na dose 3 , e o superfosfato triplo, foram sig nificativamente superiores ao tratamento sem fosfato, embora este ültimo não diferisse dos outros tratamentos com fosfato de rocha.

Quanto ao teor de potássio (\% K), os resultados também indicam que houve uma tendéncia à diminuíção nos teores em plantas micorrizadas, possivelmente devido ao mes mo efeito de diluição já comentado anteriormente. Também se observou diferenças entre as doses e os fosfatos aplicados.

Quanto às quantidades totais dos macronutrientes acumulados na planta (Tabela 5), os resultados sugerem um efeito benéfico da inoculação micorrizica. A quantidade to tal acumulada de nitrogēnio foi estatisticamente semelhante para três fosfatos de rocha (Araxá, Jacupiranga e Cataläo) na maior dose e na presença de micorriza, equiparando se ao tratamento com fosfato solúvel, embora esses tratamentos com fosfato de rocha não diferissem entre si nem das outras doses dos fosfatos. Esse feito não se repetiu em plan tas não micorrizadas, onde não houve diferenças significat vas entre os tratamentos.

A quantidade total de fósforo acumulado em plantas micorrizadas fol superior às não micorrizadas, parecendo haver nas micorrizadas uma tendéncia de maiores quantidades 


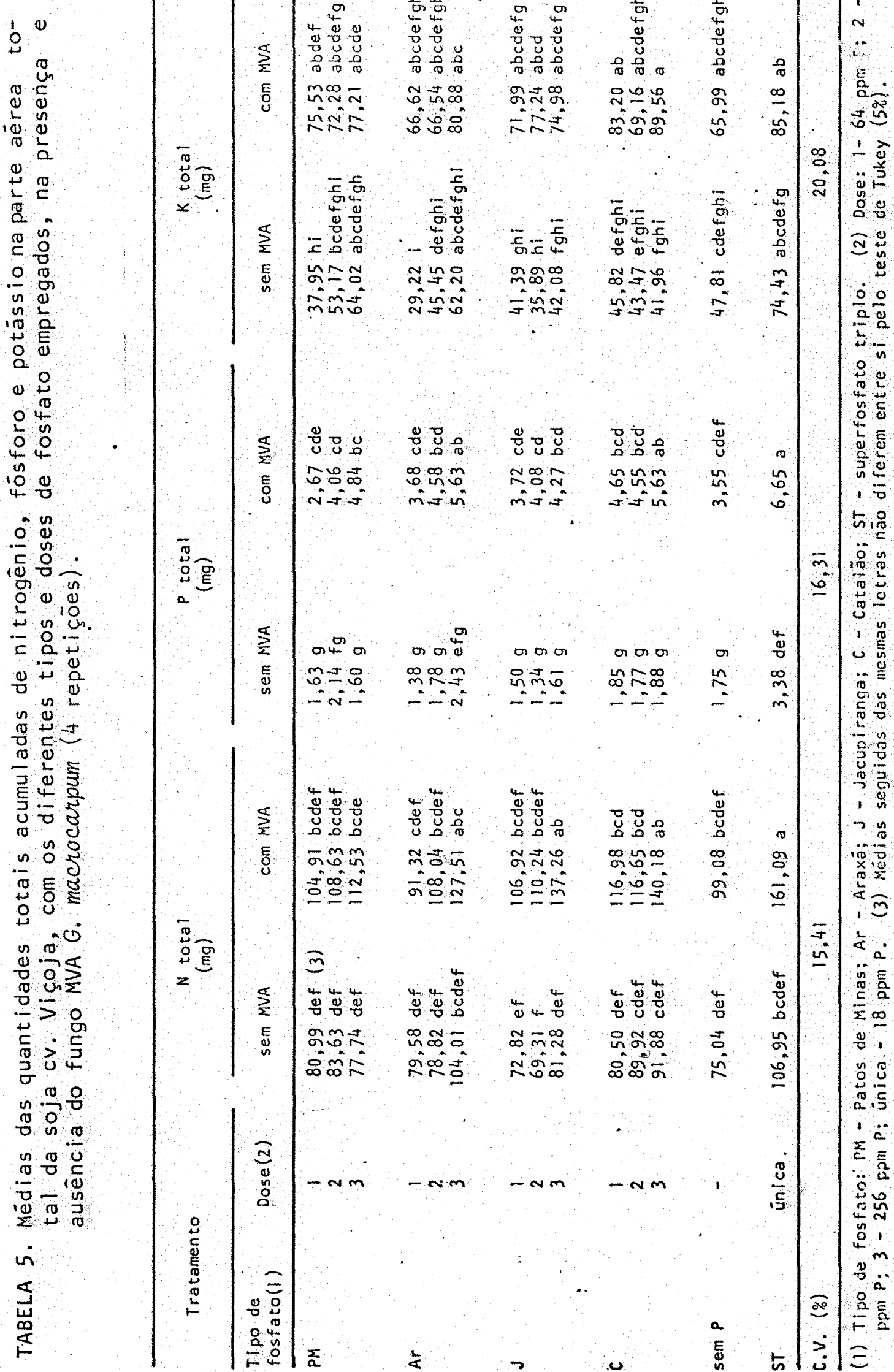


na maior dose de cada fosfato de rocha, embora sen diferenças significativas em relą̧ăo às demais doses. Aqui novamente se observa o melhor efeito do fosfato solúvel nas plantas micorrizadas, equiparando-se apenas aos fosfatos de rocha Araxá e Catalão na dose 3; e, de um modo geral, a auséncia de efeitos de tratamentos em plantas não micorrizadas.

observa-se que a quantidade total de potássio acumuladoem plantas micorrizadas fol geralmente maior em re lação às não micorrizadas, embora poucas diferissem significat ivamente em relação ao mesmo tratamento sem mi corriza. Nes te caso também não se observou efelto de tipo de fosfato ou dose em plantas inoculadas com fungo MVA, ou não.

Neste experimento, a \% foi aparentemente a mais favorecida pela presença da micorriza, enquanto que a $\%$ K fol diminuída, como observado por SIQUEIRA \& PAULA (1986). Aumentos na \% e diminuição na $\% \mathrm{~N}$ pela presença da micorriza foram observados por CRUSH (1974) em centrosema e Stylosanthes, e GIANINAZZI-PEARSON et ali i (1981a) verificaram aumen to significativo na \% em soja micorrizada. Entretanto, Ross E HARPER (1970), ROSS (1971) e CARDOSO (1985), verificaram aumentos também na $\% \mathrm{~N}$ em soja micorrizada, mas não na \%k.

MOSSE et alii (1976) observaram aumentos signi ficativos na \% nos tecidos de plantas de trevo que receberam fosfato de rocha ou micorriza, e esse aumento fol multo maior quando se combinou o fosfato e a micorriza. Resultados semelhantes foram obtidos por WAIDYANATHA et al11 (1979) em Pueraria, e SPARLING E TINKER (1978) em trevo, com fosfato solúvel em qualquer dose $(10,50,100$ e $500 \mathrm{mg} \mathrm{P} / \mathrm{kg}$ de so1o), e fosfato de rocha nas menores doses $(0,1 \mathrm{e} 1,0 \mathrm{~g} \mathrm{P} / \mathrm{kg}$ de so$10)$

As quantidades totais acumuladas dos macronutrientes neste experimento foram favorecidas pela micorriza, comprovando o efeito de simbiose na absorçäo de outros elemen- 
tos além do fósforo (ROSS, 1971, ABBOTT E GOBSON, 1984). Aumentos nas quantidades totals de $N, P$ ou $K$, causados pela MVA também já foram observados por diversos autores, sem a adi६ão de fosfato (ASIMI et alii, 1980), ou usando fosfato solü vel ou pouco solüvel (PAIRUNAN et alii, 1980, ISLAM et alii, 1980 ; GIANINAZZI-PEARSON et ali i, 1981a; MIRANDA, 1982; CARDOSO, 1986), em diversas leguminosas.

Um possível efelto sinergístico com a combinação fosfato de rocha e micorriza em relaçäo à quantidade total de fósforo acumulado na planta, fol encontrado por MosSE et ali (1976), ISLAM et ali (1980) e CARDOSO (1985), entre tanto isto năo fol verificado no presente experimento, talvez porque outros nutrientes como cálcio, magnésio, etc., es tivessem em quantidades limitantes, impedindo o pleno desenvolvimento das plantas e a expressão de melhores resultados.

\section{- Peso da matéría seca de nödulos}

Verificando-se a Tabela 6 , percebe-se claramente que a mi corriza favoreceu a nodulação da soja, uma vez que as plantas controle, sem micorriza, apresentaram valores sig nificativamente inferiores no peso da matéria seca dos nódulos.

Os fosfatos Araxá nas doses 2 e 3 e Catalão na dose 3 , combinados á micorriza, produziram maior peso de nódulos quando comparados ao tratamento só com fósforo (solú vel ou de rocha), ou só com micorriza, havendo concordáncia com trabalhos de MOSSE et alil (1976), ISLAM et al1i (1980) e WAIDYANATHA et ali (1979). Estes tratamentos com fosfato de rocha e micorriza foram superiores ao com fosfato soluvel sem micorriza, resultado tambem obtido por BONETTI \& DONALD (1986) em soja, em solo estéril. o fosfato Catalão na dose 3 com micorriza produziu efeito semelhante ao superfosfato triplo com micorriza, que foi o melhor tratamento. 
61.

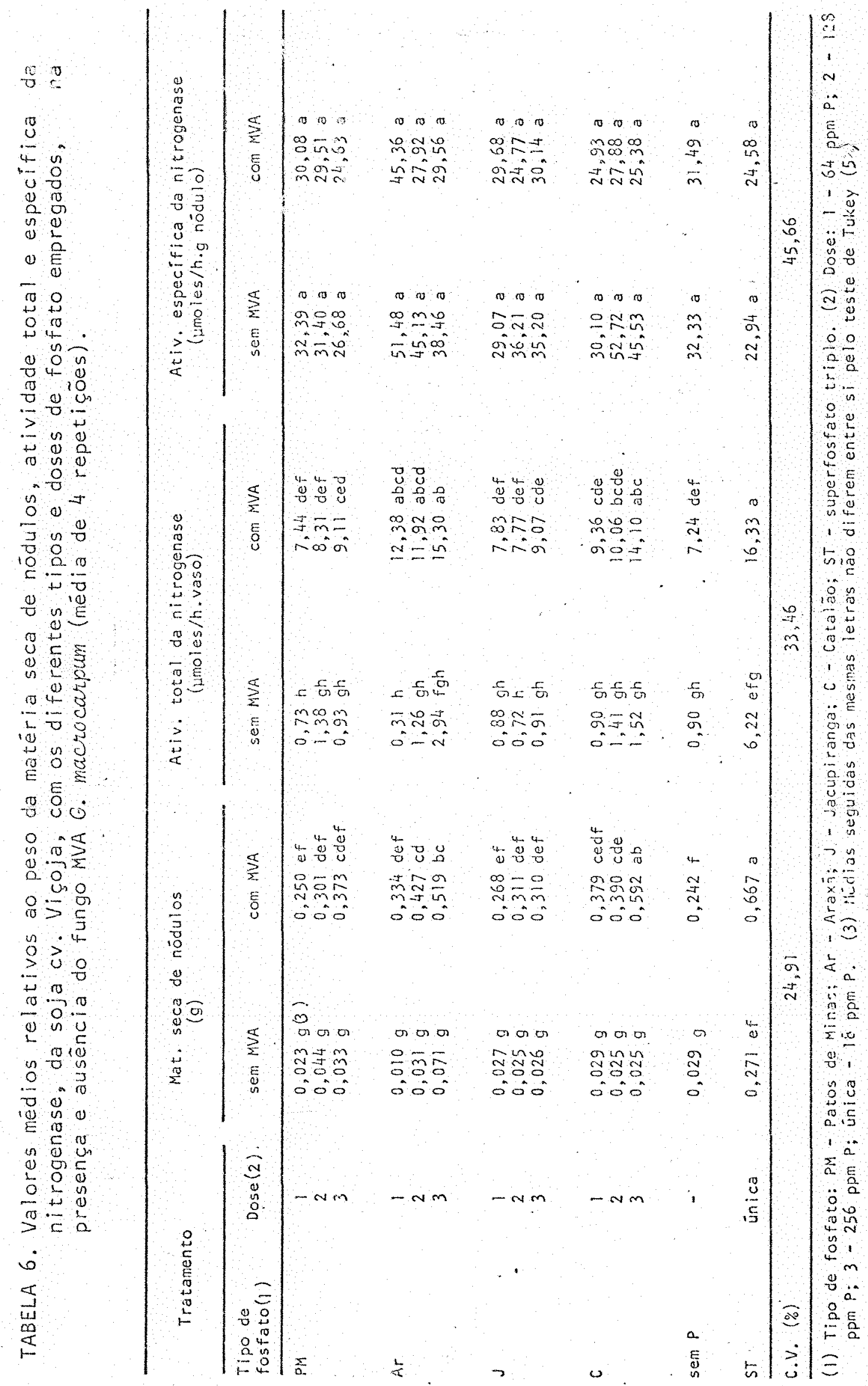


A nodulação de plantas apenas micorrizadas (sem adiça de fosfato) tol semelhante à de plantas apenas suplementadas com o fosfato solüvel, pois geralmente os efeitos só da micorriza ou sñ de fosfato adicionado em quantidades apropriadas, são similares (DAFT \& EL-GIAHMI, 1974, 1975; MOS SE, 1977b; CARDOSO, 1985).

Porém, plantas que receberam só o fosfato solüvel não diferiram da maioria das plantas micorrizadas adubadas com os outros fosfatos de rocha, talvez porque a concen tração de fósforo disponivel nesses tratamentos com fosfato de rocha ainda estivesse muito baixa, uma vez que mesmo comamicor riza a nodulação não fol elevada a nívels superiores do que aquele provocado pelo tratamento só com fosfato solúvel ou só com micorriza.

BETHLENFALVAY \& YODER (1981) obtiveram nodulação aumentada na soja tanto na presença como na ausencia de fungos micorrizicos em doses maiores de fósforo no solo. No presente experimento, tratamentos con maior disponibilidade de fósforo, provocados pelo tratamento com superfosfato triplo e Catalão na dose 3 , aparentemente foram os que promoveram mals a nodulação na presença de milcorriza, suportanto a afirmati va de que a nodulação requer alta concentração de fósforo (BER GERSEN, 1971), que também pode ser obtida pela interação fósforo e mi corriza (MOSSE et alii, 1976).

Mas observando me thor este experimento, embora as plantas micorrizadas apresentassem tendência em possuir maior teor em fósforo, isso pode não ter sido suficiente para aumentar a nodulação ou a fixação de nitrogênio, como será visto adiante. o maior peso de nódulos dessas plantas pode estar relacionado a outro efei to causado pelo fungo micorrizico, como o melhor desenvolvimento geral das plantas (ROBSON et ali i, 1981), além de possiveis efeitos secundärios de natureza hormonal (MOSSE, 1977b; ALLEN et alli, 1980 e 1982; BAGYARAJ, 1984). 
Como existe uma correlação positiva entre peso de nödulos e matéria seca da parte aérea, e desta com a produ ção (CARDOSO, 1984), pode-se levantar a hipótese de que existe a possibilidade das plantas micorrizadas superarem, em produção de grãos, as não micorrizadas, principalmente aquelas plantas que receberam o fosfato Catalão na dose 3 ou superfosfato triplo, com micorriza, que foram os tratamentos que promoveram mais a nodulação da soja neste experimento.

\section{- Atividade total e especifica da nitrogenase}

Os resultados relativos à atividade total e especifica da nitrogenase se encontram na Tabela 6.

A atividade total da nitrogenase foi maior em plantas micorrizadas, devido a maior massa de nódulos presentes nessas plantas, onde se destacaram os cratamentos com superfosfato triplo, Catalão na dose 3 e Araxá em todas as doses. Esse aumento tambem foi obtido por varios autores em diversas leguminosas, como BETHLENFALVAY \& YODER (1981), CARLING et alii (1978), ASIMI et alii (1980), enquanto MOSSE et a 11 (1976) e WAIDYANATHA et ali i (1979), obtiveram aumentos atraves da interaçäo fosfato de rocha - micorriza.

Porém, no presente trabalho, não foram observadas diferenças significativas entre os tratamentos quanto a atividade especifica da nitrogenase. ls so quer dizer que a eficiencia da fixação do nitrogênio não foi melhorada, o que também pode ser confirmado pelo teor de nitrogenio (\% $N$ da parte aérea das plantas (Tabela 4), que do mesmo modo náa aumentou, como ja comentado anteriormente. Isso concorda com BETHLENFALVAY \& YODER (1981), onde a atividade especifica da nitrogenase não foi modificada pela presença da micorriza, po rém discorda de EL-HASSANIN \& LYND (1985), LYND et alii (1985) e PURCINO \& LYND (1985). 
ISLAM et alii (1980) conseguiram insmementosna atividade especifica da nitrogenase nos nödulos de caupi quan do utilizaram fosfato de rocha combinado com mi corriza. Apesar disso, não há evidência de uma interação direta entre a bactéria fi xadora de nitrogènio atmosférico (Rhizobium) e o fungo micorrizíco (CARLING et ali i, 1978), ou seja, não há indícios de que haja uma relação simbiótica entre a bactēria e o fungo, mas sim uma relação indireta pols o fungo MVA ao promover o melhor desenvolvimento e estado nutricional da planta irá favorecer o processo de fixação do $\mathrm{N}_{2}$ pelo Rhizobium.

Pode ser que neste trabalho, o suprimento em fósforo para a planta não tenha sido suficlente para promover a atividade especifica da nitrogenase, uma vez que este elemento é considerado um fator bastante correlacionado com a at vidade especifica dos nódulos (GRAHAM \& ROSAS, 1979). E como se verifica na Tabela 4 , a $\%$ das plantas alnda estava baixa mesmo nas micorrizadas, as quals mostraram tendencia em possuir os valores mais elevados, principalmente quando se compa raram os valores obtidos por CARDOSO (1985) e SIQUEIRA E PAULA (1986). CRUSH (1982) demonstrou que o fungo MVA não afeta diretamente a atividade especifica da nitrogenase nos nodulos, mas simplesmente melhora a nodulação através da melhor nutriçäo em fósforo da planta hospedeira.

- Relacão entre os pesos da materia seca da parte aérea (MSPA) e matéria fresca de raizes (MFR)

Através da Tabela 7 , verifica-se que de maneira geral, plantas micorrizadas apresentaram tendencla em possuir maior relação entre os pesos de MSPA e MFR, embora os valores não fossem estatisticamente significativos. Verifica-se neste caso, o valor significativamente superior do tratamento com fosfato Catalão na dose 3 com micorriza em relação aos tratamentos sem micorriza, alem do efeito semelhante entre fosfato solúvel apenas e os tratamentos com micorriza. 


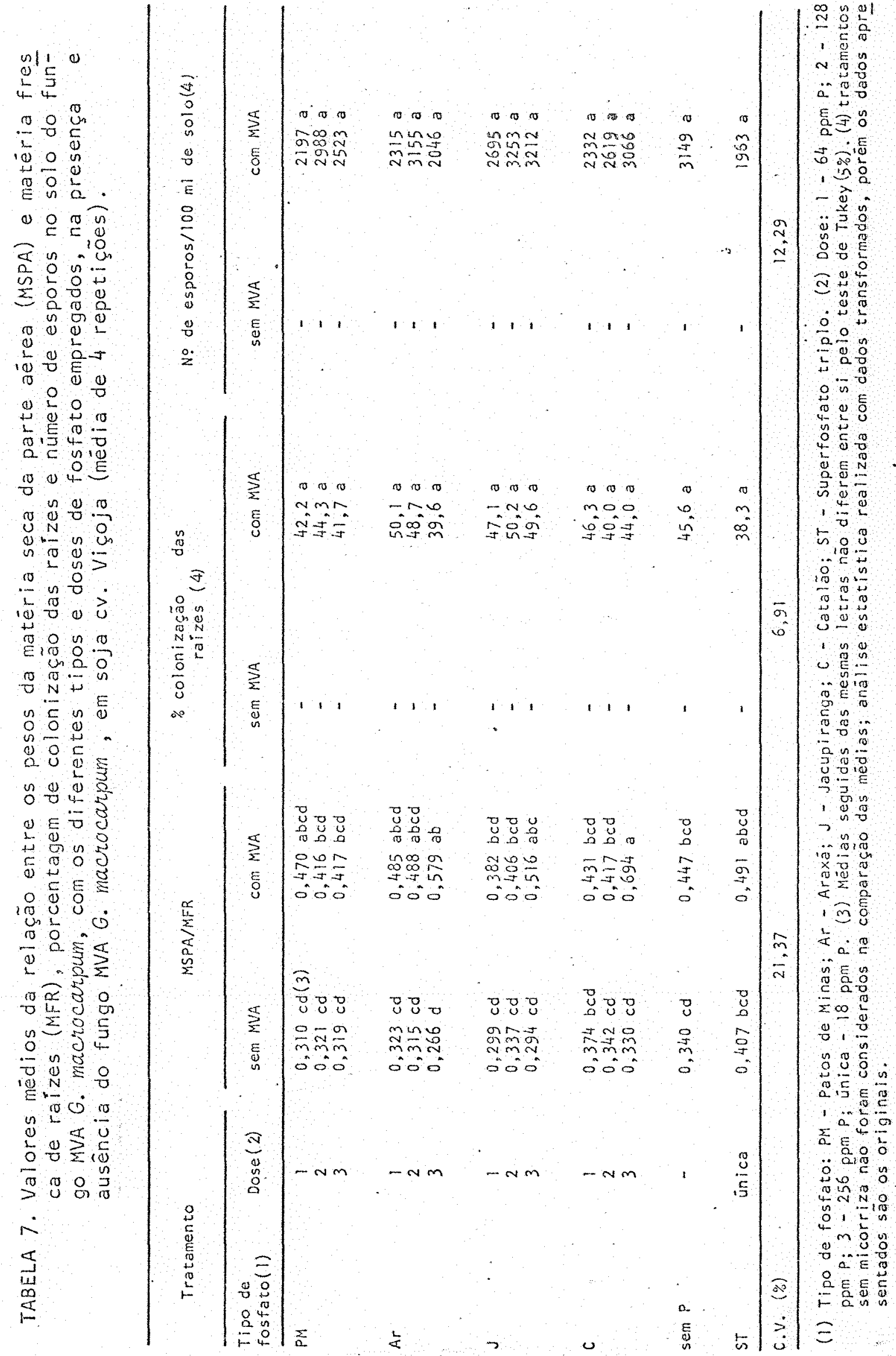


Essa variável pode refletir diferenços entre o desenvolvimento aéreo e o radicular das plantas, onde tanto o fosfato como a micorriza na ausência ou na presença de fosfato, podem levar a um menor desenvolvimento radicular relativo, observado por CAROOSO $(1984,1985)$ e ASIMI et al i (1980) em Soja. HAYMAN \& MOSSE (1971) observaram em cebola, resultados semelhantes com fosfato ou micorriza quando comparados ao controle, e CRUSH (1974), ABBOTT \& ROBSON (1978), REDENTE \& REEVES (1981) e CABALA-ROSAND \& WILD (1982), em värias legumi nosas.

- fato de plantas micorrizadas apresentarem mas sa radicular proporcionalmente menor, pode indicar que a absorção aumentada de fósforo e outros nutrientes pode ser devido às hifas dos fungos micorrizicos, pois como foi observado por HAYMAN \& MOSSE (1971), a eficiência de raízes micorrizadas enão micorrizadas è equivalente por unidade de peso.

- Porcentagem de colonizacáo das raizes e esporulaçáo do fungo MVA no solo

Os dados referentes às médias da porcentagem de raizes colonizadas e da contagem de esporos do fungo glomus machocarpun em $100 \mathrm{ml}$ de solo se encontram registrados na Tabela 7 .

Não foi encontrado esporos de fungos MVA nos tratamentos não inoculados com esse fungo, nem se detectaram estruturas fünglcas nas ralzes das plantas desses tratamentos.

Os tratamentos que haviam sido inoculados com fungo MVA apresentaram grande quantidade de esporos (em media de 1963 a 3253 esporos/100 ml de solo), ná se observando diferenças significativas entre os tratamentos. A porcen- 
tagem de colonização micorrizica das raizes variou ae 38,3 a $50,2 \%$, não havendo diferenças significativas entre os tratamentos. Fol encontrado um nümero razoavel de vesf́culas e micélio intracelular, pequenos arbúsculos nas camadas mais profundas do cörtex, e também micélio externo aderente à raiz.

Os valores médios da porcentagem de colonizafão das raízes indicam que houve afinidade entre este fungo e a cultivar Viçoja, já observada por CARDOSO (1986), indicando que em todos os tratamentos houve condiçós de ocorréncla da colonização. Embora esses valores não tenham sido tão elevados, foram aparentemente suficientes para causar efeitos mar cantes no desenvolvimento da soja.

Normalmente, a aplicação de fosforo ao solo di minui a formação de micorriza, assim como a proliferação de esporos (MOSSE, 1973) e, o aumento progressivo nas doses de fosfato soluvel tende a diminuir a porcentagem de colonização nas raizes de leguminosas, como observado por ASIMl et al1i (1980), HALL et alii (1977) e ROBSON et alii (1981). Nes te experimento não se observou inibição da colonização nos tratamentos com fosfato soluvel ou de rocha, em nenhuma dose. Isto pode ter ocorrido pois o nível de fosfato solúvel alnda estava baixo e, nos fosfatos de rocha, a malor parte do fosforo se encontrava na forma "insolúvel", não chegando portanto a afetar negativamente a porcentagem de colonização das raizes.

Segundo PAIRUNAN et alil $(1980)$, o nfvel mals baixo de fósforo aplicado como superfosfato (menor que $1,2,9$ P/vaso com $3 \mathrm{~kg}$ de solo) aumentou a porcentagem de colonização de raizes de trevo. A aplicação de um nível intermediário $(1,2 \mathrm{~g} P / v a s o)$ diminuiu um pouco a porcentagem, mas a aplicação de nível alto de fósforo $(2,4 \mathrm{~g} \mathrm{P} / v a s o)$, diminuiu marcantemente a porcentagem de rafzes colonizadas. Quando 
aplicaram fosfato de rocha, a porcentegem de raizes que estavammicorrizadas aumentou com o aumento na aplicaşa de fosfato até o nivel de $42,86 \mathrm{~g} / \mathrm{P} / \mathrm{vaso}$, mas acima desse nivel a porcen tagem diminuiu.

No trabalho em solução nutritiva de MOSSE E THOMPSON (1984), plantas micorrizadas de fejjão a que se adicionou fosfato de rocha, foram as que mostraram colonização de ratzes mais extensiva e vigorosa do que aquelas que receberam a forma solüvel.

No presente experimento, o tratamento que rece beu o fosfato solüvel apresentou porcentagem de colonização e número de esporos em $100 \mathrm{ml}$ de solo mais baixos do que os demais, com fosfato de rocha, embora sem diferenças significa tivas. Em alguns casos, com a adição de fosfato solúvel a co lonização das rajzes pode diminuir (BETHLENFALVAY E YODER, 1981 ; VARMA, 1979); não ser muito afetada pela aplicação de fosforo (SMITH \& DAFT, 1977), ou pode até aumentar a colonização das raizes (BOLAN et a 11i, 1984; PARADA, 1984). Este ü1timo caso provavelmente ocorre quando a concentração de fósforo no solo está ainda abaixo da concentraçáo crítica para inibir a colonização micorrizica (HAYMAN \& MOSSE, 1971).

Do mesmo modo, EZETA \& SANTOS (1980) observaram queda na esporulaçāo de Gigaspora margarlta com o aumento no nivel de fósforo no solo, enquanto que Ross (1971) observou que a produção de esporos de Endogone em soja não foi afe tada com a dose de fósforo aplicado. E PARADA (1984), en fel joelro, constatou maior esporulação com o aumento na dose de fosforo. 


\subsection{EXPERIMENTO COM FEIJÃO}

\section{- Peso da matéria seca da parte aérea}

Na Tabela 8 pode-se observar o efeito no peso da matéria seca da parte aérea do feijoeiro, causado pela micorriza VA. Comparando-se estatisticamente os valores obtidos pelas plantas micorrizàdas em relação às não micorriza das, nota-se que os das primeiras são maiores numericamente, embora poucos tratamentos demonstrem ser significativos.

Nota-se tambëm neste experimento, que o peso da matérla seca das plantas não foi afetado pela presença de fosfato de qualquer natureza ou dose, tanto nas plantas micor rizadas como nas não mi corrizadas. Essas ültimas foram beneficiadas apenas pela adição de superfosfato triplo, cujo efel to na planta fol semelhante à qualquer tratamento com micorr za.

Alguns tratamentos com fosfato de rocha e micorriza (Pacos de Minas, dose 1 e Jacupiranga, dose 2) foram bastante ineficientes, chegando a igualar-se ao tratamento em que não se adicionou o fosfato e nem a micorriza.

o efeito benéfico das micorrizas vesiculo-arbusculares em feijoeiro já fol estudado por diversos autores (DAFT \& EL-GIAHMI, 1974, 1975; MARTINS \& SAITO, 1986; OLIVEIRA \& ZAMBOLIM, 1986; SIQUEIRA \& OLIVEIRA, 1986). PLENCHETTE Et alii (1983) verificaram a alta dependencia do feijoeiro à micorriza, e PARADA (1984), testando a eficiencia de vários fun gos MVA, verificou que Glomus leptotichum foi o endófito mais eficiente para as diversas cultivares empregadas.

BETHLENFALVAY Et alii (1982) encontraram valores relativos ao crescimento de plantas de feijão micorriza- 


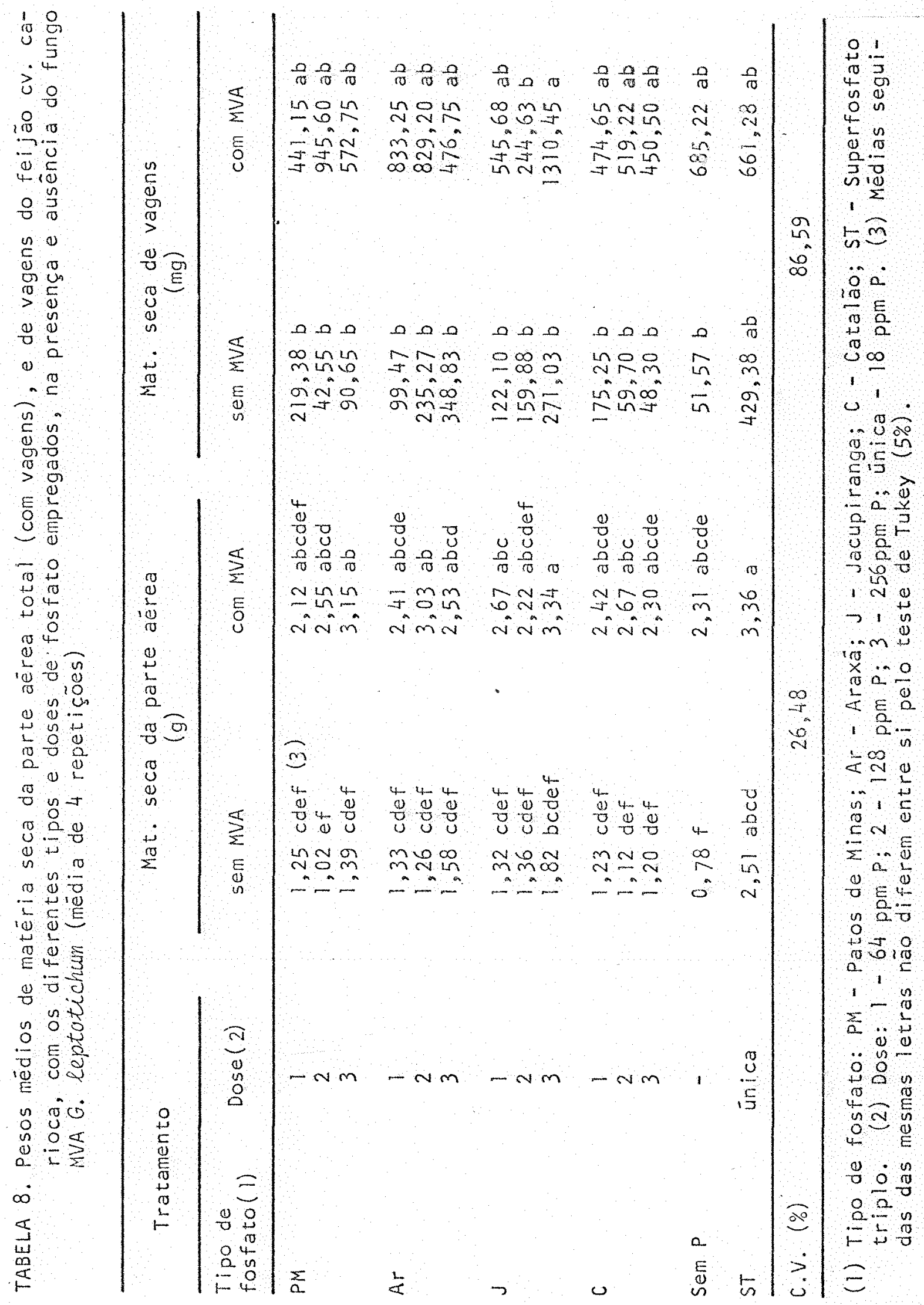


do sempre mais baixos do qua plantas controles não micorriza das. Porem esses resultados devem ser interplutados com culdado uma vez que as condiçōes para a fotossintese eram subótimas, havendo então inibição do crescimento da planta micor rizada devido à competiçäo por carboidratos.

0 fato de no presente experimento não ter havi do um crescimento mais significativo das plantas micorrizadas pode ser devido á alguma condíção ambiental desfavorável ao desenvolvimento do feijoeiro, como as baixas temperaturas ambientals e excesso de umi dade encontrado no solo dos vasos, que podem ser prejudicials ao feijoeiro (VIEIRA, 1983). As condiçoes relacionadas á luminosidade, temperatura ou umidade do solo afetam o desenvolvimento das plantas, e qualquer alte ração no sistema solo-fungo-planta pode alterar a eficiência da interação (PARADA, 1984). MULLIGAN et alii (1985) sugegiram que condiçóes fístcas do solo adversas, como compactação, seca e condiçoes anaeróbicas, podem causar um declinio na colonização simbiótica do sistema radicular do feljoeiro pelo fungo micorrizico VA, afetando o desenvolvimento da planta.

A adição do superfosfato triplo favoreceu o de senvolvimento das plantas sem micorriza, mas plantas micorrizadas näo responderam à sua adiçäo, não concordando com PARADA (1984) onde a micorriza elevou o peso da materia seca da parte aérea mesmo em doses mais elevadas $(27$ ppm de $p)$ do que a usada neste experimento (18 ppm p).

A presença do fosfato de rocha náo influiu no desenvolvimento das plantas micorrizadas ou náo. o fosfato de rocha catalão usado no experimento de CARDOSO (1984) também não trouxe nenhum beneficio ao desenvolvimento do feijoel ro, na presença ou ausência do fungo MVA. Além do mais, nào se notou o efeito superior no desenvolvimento das plantas, da 
combinação fosfato de rocha e micorriza em relação a tratamentos com apenas um dos fatores, discordando de MOSSE et ali $\mathrm{i}(1976)$, ISLAM et al11 (1980) e CARDOSO (1985), em diversas leguminosas.

A auséncia da promoção no crescimento devido à adição de fosfato de rocha em feijoeiro, independente da micorriza, condiz com alguns trabalhos publicados. BRAGA (1969), testando várias fontes de fosfato de diferentes solubilidades (superfosfato simples, farinha de ossos, termofosfato, ácido fosfórico, fosfato diamónico e fosfato de Araxá), em três níveis $\left(100,200\right.$ e $300 \mathrm{~kg} \mathrm{P} 2_{5}{ }_{5}$ ha), encontrou a melhor eficiên cia para o fosfato diamónico tanto na produção de grãos $(\mathrm{g} /$ vaso) como no fósforo recuperado (mg $P / V a s o)$. As demais fontes não se mostraram eficientes, isto em razão principalmente do curto perfodo en que foi realizado o ensaio em estufa. Este pode ter sido o motivo da balxa eficiencla dos fosfatos de rocha utilizados neste experimento, tambèm de curta duraçáo.

- fosfato de rocha (Patos) na dose de $300 \mathrm{~kg}$ $P_{2} 0_{5}$ tha náo mostrou efeito significativo nos diferentes parametros analisados nos plantios de feijoeiros "das águas" e "da seca" no trabalho conduzido por ARAOJ0 et ali1, 1982. Estudando o efeito residual na cultura de feijão após avela, SILVA et alii (1985), mostraram que, embora sem diferenças sig nificativas, o feijão produziu mais nos tratamentos com fosfa to de rocha patos de Minas e Termofosfato IPT, ambos com a in corporação de adubo verde, do que com adubação com superfosfa to triplo, e sem a incorporação, a produção fol menor em rela ção ao superfosfato triplo.

Nas condiçöes deste experimento, várias causas como condiçóes ambientais desfavoráveis, baixo nI vel de fösforo disponivel no solo, baixa eficiencia dos fosfatos de rocha e a curta duração do experimento devem ter 
contribuido para a pouca ef́cácia das AVA no desenvolvimento do feijoeiro.

\section{- Peso da matéria seca de vagens}

A Tabela 8 mostra os resultados de matéria seca de vagens do feijoeiro. Nela praticamente não se notam di ferenças entre os tratamentos, destacando-se estatisticamen te apenas aquele que recebeu o fosfato Jacupiranga na dose 3 com micorriza, em relação aos tratamentos sem fosfato ou com fosfato de rocha sem micorriza, e em relação ao Jacupiranga na dose 2 com micorriza.

Apesar disso, verifica-se que houve uma tenden cia em plantas micorrizadas apresentarem maior produçáo de va gens.

DAFT \& EL-GIAHMI (1974, 1975) e OLIVEIRA \& ZAM BOLIM (1986) verificaram aumentos na produção de vagens em fel joeiro micorrizado, e PARADA (1984) observou que a micorriza teve real importancia na produção de grăos somente até a dose intermediária de fósforo ( $16 \mathrm{ppm}$ P).

Tratamentos com fungo MVA e o superfosfato tri plo levaram à produção de vagens no feijoeiro, o que náo ocor reu com os outros tratamentos (fosfato de rocha Cataláo e/ou Rhizobium phaseoli) sem fungo MVA no trabalho de CARDOSO (1984). BRAGA (1969) e ARAOJO et alii (1982) não encontraram aumentos significativos na produção de grãos quando usaram fosfato de rocha, como jä discutido anteriormente.

ROSS E GILLIAM (1973) também não obtiveram aumentos na produção de grãos em soja devido à micorriza quando usaram fosfato de rocha, talvez devido à baixa dose empregada, como já discutido no experimento com soja. 
GIANINAZZI-PEARSON et 111 ( 1981 a) encontraram aumentos na produção de vagens em soja devido à micorriza quando usaram um fosfato pouco solüvel, mas como esse aumento não diferiu estatisticamente do aumento provocado pela micorriza quando não se adicionou fosfato, esses autores concluiram que esse aumento fol devido apenas a micorriza. o mesmo tipo de efeito pode tér sido encontrado neste experimento se levar mos em conta que houve uma tendência em que plantas micorriza das levaram a malores produçöes, tanto na presença de fosfato de rocha como na sua ausência.

\section{- Absorção de NPK}

A Tabela 9 mostra os resultados referentes aos teores de nitrogênio, fósforo e potássio na parte aérea do fel joeiro.

De maneira geral, plantas micorrizadas e não micorrizadas não apresentaram diferenças significativas entre sí quanto ao teor de nitrogênio. (\%N) na parte aérea, mas as micorrizadas mostraram tendência em possuir os menores valores, provavelmente devido ao efeito de diluição. A presença de qualquer fosfato não afetou a $\% N$ em plantas micorrizadas, mas em plantas não mi corrizadas o tratamento com superfosfato tri plo apresentou uma diminuição na porcentagem, talvez também devido ao efeito de diluição, uma vez que as plantas se desen volveram mais, provocando diferenças significativas entre este diversos outros tratamentos. Mas os teores nesses tratamentos con superfosfato triplo não diferiram de nenhum tratamento com micorriza.

0 teor de fósforo (\%) da parte aérea de plantas micorrizadas foi maior do que em plantas não micorrizadas, diferindo estatisticamente en quase todos os tratamentos. Apesar disso, não se observou efeito de tipos ou niveis de fosfato aplicado em plantas micorrizadas, notando-se apenas que tratamentos com superfosfato triplo, Araxäna dose 2 e Cataláa na dose 3 tiveram efeitos semelhantes. Em plantas não mlcor- 


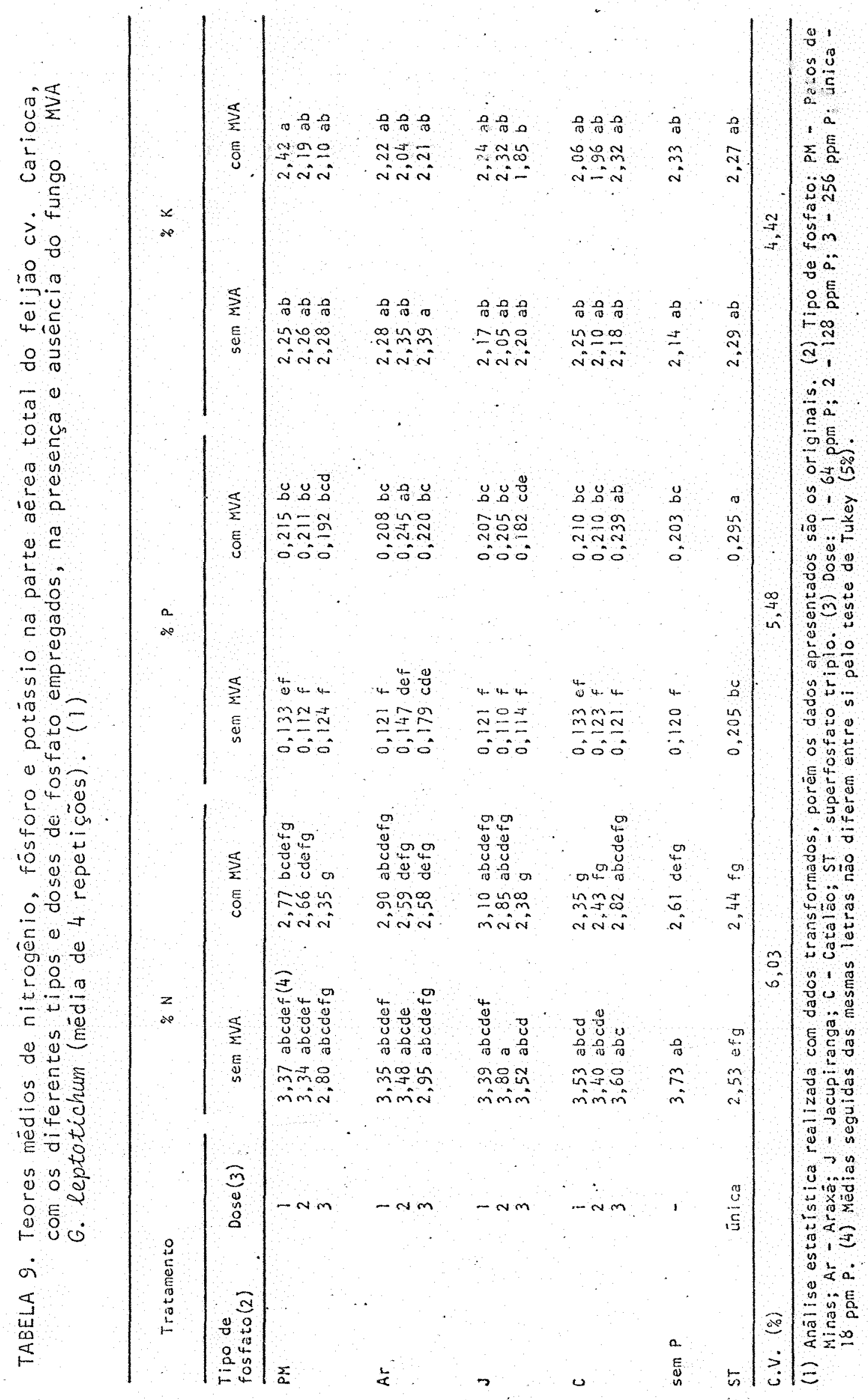

75. 
zadas, observou-se apenas a superioridade do superfosinto tri plo, efeito este que não diferlu de nenhum tratamento con fos fato de rocha ou sem fosfato, com micorriza.

Quanto ao teor de potássio (\%K), não se observaram diferenças significativas de interesse prático entre os tratamentos.

Como já comentado anteriormente, a maior importancia das MVA reside no fato delas promoverem o melhor crescimento do hospedeiro, pols graças à melhor exploração do solo pelas hifas do fungo, levam ao maior fornecimento de nutrientes, principalmente de fósforo, o qual é encontrado em altas concentraçóes em plantas mi corrizadas (MOSSE, 1973).

Neste experimento, a $\%$ p foi sem düvida a mais beneficiada pela micorriza, enquanto a $\% \mathrm{~N}$ e $\% \mathrm{~K}$ não foram incrementadas, como aconteceu no presente trabalho com soja, e no trabalho de CARDOSO (1986). SIQUEIRA \& OLIVEIRA (1986) tam bém encontraram incrementos na \% na parte aérea do feijoeiro, devido à inoculação com fungo MVA.

Muitos autores, entre eles MOSSE et alii (1976), WAIOYANATHA et alii (1979) E SPARLING \& TINKER (1978), encontraram aumentos na $\% \mathrm{P}$ em tecidos de leguminosas que receberam fosfato de rocha ou micorriza, ou com a combinação de ambos, levando a incrementos ainda maiores, como já discutido anteriormente.

CARLING et ali i (1978) não encontraram efeito na $\% N$ devido ao fungo MVA em soja, embora outros autores $j a$ tenham encontrado aumentos, como podem ser vistos nos trabaThos de NIELSEN \& JENSEN (1983) en alfafa, e no de CARDOSO (1985), em soja. 
A micorriza VA geralmente não afeta a \% K na planta, como veriflcado por PARADA (1984) em feijão, e por ROSS (1971) e ROSS \& HARPER (1970) em soja.

As quantidades totais dos macronutrientes acumulados na parte aërea do feijoeiro podem ser encontrados na. Tabela 10 .

Quanto ao $N$ total, não se observaram diferenças significativas entre os tratamentos, e quanto ao K total, poucos tratamentos com micorriza diferiram dos sem micorriza, não se destacando nenhum tipo de fosfato de rocha ou doses.

0 P total acumulado pelas plantas micorrizadas foi, exceto poucas excessões, significativamente maior em relação às näo mi corrizadas, efeito já observado por vários autores (ABBOTT \& ROBSON, 1978; ASIMI et al11, 1980; MIRANDA, 1982 ; MANJUNATH \& BAGYARAJ, 1984). Observa-se também neste experimento o melhor efeito do fosfato solüvel nas plantas $\mathrm{mi}$ corrizadas ou não. Nas mi corrizadas, o efeito do fosfato soluvel foi superior aos demais tratamentos, equivalendomse ape nas ao fosfato Araxá na dose 2 , e nas não micorrizadas o efel to do fosfato solüvel, além de ser melhor, foi estatisticamen te semelhante a quase todos os tratamentos com micorriza.

MOSSE et alii (1976) observaram que em alguns casos, a combinação fosfato de rocha e micorriza elevava o $P$ total da planta em valores maiores do que os observados com os dois fatores isolados. Esse efeito não fol observado com os fosfatos de rocha em geral, ocorrendo apenas com o fosfato so lüvel com micorriza.

\section{- Peso da matéria seca de nödulos}

os resultados referentes ao peso da matéria se 


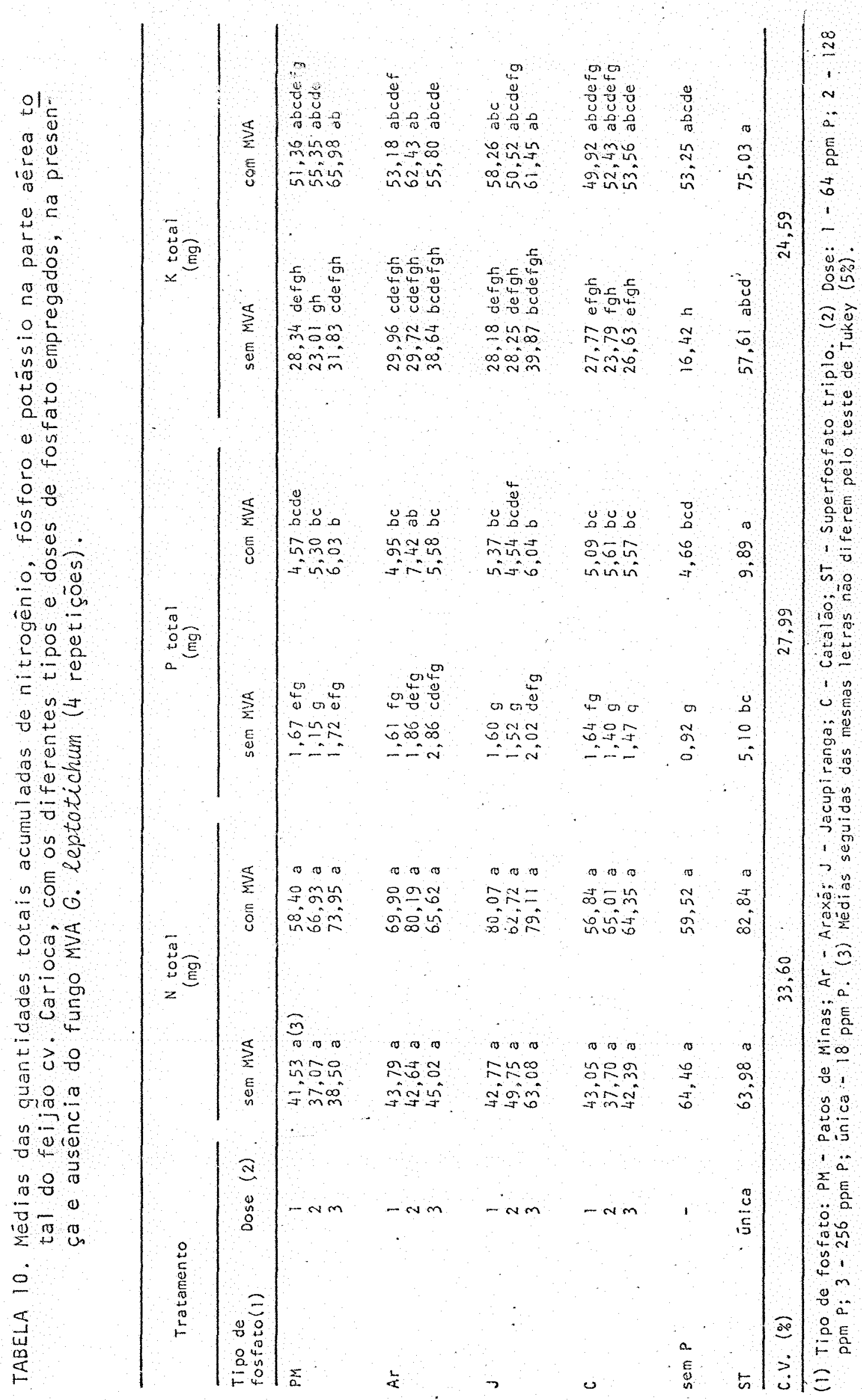


ca de nódulos do feijoeiro se encontram na Tabela 11.

Nela verifica-se que, embora sem diferenças significativas, houve tendència de plantas micorrizadas nodularem ma is que as náo mi corrizadas. Tambèm não se verificam efeitos de tipos ou doses de fosfato aplicado em plantas não micorrizadas, enquanto que em plantas micorrizadas, as únicas diferenças significativas observadas foram entre os tratamentos com superfosfato triplo em relação ao fosfato Patos de Minas na dose 1 , ao Catalão na dose 3 , e ao sem adição de fosfato, os quais foram inferiores.

Deve-se levar em consideração a grande variabi lidade encontrada neste experimento, como mostra o alto coeficiente de variação, principalmente nesta variáael (c.V. $=$ $137,02 \%)$, e talvez por isso não se observaram diferenças significativas entre plantas micorrizadas e náo micorrizadas. Co mo exemplo, no tratamento sem fosfato, com e sem micorriza, ob serva-se apenas diferença qualitativa, pois em um tratamento as plantas nodularam e no outro não. Essas consideraçós poderão ser feitas também para outras variáveis deste experimento, sugerindo que se deve trabalhar com um numero maior de repetições para cada tratamento.

A fixação simbiótica do nitrogênio por Rhizobium em nódulos de leguminosas requer um alto suprimento em fósforo. GRAHAM \& ROSAS (1979) verificaram que o desenvolvimento e a \% p da planta, o desenvolvimento dos nódulos, a at vidade total e especifica da nitrogenase em nódulos do feljoeiro foram altamente correlacionadas com fertilização fosfatada, mesmo no nível mais elevado de fósforo aplicado $(315 \mathrm{~kg}$ $\mathrm{P}_{2} \mathrm{O}_{5} / \mathrm{ha}$ )

Em muitos experimentos a nodulação e fixação simbiótica do nitrogênio foram marcantemente incrementadas pe la infeç̧äomicorrizica (CRUSH, 1974; ABBOTT \& ROBSON, 1977; 


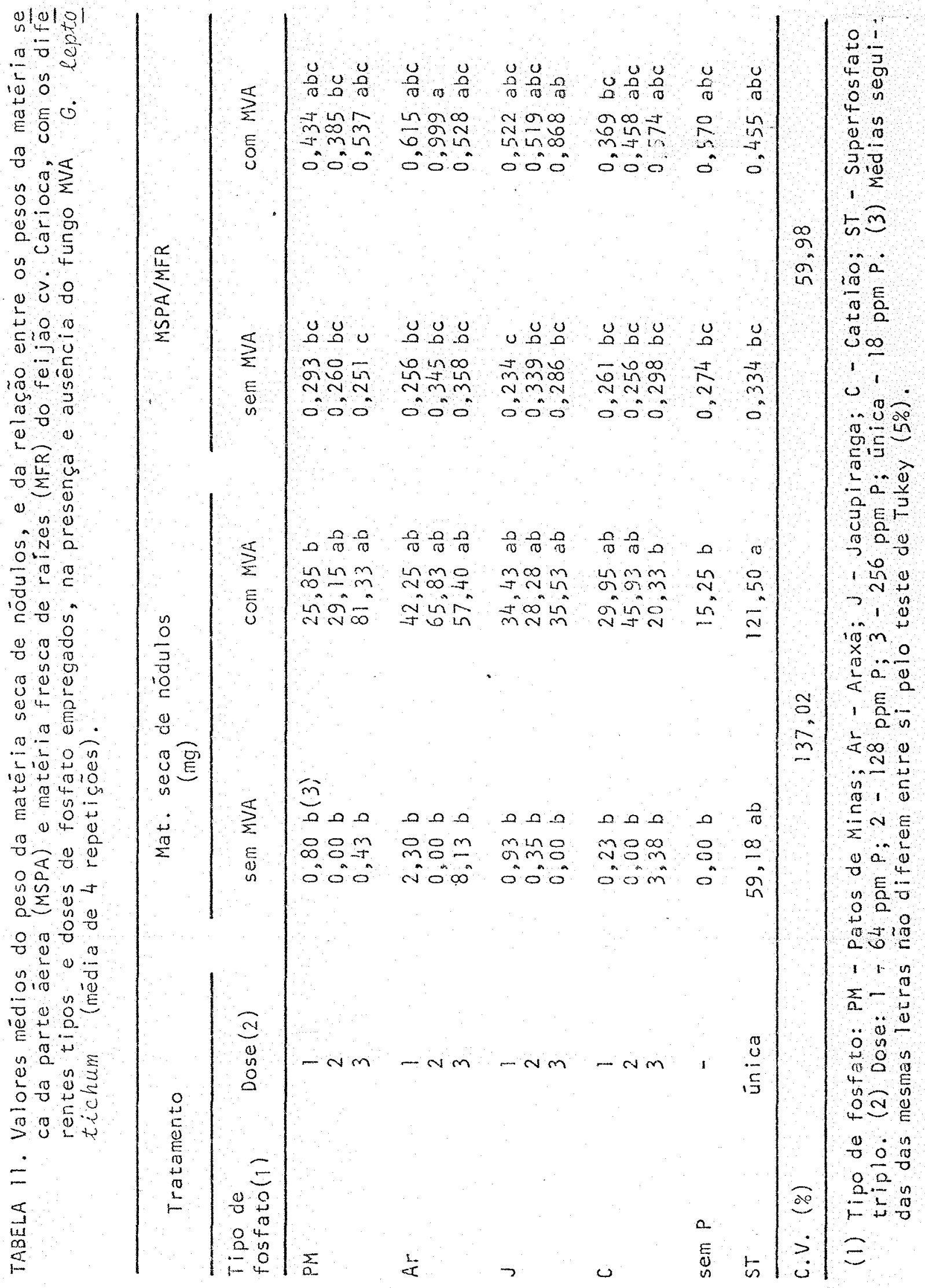


SNITH E DAFT, 1977). Em feijoeiro, a micorriza melhorou a nodulsção em trabalhos de DAFT \& EL-GIAHMI (1974, 1975), PARA DA (1984), EARTINS \& SAITO (1986) demonstraram a dependêncla de micorriza para que ocorresse a fixação simbiotica do nitrogénio, onde o numero, peso e atividade dos nódulos foram diminuídos na auséncia de fungos MVA. Os melhores resultados no crescimento e atividade dos nödulos foram observados com a introdução de Glomus leptotichum.

Alguns trabalhos mostram que a nodulação meIhora ainda mais com a introdução de micorriza e fostato,efeito este que pode ser superior aos dois fatores isolados. Como exemplo, pode-se citar ABBOTT \& ROBSON (1977) e MANJUNATH \& BA GYARAJ (1984), usando fosfato solúvel. Mas à medida em que se eleva o nivel de fósforo aplicado, o efelto da micorriza tende a diminuir (ASIMI et ali1, 1980). Vários autores obser varam incremento maior na nodulação em plantas que receberam micorriza e fosfato pouco solüvel (MOSSE, 1977a; ISLAM et al11, 1980; WAIDYANATHA et al11, 1979; BONETTI; E DONALD, 1986). MOSSE et alii (1976) sugeriram que o fosfato de rocha e a micorriza interagiam sinergisticamente em alguns solos, em trevo e centrosema, uma vez que o efeito na nodulaçáo foi mais do que aditivo em relação aos dois fatores isolados.

No presente experimento, algumas plantas com fosfato de rocha sem MVA nem nodularam, como tambem aconteceu em soja no estudo de BONETTI E DONALD (1986). Isto pode ter acontecido devido à baixa disponibilidade de fósforo no solo. As plantas com micorriza nodularam um pouco mais, provavelmente por causa da melhor exploração do fósforo no solo pelas hi fas do fungo.

0 fato de näo ter havido aumentos significativos na nodulação de plantas mi corrizadas neste experimento po de explicar tambēm a baixa eficiência da fixação do nitrogê- 
nio, uma vez que as plantas não diferiram entre si cuanto ao teor e acúmulo de nitrogénio na parte aérea. o pequeno aumento na nodulação de plantas micorrizadas pode ter sido provocado pelo também pequeno aumento no peso da matéria seca da parte aérea, uma vez que estas plantas estavam um pouco mals bem nutridas em fósforo do que as näo micorrizadas, concordando com CRUSH (1982), devido mais uma vez à melhor explora ção desse ou outros nutrientes do solo pelas hifas do fungo.

Embora as doses de fosfato de rocha aplicadas tivessem sido relativamente elevadas, estas se mostraram alnda insuficientes para suprir o fósforo necessário ao bom desenvolvimento do feijoeiro.

\section{- Relacão entre os pesos da matéria seca da parte aerea (MSPA) e materia fresca de raizes (MFR)}

os valores das relações entre os pesos da MSPA e MFR se encontram na Tabela 11, onde de uma maneira geral näo se observam diferenças significativas entre os tratamentos. O maior valor encontrado se refere a tratamento com fosfato Araxäna dose 2 com micorriza, que difere significat vamente de todos os tratamentos sem micorriza e dos tratamentos com fosfato Patos de Minas na dose 2 e catala na dose 1 , com micorriza. Apesar disso, houve tendéncia em plantas micorrizadas apresentarem os maiores valores em relação às não micorrizadas, embora sem significado estatistico.

- fato de plantas micorrizadas apresentarem ten déncia em possuir maior MSPA/MFR pode significar uma reduça na quantidade de material radicular requerida para produçáo da parte aérea da planta, uma vez que as hifas do fungo aumentam a superfície de absorçäo, alem das raizes.

Existem evidéncias na literatura que a presen- 
ça da MVA dim nui o sesenvolvimento radicular relativo, como jä discutidas anterisımente.

- Porcentagem le colonização das raizes e esporulacáo do fungo RVA no solo

As porcentagens de raizes colonizadas e a contagem do nümero de esporos de Glomus leptotichum no solo se encontram na Tabela 12 .

Nos tratamentos em que não se inoculou o fungo MVA, não se detectou a presença de esporos de fungos micorrízicos no solo, e nem estruturas füngicas nas raízes das plantas.

Nos tratamentos inoculados com o fungo MVA, foi encontrado um nümero de esporos que variou de 385 a 1063 espo ros de G. Reptotichum em $100 \mathrm{ml}$ de solo, näo havendo diferenGas significativas entre os tratamentos. A porcentagem de co Ionização das raízes variou em torno de 40,9 a $55,6 \%$, não havendo também diferenças significativas entre os tratamentos. Foram encontrados vesículas, micélio intracelular e arbusculos no interior do córtex das raízes, e micëlio externo aderente às raízes.

A porcentagem de colonização das raízes è o parametro mais comumente usado pelos autores para avaliar a eficiencia da simbiose entre o fungo micorrizico VA e a planta hospedeira (ANDREOLA, 1982). Embora a média geral da porcentagem de colonização encontrada neste experimento $(46,4 \%)$ tenha sido superior à encontrada em feijoeiro por KRUCKELMANN (1975), e por SAlTO et alii (1983) en casa de vegetação; e um pouco inferior à encontrada também por sAlTo et alii (1983) no campo, essa porcentagem talvez não tenha sido suficiente para promover grandes incrementos nas variáveis ana 


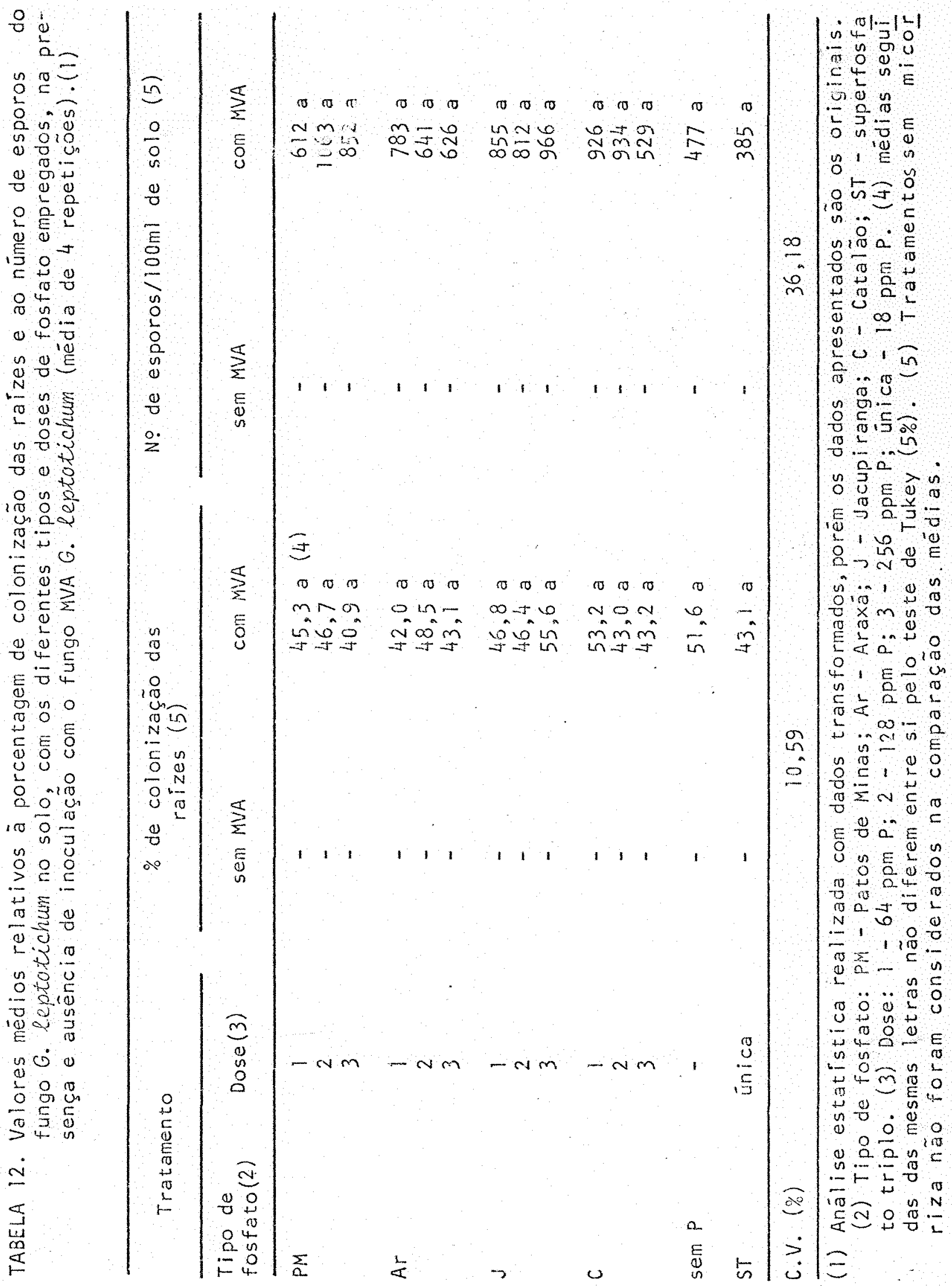


lisadas. Entretanto, convém lembrar que embora a colonização seja uma avallação essencial em trabalhos com micorrizas, o indice de colonização das ráizes ê um dado subjetivo e as com paraçóes de dados apresentados por diferentes autores devem ser efetuados com ressalvas, principalmente quanto ao seu valor absoluto (LOPES, 1980).

Existem algumas hipóteses sobre o possivel mecanismo de ação do fósforo sobre a colonização das raizes. Se gundo RATNAYAKE et ali i (1978), a concentração de fósforo no tecido da planta pode afetar a permeabilidade da membrana fos follipídica da célula do hospedeiro, afetando então a exsudação da raiz, a qual é determinante no estabelecimento da infec ção. SAME et alii (1983) verificaram a correlação entre a diminuição na colonização da raiz e a diminuiçăo na concentra ção de carboidratos soluve is na ralz em plantas que receberam niveis altos de fósforo.

Neste experimento, a adif̧äo de fosfato solüvel ou de rocha em qualquer dose não chegou a afetar a colonização das raízes, talvez porque o fósforo disponivel ainda estivesse baixo, como no experimento com soja. Em muitos casos, a aplicação de fösforo estimula a colonização micorrizica quando ela alivia uma deficiencia severa (BOLAN et alli, 1984). Jasper et alii l citados por BOLAN et alii (1984), demonstraram que isolados de fungos micorrizicos diferem em sua habilidade em infectar as raizes com o aumento nos niveis de fósforo. Segundo PARADA (1984), o feijoeiro inoculado com - fungo MVA Glomus machocarpum apresentou maior porcentagem de raizes colonizadas na maior dose de fósforo aplicado ppm P).

1. JASPER, D.A.; ROBSON, A.D.; ABBOTT, L.K. Phosphorus and the formation of vesicular-arbustular mycorrhizas. Soil Biol. Biochem, Oxford, 11: $501-505,1979$. 
os efeitos de fosfato solúvel e de rorha, e também de doses, na colonização de rarzes das leguminosas, já foi discutido anteriormente, ressaltando aqui, o melhor efeito do fosfato de rocha em relaçăo ao solúvel, na colonização de raizes de feljoeiro em solução nutritiva, no trabalho de MOSSE \& THOMPSON $(1984)$.

A esporulação do fungo neste experimento não foi afetada pela adição de qualquer fosfato, como encontrado por MIRANDA (1982), onde a esporulação dos fungos introduzidos Glomus macrocarpum e Gigaspora margarita no campo em solo na ral, na cultura da soja, não foi afetada pelo tipo de fosfato (solúvel ou de rocha), embora G. macrocarpum tenha esporula do mals do que G. margarita e o fungo nativo. PARADA (1984) encontrou aumento na esporulação do fungo MVA no feijoelro com o aumento na dose de fosfato soluvel aplicado. 0utros aspectos relacionados à esporulaçăo dos fungos micorrizicos em relação à adição de fosfatos jã foram discutidos no experimento com soja.

Os dados relacionados à porcentagem de colonização das raízes e esporulação do fungo no solo permite concluir que houve um bom estabelecimento do fungo no solo e por tanto, outros fatores estariam limitando a eficiencia da asso ciação micorrizica VA no feijoeiro, talvez a baixa disponibilidade de fósforo no solo e condições ambientais inadequadas.

Podemos verificar que o fosfato Catalão na dose 3 e na presença de micorriza, seguido do fosfato Araxá nas doses 2 e 3 , com nicorriza, foi o que mais sedestacou entre os fosfatos de rocha utilizados, chegando inclusive a igualar seu efeito ao de fosfato solüvel na maioria das variávels analisadas no experimento com soja, mas não com fej jão.

A soja micorrizada parece que respondeu mais à adição de fosfato de rocha do que o feijoeiro. A grande va- 
riabilidade escontrada no experimento com feljão pode ter con triburdo para que nãu se notassem diferenças significativas en tre plantas micorrizadas e não micorrizadas, pois apesar dis so, verifica-se que hnuve tendéncia de efeito benéfico das micorrizas na maioria das variáaeis analisadas. Por isso su gere-se que trabalhos dessa natureza devam ser conduzidos com nümero maior de repetiçōes, além de se oferecer as melhores condições ambientais para o desenvolvimento das plantas.

Deve-se também levar en consideração que as espécies de plantas diferem em sua habilidade em utilizar o fósforo dos fosfatos do solo, ou daquele aplicado como fertilizante, neste caso, dos fosfatos de rocha (KHASAWNEH \& DOLL, 1978; RAIJ E DIEST, 1979). O pH do solo é outro fator que exerce grande influência na eficiência agronomica dos fosfatos de rocha, pois a solubilização desses materiais é favorecida pela acidez do solo. No entanto, os valores de pH nes te experimento foram ajustados entre 6,0 e 6,5 para atender as necessidades das plantas, e isso pode ter contribuído para a baixa eficiencia geral dos fosfatos de rocha usados nos experimentos. Portanto, para se obter melhor desenvolvimento do vegetal, exige-se um equilíbrio entre os fatores: acidez do solo, adaptação de plantas e disponibilidade de fósforo (GOE DERT \& LOBATO, 1980).

A dose aplicada de fosfato solúvel fol a recomendada para essas leguminosas, nas condições do solo empregado. Ressalta-se que as altas doses de fosfato de rocha usa das em ambos os experimentos, em relação à dose de fosfato solüvel se explica pela afirmação de PAIRUNAN et alii (1980), os quals dizem que a aplicaçäo equitativa de fosfato soluvel e insolúvel pode levar à conclusós erroneas, pois na presença de certa quantidade de fosfato solúvel as plantas podem es tar adequadamente supridas com fósforo, enquanto que na presença da mesma quantidadé de fosfato insolúvel as plantas podem estar em extrema deficiencia deste nutriente. 
Como os solos braslleilos são geralmente ácidos e pobres em fósforo, recomenda-se em certas áreas o uso de adubação fosfatada corretiva (fosfatagem), is is do aumentar o nível de fósforo disponivel em toda a camada arável do solo. Com essa prática utilizam-se quantidades elevadas de fósforo, sendo portanto necessário o uso de formas mais baratas de fertilizantes, com os fosfatos de rocha, que devido ao menor processamento industrial apresentam custos de fabricaf̧ão mais baixos (RAIJ et alii, 1982).

No entanto os fosfatos de rocha brasileiros (Pa tos de Minas, Araxá, Catalão e outros), têm mostrado em rela ção ao superfosfato triplo, uma eficiencia inicial baixa, melhorando um pouco com o passar do tempo, sendo que o Catalão tem-se comportado de maneira inferior aos demais (GOEDERT $\varepsilon$ LOBATO, 1984). Contudo, segundo LOBATO (1982), em alguns ensaios o desempenho deste fosfato tem sido melhor.

Portanto, dois aspectos bäsicos devem ser considerados na comparação de fosfato de rocha com superfosfatos: a resposta imediata e o efeito residual (Jackson', citadopor MACEDO et alii, 1985). Porém, no presente trabalho estudouse apenas o efelto imediato dos fosfatos, em ambas as leguminosas. 0 efeito residual dos fosfatos de rocha que se dissol vem mals lentamente pode ser maior que a dos superfosfatos. Quando duas fontes de fósforo de diferentes solubilidades, uma prontamente soluvel e outra de baixa disponibilidade, sáo adicionadas ao mesmo tempo no solo, observa-se que o fosfato so luvel tem a disponibilidade maxima no tempo zero, a qual decresce continuamente tendendo a se estabilizar. 0 fosfato de baixa solubilidade tem sua disponibilidade aumentada gra-

1 JACKSON, E.A. Phosphorus fertilizers research on Australia, Melbourne, CSIRO, 284: 1-59, 1966 . 
dativamente om o lempo, até atingir um māximo, após o qual entra em decréscimo. Com o passar do tempo, o efeito residual do fosfato natural pode ser então malor do que o do fosfato solúvel, como consequéncia de sua menor velocidade de dis soluçäo. Istoé, o fosfato de rocha se dissolve lentamente na solução e à medida em que de dissolve, as reaçós de adsorção ocorrem como no caso dos superfosfato, sendo apenas $11 \mathrm{mi}-$ tadas pela velocidade de dissolução do fosfato (VOLKWEISS \& RAIJ, 1976).

Outrofator a ser também considerado é o económico. RAlJ (1986) demonstrou a dificuldade de fosfatos alternativos encontrarem utilização, dentro de condiçós economicas corretas, se não tiverem eficiência próxima a de superfosfato. Produtos de eficiencia inferior conduzem à diminuição da produtividade e a resultados economicamente desfavorá veis. Náo foi possivel realizar neste experimento, um estudo económico semelhante ao sugerido por RAlJ (1986), uma vez que näo se empregaram doses iguais, em termos de kg de $P_{2} 0_{5} /$ ha, para as diferentes fontes de fosfato.

Porém é de se esperar que o fosfato de rocha, particularmente o Catalão e Araxá, usado en doses relativamente altas (fosfatagen), considerando o menor custo por unidade de $\mathrm{P}_{2} \mathrm{O}_{5}$ aplicado em relação ao superfosfato triplo, e seu melhor aproveitamento atraves da introdução de fungos MVA eficientes, poderà ser utilizado na cultura de soja principalmente, como fonte alternativa de adubo fosfatado em regiōes onde seu uso possa ser viävel economicamente. 


\section{CONCLUSÕES}

os resultados obtidos no presente trabalho levam às seguintes conclusões:

1) A micorriza conduziu a aumentos na maioria das variáveis analisadas, sendo este efeito mais pronunciado na soja do que no feljão.

2) Nenhum fosfato de rocha na ausencia de $\mathrm{mi}$ corriza promoveu o desenvolvimento da cultura da soja e/ou do feijäo; portanto năo se pode recomendar o uso desses fosfatos nessas condiçóes.

3) Na presença de micorriza eficiente, os fosfatos Cataläo e Araxá em altas doses (256 ppm de p) podemequi valer à adubação convencional da soja com 18 ppm de p como superfosfato triplo, porém antes de se fazer tal recomendação, deve ser verificada a viabilidade económica e o efeito residual desses fosfatos em culturas subsequentes. 


\section{REFERENNCIAS BIBLIỌGRAFICAS}

ABBOTT, L.K. \& ROBSON, A.D. Growth stimulation of subterraneum clover with vesicular-arbuscular mycorrhizas. Aust. J. Agric. Res., Melbourne, 28: $639-649,1977$.

ABBOTT, L.K. E ROBSON, A.D. Growth of subterraneum clover in relation to the formation of endomycorrhizas by introduced and indigenous fungi in a field soil. New Phy tol., oxford, $81: 575-585,1978$.

ABBOTT, L.K. E ROBSON, A.D. The effect of VA mycorrhizae on plant growth. In: POWELL, C.L. E [BAGYARAJ, D.J., ed. VA mycorrhiza, Boca Raton, CRC Press, Inc., 1984, cap. 6. p. $113-130$.

ALLEN, M.F.; MOORE Jr., T.S.; CHRISTENSEN, M. Phytohormone changes in Bouteloua gracilis infected by vesicular - arbuscular mycorrhizae. 1. Cytokimin increases in the host plant. Can. J.Bot., Ottawa, 58: 371-374, 1980.

ALLEN, M.F.; MOORE Jr., T.S.; CHRISTENSEN, M. Phytohormone changes in Bouteloua graclels infected by vesicular - ar buscular mycorrhizae: 11. Altered levels of gibberellin like substances and abscisic acid in the host plant. Can. J.Bot., Ottawa, 60: $468-471$, 1982 .

ANDREOLA, F. Micorrizas vesiculares-arbusculares em cana-deaçücar. Piracicaba, 1982.74p. (Mestrado-Escola Superior de Agricultura "Luiz de Queiroz"/USP). 
ANTUNES, V.; LAMBAIS, M.R.;,IIVEIRA, H.H.A.; PARADA, A.; CAR Dosn, E.J.B.N. Influência da concentração do inóculo do fungo micorrizico Glomus macrocarpus em soja [Glycine $\max (\mathrm{L})$.$] . 0$ solo, Piracicaba, $75: 17-21,1933$.

ANUARIO ESTATTSTICOO DO BRASIL - 1985, Rio de Janeiro, 46 , 1985. $760 \mathrm{p}$.

ARAOJ0, R.S.; MACHADO, N.F.; PESSANHA, G.G.; ALMEIDA, D.L.; DUQUE, F.F. Efeitos da adubação fosfatada, do esterco de curral e da inoculação na nodulação, fixação do nitrogê nio atmosférico e rendimento do feijoeiro. R. bras. Ci. Solo, Campinas, $6: 105-112$, 1982 .

ASAI, T. Uber die mycorrhizenbildung der leguminosen - pflan zen. Jap. J.Bot., Amani, 13: 463-485, 1948.

ASIMI, S.; GIAN|NAZZI-PEARSON, V.; GIAN|NAZZI, S. Influence of increasing soil phosphorus levels on interactions between vesicular-arbuscular mycorrhizae and Rhizobium in soybeans. Can.J.Bot., Ottawa, 58:2200-2205, 1980.

AZCON-AGUILAR, C. E BAREA, J.M. Field inoculation of Medicago with V.A. mycorthiza and Rhizobium in phosphate-fixing agricultural soil. Soil Biol. Biochem, oxford, 13: 1922,1981 .

BAGYARAJ, D.J. Biological interactions with VA mycorrhizal fungi. In: POWELL, C.L. \& BAGYARAJ, D.J., ed. VA mycorrhiza, Boca Raton, CRC press, Inc., 1984. Chapter 7. p. $131-153$.

BAGYARAJ, D.J.; MANJUNATH, A.; PATIL, R.B. Interactions between a vesicular-arbuscular mycorrhiza and Rhizabium and their effects on soybean in the field. New Phytol., $0 x-$ ford, $82: 141-145,1979$. 
BAREA, J.M. E AZCON-AGUILAR, C, Mycorthizas and their significance in nodulating nitrogen-fixing piants. Adv. Agron, New York, 36: 1-54, 1983.

BAYLIS, G.T.S. Root hairs and phycomycetous mycorrhizas in phosphate deficient soil. Pl. Soil, Hague, 33 : 713-716, 1970 .

BAYLIS, G.T.S. The magnolioid mycorrhiza and mycotrophy in root systems derived from it. In: SANDERS, F.E.; MOSSE, B.; TINKER, P.B., ed. Endomycorrhizas, London, Academic Press, 1975. p. 373-389.

BERGERSEN, F.J. Biochemistry of symbiotic nitrogen fixation in legumes. Ann. Rev. Plant Physiol., Stanford, 21: 121140,1971 .

BETHLENFALVAY, G.J.; BAYNE, H.G.; PACOVSKY, R.S. Parasitic and mutualistic associations between a mycorrhizal fungus and soybean: The effect of phosphorus on host plant - endophyte interactions. Physiol. Plant, Copenhagen, 57: 543$548,1983$.

BETHLENFALVAY, G.J.; PACOVSKY, R.S.; BAYNE, H.G.; STAFFORD, A.E. Interactions between nitrogen fixation, mycorrhizal colonization, and host-plant growth in the Phaseolus - Rhe zobium - Glomus symbiosis. Plant Physiol., Lancaster, 10: $446-450, \quad 1982$.

BETHLENFALVAY, G.J. E YODER, J.F. The Glycine - Glamus - Rhe zobium symbiosis. 1. Phosphorus effect on nitrogen fixation and mycorrhizal infection. Physiol. Plant, Copenhagen, 52: 141-145, 1981 . 
BOLAN, N.S.; ROBSON, A.D.; DARROW, N.J. Increasing phosphorus supply can increase the infection of plant roots by vesicular-arbuscular mycorrhizal fungi. Soll Biol. Biochem, Oxford, $16(4): 419-420,1984$.

BONETTI, R. Efeito de micorrizas vesiculares arbusculares na nodulação, crescimento e absorção de fósforo e nitrogênio em siratro. R. bras. Ci. Solo, Campinas, $8(2)$ : 189-192, 1984.

BONETTI, R. E DONALD, E.S.F. Efelto da micorriza V.A. nodulação e crescimento da soja (Glycine max (L.) Merril) com aplicação de fosfato natural e solüvel. In. REUNIAAO LATINOAMERICANA SOBRE RHIZOBIUM, 12, Campinas, 1984. Anais. Campinas, Instituto Agronômico, 1986. p.421-427.

BRAGA, J.M. Comparação entre fosfatos aplicados ao feijoeiro. 1. Trabalhos em casa de vegetaçăo. R. Ceres, Viçosa, $16(88): 88-101,1969$.

BRAGA, N.R.; MASCARENHAS, H.A.A.; FEITOSA, C.T.; HIROCE, R.; RAIJ, B. van. Efeitos de fosfatos sobre o crescimento e produção de soja. R. bras. Ci. Solo, Campinas, 4 : $36-$ 39,1980 .

CABALA-ROSAND, P. \& WILD, D.A. Direct use of low grade phosphate rock from Brazil as fertilizer. 11. Effects of mycorrhizal inoculation and nitrogen source. Pl. Soil, Hague, 65: $363-373,1982$.

CARDOSO, E.J.B.N. Efeito de micorriza vesiculo-arbuscular e de fosfato de rocha nas culturas da soja e do feijão. Piracicaba, 1984. 220p. (Livre-docência-Escola Superior de Agricultura "Luiz de Queiroz"/USP). 
CARDOSO, E.J.B.N. Efelto de micorriza vesiculo-arblacular e fosfato-de-rocha na simbiose soja-Rhizobium. Rev. bras. Ci. Solo, Campinas, $9(2): 125-130,1985$.

CARDOSO, E.J.B.N. Eficiência de fungos micorrizicos vesiculo - arbusculares em soja, com Rhizobium japonicum e fosfato de rocha, em função do tipo de solo. R. bras. Ci. Solo, Campinas, 10(1): 17-23, 1986 .

CARLING, D.E.; RIEHLE, W.G.; BROWN, M.F,; JOHNSON, D.R. Effects of a vesicular-arbuscular mycorthizal fungus on nI trate reductase and nitrogenase activities in nodulating and non-nodulating soybeans. Phytopathology, Lancaster, 68: $1590-1596,1978$.

CATANI, R.A. E GLORIA, N.A. A disponibilidade do fósforo de diversos fosfatos estudada por meio do método de Neubauer. In: CONGRESSO BRASILEIRO DE CIENCIA DO SOLO, 9., BeIEm, $1961 . \quad$ p.23.

COOPER, K.M. Growth responses to the formation of endotrophic mycorrhizas in Solanum, Leptospermum, and New Zeal and ferns. In: SANDERS, F.E.; MOSSE, B.; TINKER, P. B., ed. Endonycorrhizas. London, Academic Press, 1975. p. $391-407$.

COOPER, K.M. E LOSEL, D.M. Lipid physiology of vesicular-arbuscular mycorrhiza. 1. Composition of lipids in roots of onion, clover and ryegrass infected with Glomus mosseae. New Phytol., oxford, 80: 143-151, 1978.

COX, G. E SANDERS, F.E. Ultrastructure of the host - fungus interface in a vesicular - arbuscular mycorrhiza. New Phytol., oxford, 73: 901-912, 1974 . 
CRU:H, J.R. Pant gronth responses to vesicular arbuscular mycorrhiza. VIl. frowth and nodulation of some herbage legumes. New Phytol, oxford, $73: 743-749,1974$.

CRUSH, J.R. Occurrence of endomycorrhizas in soil of the Mackenzie Basin, Canterbury, New Zealand. N.Z.J. Agric. Res., Wellington, 18: $361-364,1975$.

CRUSH, J.R. Effects of endomycorrhizas and phosphorus fertilizer on nodulation and acetylene reduction activity of white clover seedlings. N.Z.J. Exp. Agric., Wellington, $10: 297-299,1982$.

DAFT, M.J. E EL-GIAHMI, A.A. Effect of Endogone mycorrhiza on plant growth. VII. Influence of infection on the growth and nodulation in french bean (Phaseolus vulgaris). New Phytol, oxford, $73: 1139-1147,1974$.

DAFT, M.J. E EL-GIAHMI, A.A. Effects of Glomus infection on three legumes. In: SANDERS, F.E.; MOSSE, B.; TINKER, P. B., ed. Endomycorrhizas. London, Academic Press, 1975. p. $581-592$.

DAFT, M.J. E EL-GIAHMI, A.A. Studies on nodulated and mycorhizal peanuts. Ann. Appl. Biol, Cambridge, 83: 273-276, 1976 .

DAVIS, R.M. E MENGE, J.A. Phytophthora parasitica inoculation and intensity ofvesicular-arbuscular mycorrhizae in citrus. New Phytol., Oxford, 87: 705-715, 1981.

DEMETRIO, J.L.; ELLIS Jr., R.; PAULSEN, G.M. Nodulation and nitrogen fixation by two soybean varieties as affected by phosphorus and zinc nutrition. Agron. J., Madison, 64: $566-568,1972$. 
EL HASSANIN, A.S. E IYND, J.Q. Soil fertility effects with tipartite symbissis for growth, nodulation and nitrogena se activity of Vicia faba L. J. Plant Nutr., New York, $\underline{8}(6): 491-504,1985$.

ELMES, R.B. E MOSSE, B. Vesicular-arbuscular endomychrrhizal inoculum production. 11. Experiments with maize (Zea mays) and other hosts in nutrient flow culture. Can. J._Bot, Ottawa, 62: 1531-1536, 1984 .

EZETA, F.N. E SANTOS, 0.M. Benefício da introdução de endomicorriza eficiente na utilização de nutrientes em latossolos do sul da Bahia. R. bras.Ci. Solo, Campinas, 4 : $13-17,1980$.

FRANCO, A.A. E DOBEREINER, J. Interferência do cálcio e nitro gênio na fixação do nitrogênio por duas variedades de Pha seolus vulgaris L... Pesq. agropec. bras., Sërie Agronomia, Brasilia, 3: 223-227, 1968.

FRONTERA, G.M. E DELORENZINI, C. Micorrizas en Cruciferas de importancia agricola y su influencia sobre la absorción de nitrógeno y fósforo. R. Lat-amer. Microbiol., México, 23: $157-160,1981$.

GANRY, F.; DIEM, H.G.; DOMMERGUES, Y.R. Effect of inoculation with Glomus mosseae on nitrogen fixation by field grown soybeans. Pl. So 11, Hague, 68: 321-329, 1982.

GERDEMANN, J.W. Vesicular-arbuscular mycorrhiza and plant growth. Ann. Rev. Phytopathology, Palo Alto, 6: 397-418, 1968.

GERDEMANN, J.W. Mycorrhizae. In: CARSON, E.W., ed. The plant root and its environment. Charlottesville, University Press of Virginia, 1974, p.205-217. 
GERDEMANN, J.W. Vesicular-arbuscular mycorrhizae. 10. TORREY, J.G. E CLARKSON, D.T., ed. The development and func tion of roots, London, Academic press, 1975. p.575-591.

GERDEMANN, J.W. E NICOLSON, T.H. Spores of mycorrhizal Endogone species extracted from soil by wet sieving and decan ting. Trans. Br. Mycol. Soc., London, 46: 235-244, 1963.

GERDEMANN, J.W. E TRAPPE, J.M. The Endononaceae in the Pacific Northwest. Mycologia Memoir n.5. The New York Botanical Garden E The Mycological Society of America, 1974. $75 \mathrm{p}$.

GIANINAZZI-PEARSON, V.; FARDEAU, J.C.;ASIMI, S.; GIANINAZZI, S. Source of additional phosphorus absorbed from soil by vesicular-arbuscular mycorrhizal soybeans. Physiol. Vég., Paris, $19(1): 33-43,1981 \mathrm{a}$.

GIANINAZZI -PEARSON, V.; MORANDI, D.; DEXHEIMER, J.; GIANINAZ 21, S. Ultrastructural and ultracytochemical features of a Glomus tenuis mycorriza. New Phytol., oxford, 88:633$639, \quad 1981 \mathrm{~b}$.

GILMORE, A.E. The influence of endotrophic mycorrhizae on the growth of peach seedlings. J. Amer. Soc. Hort. Sci, New York, $96(1): 35-38,1971$.

GIOVANNETTI, M. E MOSSE, B. An evaluation of techniques for measuring vesicular-arbuscular mycorrhizal infection in roots. New Phytol., oxford, 84: 489-500, 1980.

GOEDERT, W.J. E LOBATO, E. Eficiência agronómica de fosfatos em solo décerrado. Pesq.agrop.bras., Brasii ia, 15(3): $311-318,1980$. 
GOEDERT, W.J. \& LOBATO, E. Avaliação agronóm ca de fosfatos em solo de cerrado. R. bras. Ci.Solo, Compinas, $8(1): 97$ $-102,1984$.

GOEPFERT, C.F.; HILGERT, E.; GONÇALVES, H.; MOURA, R.L.; TEDESCO, P.; SALIM, O. Avaliação da influência de cinco adubos fosfatados em três solos ácidos do Rio Grande do Sul. Agron. Sulriogr, Porto Alegre, 12(2): $179-188$, 1976.

GRAHAM, P.H. \& ROSAS, J.C. Phosphorus fertilization and symbiotic nitrogen fixation in common bean. Agron. J., Madison, 71 : $925-926,1979$.

HADLEY, G. Organization and fine structure of orchid mycorrhiza. In: SANDERS, F.E.; MOSSE, B.; TINKER, P.B., ed. En domycorrhizas. London, Academi c Press, 1975. p.335-351.

HALL, J.R.; SCOTT, R.S.; JOHNSTONE, P.D. Effect of vesicular arbuscular mycorthizas on response of "Grasslands Huia" arid "Tamar" white clovers to phosphorus. N.Z.J. Agric. Res., Wellington, 20:349-355, 1977.

HALOS, P.M.; LUIS, E.M.; BORJA, M.S. Synergism between endomycorrhizas, Rhizobium japonicum CB 1809 and soybean (Glycine max (L.) Merr.). Phil. Agr., Laguna, 65:93-102, 1982.

HALOS, P.M. E ZORILLA, R.A. Vesicular-arbuscular mycorrhizae increase growth and yield of tomatoes and reduce infection by Pseudomonas solanacearum. Phil. Agr., Laguna, 62: $309-315, \quad 1979$. 
HARDIE, K. \& LEYTON, L. The influence of vesicular - arbuscu lar mycorrhiza on growth and water relations of red clover. I. In phosphate deficient soil. New Phytol., oxford, 89: $599-608,1981$.

HARDY, W.F.; HOLSTEN, R.D.; JACKSON, E.K.; BURNS, R.C. The acetylene-ethylene assay for $\mathrm{N}_{2}$ fixation: laboratory and field evaluation. Plant Physiol., Lancaster, 43 . 1185-1207, 1968.

HAYMAN, D.S. Plant growth responses to vesicular-arbuscular mycorrhiza. VI. Effect of light and temperature. New Phytol, oxford, 73 : 71-80, 1974.

HAYMAN, D.S. Endomycorrhizae. In: DOMMERGUES, Y.R. E KRUPA, S.V., ed. Interactions between non pathogenic soll microorganisms and plants, Elsevier, Amsterdam, 1978 . 0.401.

HAYMAN, D.S. E MOSSE, B. Plant growth responses to vesicular -arbuscular mycorrhiza.. 1. Growth of Endogone inoculated plants in phosphate-deficient soils. New Phytol, oxford 70: $19-27, \quad 1971$.

HIRREL, M.C. E GERDEMANN, J.W. Improved growth of onion and bell pepper in saline soil by two vesicular-arbuscular my corrhizal fungi. Soil sci. Soc. Am. J., Madison, 44:654$655, \quad 1980$.

ISLAM, R.; AYANABA, A.; SANDERS, F.E. Response of cowpea (Vigna unguiculata) to inoculation with VA-mycorrhizal fun gi and to rock phosphate fertilization in some unsteril zed Nigerian soils. P1. Soil, Hague, 54:107-117, 1980.

KELLAM, M.K. E SCHENCK, N.C. Interaction between a vesicular arbuscular mycorrhizal fungus and root knot nematode on soybean. Phytopathology, Lancaster, 70: 293-296, 1980. 
KHASAWNEH, F.E. E DOLL, E.C. The use of phosphate,ock for direct application to soils. Adv. Agron., New York, 30 : $159-206,1978$.

KINDEN, D.A. E BROWN, M.F. Electron microscopy of vesicular arbuscular mycorrhizae of yellow poplar. l. Characterization of endophytic structure by scanning electron stereos copy. Can.J.Microb., Ottawa, 21:989-993, 1975a.

KINDEN, D.A. E BROWN, M.F. Electron microscopy of vesiculararbuscular mycorrhizae of yellow poplar. 11. Intracellu lar hyphae and vesicles. Can. J. Microb., 0ttawa, 21: $1768-1780, \quad 1975 b$.

KRISHNA, K.R.; SURESH, H.M.; SYAMSUNDER, J.; BAGYARAJ, D.J. Changes in the leaves on finger millet due to VA mycorrhizae infection. New Phytol, oxford, 87: 717-722, 1981 .

KRUCKELMANN, H.W. Effect of fertilizers, soils, soil tillage, and plant species on the frequency of Endogone chlamydospores and mycorrhizae infection in arable soils. In: SAH DERS, F.E.; MOSSE, B.; TINKER, P.B., ed : Endomycorrizas. London. Academic press, 1975. p.511-525.

KUO, C.G. E HUANG, R.S. Effect of vesicular-arbuscular mycorrhizae on the growth and yield of rice - stubble cultured soybeans. P1. So il, Hague, 64: $325-330,1982$.

LAMBERT, D.H.; COLE Jr., H.; BAKER, D.E. Adaptation of vesicular-arbuscular mycorrhizae to edaphic factors. New Phytol., Oxford, 85: $513-520,1980 \mathrm{a}$.

LAMBERT, D.H.; COLE Jr., H.; BAKER, D.E. Variation in the response of alfafa clones and cultivars to mycorthizae and phosphorus. Crop Scl, Madison, 20:615-618, 1980b. 
LEWIS, D.H. Comparative aspects of the carbon nutrtion of mycorrhizas. In: SANDERS, F.E.; MOSSE, B.; TINKER, P.B., ed. Endomycorrhizas. London, Academic press, 1975. p. $119-148$.

LIM, L.L. \& COLE, A.L.J. Growth response of white clover to vesicular-arbuscular mycorrhizal infection with different levels of applied phosphorus. N.Z.J.Agric. Res., WelIington, 27 : $587-592,1984$.

LOBATO, E. Adubação fosfatada em solos da região Centro-oeste. In: OLIVEIRA, A.J.; LOURENÇO, S.; GOEDERT,W.J., ed. Adubacão fosfatada no Bras 11. EMBRAPA-D10. Documentos, 21. 1982. p. 201 -240 .

LOPES, A.S. Solos sob "cerrado": caracteristicas, propriedades e manejo. Piracicaba, Instituto da Potassa \& Fosfato, Instituto Internacional da Potassa, 1983. 162p.

LOPES, E.S. Eficiencia e especificidade das associaçōes micorrizicas do tipo vesicular-arbuscular em gramineas e le guminosas forrageiras, e no cafeeiro (cojfea arabica L.). Piracicaba, 1980. H11p. (Doutorado-Escola Superior de Agricultura "Luiz de Queiroz"/USP).

LOPES, E.S.; OLIVEIRA, E.; NEPTUNE, A.M.L. Efeito de especies de micorrizas vesicular-arbusculares em siratro ( $M a-$ croptilium atropurpureum). Bragantia, Campinas, 39: 241 $-245, \quad 1980$.

LOPES, E.S.; SIOUEIRA, J.0.; ZAMBOLIM, L. Caracterização das micorrizas vesicular-arbusculares (MVA) e seus efeitos no crescimento das plantas. R. bras. Ci. Solo, Campinas, I: $1-19,1983$. 
LYAD, J.Q.; TYQL, R.A; PURCINO, A.A.C. MYcorrhiza-soil fert:lity effects on egrowth, nodulation and nitrogenase ac tivity of siratro (Macroptilium atropurpureum (DC) Urb.). 1. Plant Nutr., New York, 8(1): 1047-1059, 198.

MACEDO, W.; GONÇALVES, J.O.N.; GIRARDI-DEIRO, A.M. Mel horamen to de pastagem natural com fosfatos e introdução de leguminosas em solo da fronteira oeste do Rio Grande do Sul. R. bras. Ci. Solo, Campinas, $9(3): 231-235,1985$.

MANJUNATH, A. E BAGYARAJ, D.J. Response of pigeon pea and. cowpea to phosphate and dual inoculation with vesicular arbuscular mycorrhiza and Rhizobium. Trop.Agr,, Trini dad, 61 (I): $48-52,1984$.

MARTINS, E.C.S. E SAITO, S.M.T. Contribui ̧ăo de micorriza VA no desenvolvimento e fixaçäo de $N_{2}$ em feijoeiro (phaseolus vulgaris L.). In: REUN IAAO BRASILEIRA SOBRE MICORIIZAS, 1 , Lavras, 1985. Anais. Lavras, Ediçōes FAEPE, 1986. p.159.

MARX, C.; DEXHEIMER, J.; GIANINAZZI-PEARSON, V.; GIANINAZZI, S. Enzymatic studies on the metabolism of vesicular - ar buscular mycorrizas. IV. Ultracytoenzymological evidence (ATPase) for active transfer processes in the host - arbuscule interface. New Phytol, oxford, $90: 37-43,1982$.

MASCARENHAS, H.A.A.; BATAGLIA, 0.C.; FEITOSA, C.T.; NAGAI, R; BRAGA, N.R. Adubação da soja em solos de cerrado. Campinas, Instituto Agronômico. Boletim Técnico n? $54, \quad 1978$. $28 \mathrm{p}$

MENGE, J.A.; DAVIS, R.M.; JOHNSON, E.L.V.; ZENTMYER, G.A. MYcorrhizal fungi decrease growth and reduce transplant in jury in avocado. Calif.Agric,, Berkeley, 32: $\quad 6-7$, 1978 . 
MILLER, R.H., CARDOSO, E.J., N., CARDO.0, C.O.A. Some observations on mycorrhizal infection on tropical forage legumes and grasses in Brazil. Summa Phytopath,. Piracicaba, 5. $168-172,1979$.

MIRANDA, J.C.C. Influência de fungos endomicorrízicos inoculados a campo, na cultura de sorgo e soja em um solo sob cerrado. R.bras.Ci.Solo, Campinas, $6.19-23,1982$.

MOSSE, B. Growth and chemical composition of mycorrhizal and nonmycorrhizal apples. Nature, London, 179 : 922-924, 1957.

MOSSE, B. Advances in the study of vesicular-arbuscular mycorrhiza. Ann. Rev. Phytopathology, Palo Alto, 11: 171196,1973 .

MOSSE, B. Plant growth responses to vesicular-arbuscular mycorrhiza. X. Responses of Stylosanthes and maize to inoculation in unsterile soils.. New Phytol,, oxford, 78 : $277-288,1977 \mathrm{a}$.

MOSSE, B. The role of mycorrhiza in legume nutrition on marginal soils. In: VINCENT, J.M.; WHITNEY, A.S.; BOSE, J. ed. Exploiting the legume - Rhizobium Symbiosis in tropical agriculture. College of Tropical Agriculture Miscellaneous Publication, $275-292,1977 \mathrm{~b}$.

MOSSE, B. Vesicular arbuscular mycorrhiza research for tropl pical agriculture. Hawai Institute for Tropical Agricul ture and Human Resources. Research Bulletin, 194, 1981. $82 \mathrm{p}$.

MOSSE, B. E HAYMAN, D.S. Mycorrhiza in agricultural plants. In: MIKOLA, P., ed. Tropical mycorrhizal research, oxford, oxford University Press, 1979. Chapter 25.p.213-229. 
MOSSE, B.; POWELL, . E.; HAYMAN, D.S. Plant growth responses to vesicular-arbuscular mycorrhiza. IX. Interactions bet ween VA mycorrhiza, rock phosphate and symbiotic nitrogen fixation. New Phyt 1., Oxford, $76: 331-342,1976$.

MOSSE, B. E THOMPSON, J.P. Vesicular-arbuscular endomicorrhi zal inoculum production. 1. Exploratory experiments with beans (Phaseolus vulgaris) in nutrient flow culture. Can. J.Bot., Ottawa, 62:1523-1530, 1984 .

MULLIGAN, M.F.; SMUCKER, A.J.M.; SAFIR, G.F. TIIIage modifications of dry edible bean root colonization by VAM fun gi. Agron..J., Madison, 77: 140-144, 1985.

MURDOCH, C.L.; JACKOBS, J.A.; GERDEMANN, J.W. Utilization of phosphorus sources of different availability by mycorrhi zal and non-mycorrhizal maize. Pl. Soil, Hague, $27(3)$ : $329-334, \quad 1967$.

NAGY, S.; NORDBY, H.E.; NEMEC, S. Composition of lipids in roots of six citius cultivars infected with the vesicular arbuscular mycorrhizal fungus, Glomus mosseae. New Phytol. oxford, $85: 377-384$, 1980 .

NICOLSON, T.H. Vesicular-arbuscular mycorrhiza - a universal plant symbiosis. Sci. Prog., Oxford, 55: 561-581, 1967.

NIELSEN, J.D. E JENSEN, A. Influence of vesicular-arbuscular mycorrhizal fungi on growth and uptake of various nutrients as well as uptake ratio of fertilizer p for lucer ne (Medicago sativa). P1. Sol1, Hague, 70: 165-172, 1983.

NORDBY, H.E.; NEMEC, S.; NAGY, S. Fatty acids and sterols as sociated with citrus root mycorrhizae. J.Agric. Food. Chem., Washington, 29: $396-401,1981$. 
NORRIS, D.0. Techniques used in work with Rhizobiun.

In:

Some concepts and methods in sub-tropical pasture research. The staff of the Cunningham Laboratory, C.S.1. R.0. Brisbane, Australia, Bull. 47, 1964.

OLIVEIRA, E.L.; MUZILLI, 0.; IGUE, K.; TORNERO, M.T.T. AValia ção da eficiência agronômica de fosfatos naturais. R.bras. Ci. Solo, Campinas, 8(1): 63-67, 1984.

OLIVEIRA, A.A.R. E ZAMBOLIM, L. Influencla de duas texturas de solo na interação sobre Glomus etunicatum Becker $\quad$ \& Gerd. e Meloidogyne javanica (Treub.) Chitwood em feijoeiro. In: REUNIÃO BRASILEIRA SOBRE MICORRIZAS, 1., Lavras, 1985. Anais. Lavras, Edições FAEPE, 1986. p.163.

OWUSU-BENNOAH, E. E MOSSE, B. Plant growth responses to ves $\mathbf{i}$ cular-arbuscular mycorrhiza. X1. Field inoculation responses in barley, lucerne and onion. New Phytol., oxford, 83: $1-10,1979$.

PAIRUNAN, A.K.; ROBSON, A.D.; ABBOTT, L.K. The effectiveness of vesicular-arbuscular mycorrhizas in increasing growth and phosphorus uptake of subterranean clover from phospho rus sources of different solubities. New Phytol, $0 x-$ ford, $84, \quad 327-338,1980$.

PARADA, A. Efeito de fósforo e de micorriza vesículo-arbuscu lar no feijoeiro. Piracicaba, 1984. 137p. (Mestrado-ES cola Superior de Agricultura "Luiz de Queiroz"USP).

PAULA, M.A. E SIQUEIRA, J.0. Influêncla da adubação fosfatada e de micorrizas vesicular-arbusculares (MVA) no desenvolvimento da soja (Glycine max (L.) Merrill). In: REUNIAOO BRASILEIRA SOBRE MICORRIZAS, 1., Lavras, 1985. Anais. Lavras, Edições FAEPE, 1986. p.164. 
PA:LLINO, V.T., PICC.I,, D.F.; BAREA, J.M. Influéncla de fun ses micorrizicos vesículo-arbusculares e fosfatos em legu minosas forrageiras tropicais. R. bras. Ci. Solo, Campinas, $10(2): 103-108,1986$.

PFEIFFER, C.M. E BLOSS, H.E. Vesicular-arbuscular mycorrhizal fungi on soybean in Arizona. Mycologia, New York, 72: $1038-1041,1980$.

PHILLIPS, J.M. E HAYMAN, D.S. Improved procedures for clea ring roots and staining parasitic and vesicular - arbuscu lar mycorrhizal fungi for rapid assessment of infection. Trans. Br.Mycol. Soc., London, $55(1): 158-161,1970$.

PIMENTEL GOMES, F. A estatistica moderna na pesquisa agropecuäria. Piracicaba, POTAFOS, 1984. 160p.

PLENCHETTE, C.; FORTIN, J.A.; FURLAN, V. Growth responses of several plant species to mycorrhizae in a soil of moderate p-fertility. I. Mycorrhizal dependency under field con ditions. Pl. Soil, Hague, 70: 199-209, 1983.

POWELL, C.L. Development of mycorrhizal infections from Endogone spores and infested root segments. Trans. Br. My col. Soc., London, $66: 439-445,1976$.

POWELL, C.L. E BAGYARAJ, D.J. VA MYCorrhizae: Why all the interest? In: POWELL, C.L. E BAGYARAJ, J., ed, VA Mycorrhiza Boca Raton, CRCPress, Inc., 1984. cap.1, p. $1-3$.

PURCINO, A.A.C. E LYND, J.Q. Tripartite symbiosis of Stylosanthes scabra Vog. influenced by soil fertility treatments of a Typic Eutrustox. Agron. J., Madison, 77: 455$458, \quad 1985$. 
PURVES, S. \& HADLEY, . Movement of carbon compounds betwen the partners in orchid mycorrhiza. In: SANDERS, F. E.; MOSSE, 8.; TINKER, P.B., ed. Endomycorrhizas. London, Academic press, 1975. p.175-194.

RAlJ, B. van. Condiçöes mínimas de eficiência para fosfatos alternativos ao superfosfato. R. bras. Ci. Solo, Campinas, $10(3): 235-239, \quad 1986$.

RAIJ, B. van E DIEST, A. van. Utilization of phosphate from different sources by six plant species. Pl. Soil, Hague, L1: $577-589,1979$.

RAIJ, B. van; ROSAND, P.C.; LOBATO, E. Adubação fosfatada no Brasil - apreciação geral, conclusōes e recomendações. In: OLIVEIRA, A.J.; LOURENÇO, S.; GOEDERT, W.J, ed. Adubação fosfatada no Bras:1. EHBRAPA-DID, Documentos, 21 , $1982 . \mathrm{p} .9-28$.

RAMOS, M.G. Avaliação da eficiência de olto fośfatos para as culturas de trigo e soja em um latossolo vermelho - escuro argiloso. R. bras.Ci.Solo, Campinas, $6: 38-42,1982$.

RATNAYAKE, M.; LEONARD, R.T.; MENGE, J.A. Root exudation in relation to supply of phosphorus and its possible relevan ce to mycorrhizal formation. New Phytol, oxford, 81: $543-552,1978$.

READ, D.J. Pezizela ericae, the perfect stage of a typical mycorrhizal endophyte of Ericaceae. Trans.Br.Mycol Soc., London, 63: $381-383,1974$.

READ, D.J. E STRIBLEY, D.P. Some nycological aspects of the biology of mycorrhiza in the Ericaceae. In: SANDERS, F.E.; MOSSE, B.; TINKER, P.B., ed. Endomicorrhizas. London, Acade mic press, 1975, p.105-117. 
READHEAD, J.F. Enow, ophic mycorrhizas in Nigeria: some asiacts of tis ecology of the endotrophic mycorrhizal as sociation of Khaya grandifoliola C.OC. In: SANDERS, F.E.; MOSSE, B.; TINKER, F.B., ed. Endomycorrhizas, London, Academio press 1515 . p. $447-459$.

REDENTE, E.F. E REEVES, F.B. Interactions between vesicular - arbuscular mycorrhiza and Rhizobium and their effects on sweetvetch growth. Soll Sci., Baltimore, 132: $410-415$, 1981.

ROBSON, A.D.; O'HARA, G.W.; ABBOTT, L.K. Involvement of phos phorus in nitrogen fixation by subterranean clover (Thi folium subterraneum L.). Aust.J.Plant Physiol., Melbourne, $8: 427-436$, 1981 .

ROSOLEM, C.A. Nutrição mineral e adubação da soja. Piracica ba, Instituto da Potassa. Boletim Técnicon: 6, 1982 . $80 \mathrm{p}$.

ROSS, J.P. Effect of phosphate fertilization on yield of mycorthizal and nonmycortizal soybeans. Phytopathology, Lancaster, 61: 1400-1403, 1971 .

ROSS, J.P. G GILLIAM, J.W. Effect of Endogone mycorrhiza on phosphorus uptake by soybeans from inorganic phosphates. Soil Sci. Soc. Amer. Proc, Madison, 37: 237-239, 1973.

ROSS, J.P. E HARPER, J.A. Effect of Endogone mycorrhiza on soybean yiélds. Phytopathology, Lancaster, 60: 1552-1556, 1970 .

SAFIR, G.R.; BOYER, J.S.; GERDEMANN, J.W. Mycorrhizal enhancement of water transport in soybean. Science, Lancaster $172: 581-583,1971$. 
SATIR, G.R.; SOYER, IS.; GERDEMANN, J.W. Nutrient status and mycorrhizal erhancement of water transport in soybean. Plant Phys101, Lancaster, 49: $700-703,1972$.

SAIF, S.R. The injluence of soll aeration on the efficiency of vesicular-arbuscular mycorrhizae. 1. Effect of soil oxygen on the growth and mineral uptake of Eupatorium odo ratum L. inoculated with Glomus macrocarpum. New Phytol, ox ford, $88: 649-659, \quad 1981$.

SAITO, S.M.T.; MARTINS, E.C.S,; FREITAS, J.R.; ROSTON, A.J. ocorrência natural de micorriza e Rhizobium phaseoli em äreas com feijoeiro. Pesq. agropec. bras., Brasília, 18 (8): $855-861,1983$.

SAME, B.1.; ROBSON, A.D.; ABBOTT, L.K. Phosphorus, soluble carbohydrates and endomycorrhizal infection. Soll Biol. Biochem., oxford, $15(5): 593-597,1383$.

SANDERS, F.E. E TINKER, P.B. Mechanism of absorption of phos phate from soil by Endogone mycorrhizas. Nature, London, 233: $278-279, \quad 1971$.

SARRUGE, J.R. E HAAG, H.P. Anälises químicas em plantas.Plracicaba, ESALQ/USP, 1974. $57 \mathrm{p}$.

SCHENCK, N.C. E HINSON, K. Response of nodulating and nonnodulating soybeans to a species of Endogone mycorrhiza. Agron. J., Madison, 65: 849-850, 1973 .

SCHENCK, N.C. E SCHRODER, V.N. Temperature response of Endogone mycorrhiza on soybean roots. Mycologia, New York, 66: 600-605, 1974 . 
SILVA, E.M.R.; ALMEIDA, D.L.; FRANCO, A.A.; DUBEREINER, J. Adu bação verde no aproveitamento de fosfato em solo ácldo. R.bras.Ci. Solo, Campinas, $\underline{9}(1): 85-88,1985$.

SIQUEIRA, J.0. E OLIVEIRA, E. Efeito da calagem na micorriza ção, crescimento e nutrição de dois cultivares de feljāo (Phaseolus vulgaris L.). In: REUNIÃO BRASILEIRA SOBRE MI CORRIZAS, 1., Lavras, 1985. Anais. Lavras, Edição FAEPE, 1986. p. 187 .

SIQUEIRA, J.0. E PAULA, M.A. Efeito de micorrizas vesículoarbusculares na nutrição e aproveitamento de fósforo pela soja em solo sob cerrado. R. bras.Ci. Solo, Campinas, $10(2): 97-102,1986$.

SKIPPER, H.D.E SMITH, G.W. Influence of soil pH on the soybean - endomycorrhiza symbiosis. P1. Soil, Hague, 53: $559-563,1979$.

SMITH, S.E. E BOWEN, G.D. Soil temperature, mycorrhizal infection. and nodulation of Medicago trunculata and Trifolium subterraneum. Soil Biol. Biochem,, $0 \times$ ford, 11: 469473,1979 .

SMITH, S.E. \& DAFT, M.J. Interactions between growth, phosphate content and nitrogen fixation in mycorrhizal and non-mycorrhizal Medica go sativa. Aust. J. Plant Physiol., Melbourne, 4: 403-413, 1977.

SMITH, S.E.; NICHOLAS, D.J.D.; SMITH, F.A. Effect of early mycorrhizaT in fection on nodulation and nitrogen fixation in Trifolium subterra neum L. Aust. J. Plant Physiol., Melbourne, 6: 305-316, 1979.

SPARLING, G.P. E TINKER, P.B. Mycorrhizal infection in Pennine grass land. 111. Effects of mycorrhizal infection on the growth of white clover. J.Appl. Ecol., Oxford, 15: 959-964, 1978. 
STRZEMSKA, J. Occurrence and intensity of mycorrhiza and deformation of roots without mycorriza in cultivated plants. In: SANDERS, F.E.; MOSSE, B.; TINKER, P.B., ed. EndomyCorrizas. London, Academic Press, 1975. p. $537-543$.

SWARD, R.J. Infection of Australian heathland plants by $G i-$ gaspora margarita (a vesicular-arbuscular mycorrhizal fun gus). Aust..J. Bot., Melbourne, 26: 253-264, 1978.

TINKER, P.B. Role of rhizosphere microorganisms in phosphorus uptake by plants. In: KHASAWNEH, F.E., SAMPLE, E.C.; KAM PRATH, E.J., ed. The role of phosptiorus in agriculture, Madison, ASA-CSSA-SSSA, 1980. cap. 22, p.617-654.

VARMA, A.K. Vesicular-arbuscular mycorrhiza and nodulation in soybean. Folia Microbiol., s.1., 24: 501-502, 1979 .

VIEIRA, C. Cultura do feijāo. 2.ed. Viçosa, Imprensa Universitária - Universidade Federal de Viçosa, 1983. $146 \mathrm{p}$.

VOLKWEISS, S.J. E RAIJ, B. van. Retenção e disponibilidade de fösforo em solos. In: SIMPOSIO SOBRE O CERRADO, 4, , Brasilia, Ed. Itatiaia, p.317-332, 1976.

WAIDYANATHA, U.P. de S.; YOGARATHAM, N.; ARIYARATNE, W.A. MYcorrhizal infection on growth and nitrogen fixation of Pueraria and Stylosanthes and uptake of phosphorus from two rock phosphates. New Phytol., Oxford, 82: $147-152$, 1979.

WARCUP, J.H. Factors affecting symbiotic germination of orchid seed. In: SANDERS, F.E.; MOSSE, B.; TINKER, P.B., ed. Endomycorrhizas. London. Academic Press, 1975. p. $87-104$ 